TOWARDS A NATIONAL STRATEGIC FRAMEWORK FOR THE CIRCULAR ECONOMY IN THE CZECH REPUBLIC

ANALYSIS AND A PROPOSED SET OF KEY ELEMENTS

OECD ENVIRONMENT POLICY PAPER NO. 27 


\section{Towards a National Strategic Framework for the Circular Economy in the Czech Republic}

Analysis and a Proposed Set of Key Elements 


\section{Disclaimers}

This work is published under the responsibility of the Secretary-General of the OECD. The opinions expressed and arguments employed herein do not necessarily reflect the official views of OECD member countries.

This document, as well as any data and any map included herein, are without prejudice to the status of or sovereignty over any territory, to the delimitation of international frontiers and boundaries and to the name of any territory, city or area.

This work was carried out with funding by the European Union via the Structural Reform Support Programme and in cooperation with the European Commission's Structural Reform Support Service. The views expressed herein can in no way be taken to reflect the official opinion of the European Union.

The statistical data for Israel are supplied by and under the responsibility of the relevant Israeli authorities. The use of such data by the OECD is without prejudice to the status of the Golan Heights, East Jerusalem and Israeli settlements in the West Bank under the terms of international law.

\section{(C) OECD (2021)}

The use of this work, whether digital or print, is governed by the Terms and Conditions to be found at http://www.oecd.org/termsandconditions.

Photo credit: Cover (C) 2021; Cover Illustration: Christophe Brilhault. 


\section{Foreword}

The past decades have witnessed unprecedented growth in global consumption of raw materials. In light of a growing world population and increasing living standards, this trend is expected to further increase and more than double by 2060 , if no further policy action is taken. The extraction, processing and disposal of materials provokes a variety of environmental impacts, among others increases in greenhouse gas emissions, which put countries at risk of missing important environmental goals.

Over the years, the OECD has accumulated extensive experience in developing policy recommendations in resource efficiency and circular economy. In its analytical work, it has been focusing on topics as diverse as plastics, economic instruments, macroeconomic consequences, circular business models, digitalisation and trade.

Through our Environmental Performance Reviews, which involve country benchmarking and the development of recommendations for policy reform, the OECD has also been advising individual governments for several decades to address environmental challenges, including on materials and waste management and the transition to a circular economy. Buidling on these insights, the OECD is now also advising governments on developing circular economy strategies and roadmaps.

The OECD has been privileged to have had the opportunity to support the government of the Czech Republic, jointly with the Directorate General for Structural Reform Support (DG REFORM) of the European Commission, in its endeavour of developing a national circular economy strategic framework (Circular Czechia 2040). To restrain materials consumption and improve environmental protection, the Czech Republic has made a strong commitment to transitioning to circular economy by 2040 and implementing significant changes and extensions to its existing plans, policies and programmes.

Our analysis shows that although the Czech Republic made notable progress in decoupling environmental pressures from economic activity, future materials consumption in the country is projected to increase by about one third by 2050 (compared to 2017 levels). The measures proposed therefore aim at improving incentives for circular product design and manufacturing, encouraging consumers to purchase circular products, decreasing landfilling and stimulating the use of secondary raw materials, and leveraging research, innovation and digitalisation to better support the circular economy transition.

Overall, the identified policy measures can contribute to accelerating the transition towards circularity and greater resource efficiency, generating less waste and more value added for the Czech Republic. In doing so, they can support efforts towards a green recovery from the COVID-19 pandemic, that are an important policy priority for the country.

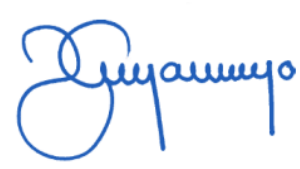

Rodolfo Lacy
Director, OECD - Environment Directorate

TOWARDS A NATIONAL STRATEGIC FRAMEWORK FOR THE CIRCULAR ECONOMY IN THE CZECH REPUBLIC 


\section{Acknowledgments}

This report was carried out under the overall responsibility of Shardul Agrawala, Head of the Environment and Economy Integration Division of the OECD Environment Directorate. Eva Barteková and Katarína Svatíková prepared the report and carried out the underlying policy analysis under the guidance of Peter Börkey, Principal Administrator and Circular economy lead (all OECD Environment Directorate).

Jean Chateau, Ruben Bibas and Eleonora Mavroeidi (all OECD Environment Directorate) provided the modelling analysis. Frithjof Laubinger of the OECD Environment Directorate provided support in drafting parts of the report. Rosaria Chifari, Ignasi Puig Ventosa and Sergio Sastre Sanz (all ENT Environment \& Management) supported the analysis on consumption and consumers in a circular economy. Pavel Růžička (from ENVIROS), Vladimír Dobeš, Jan Stejfa and Pavel Novák (independent consultants) prepared the analysis on Czech waste management. Stephen Smith (Professor of Economics at University College London) contributed to the analysis on economic instruments.

Katjusha Boffa, Aziza Perrière, Jack McNeill and Ijeoma Inyama-Dalles (all OECD Environment Directorate) provided administrative support. Norbert Monti of the OECD Environment Directorate supported the creation of communication materials for the report and the report's publishing. Peter Vogelpoel (independent graphic designer) created the graphic design of communication material for the report.

The report also benefited from expert input and feedback on earlier drafts by Vladislav Smrž, Deputy Minister of the Environment, Jan Maršák, Director of the Waste Management Department, Petra Urbanová, Gabriela Bulková, Vojtěch Pilnáček and other colleagues from the Ministry of the Environment of the Czech Republic. Christoph Klockenbring and Hana Huzjak of the DG REFORM of the European Commission also provided valuable inputs on the report and coordinated feedback from other Directorates General of the European Commission. The stakeholder working group set up by the Czech Ministry of the Environment reviewed earlier drafts of the report and was consulted on the content of the different chapters of the report. The stakeholder working group consisted of representatives from the Czech ministries, agencies and other public bodies, industry as well as representatives of NGOs.

This work was carried out with funding by the European Union via the Structural Reform Support Programme and in cooperation with the European Commission's Structural Reform Support Service. The views expressed herein can in no way be taken to reflect the official opinion of the European Union. 


\section{Table of Contents}

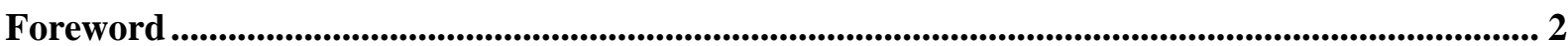

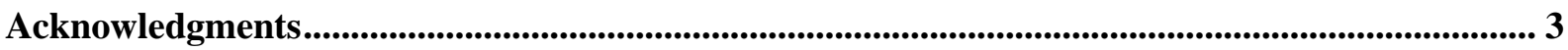

Abbreviations and acronyms.................................................................................................................... 7

1. Executive summary ................................................................................................................................. 9

2. Introduction ........................................................................................................................................................... 13

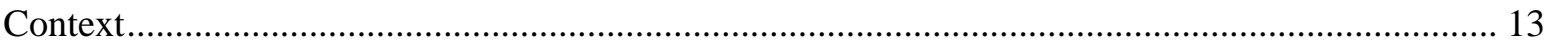

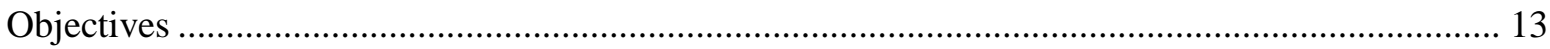

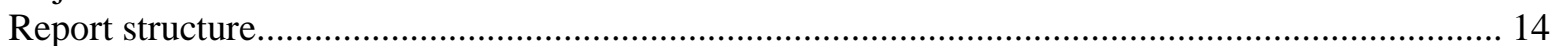

3. Circular economy as a systemic paradigm change towards achieving sustainability in face of global challenges....................................................................................................................................... 15

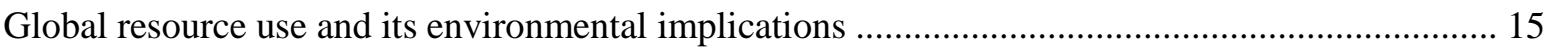

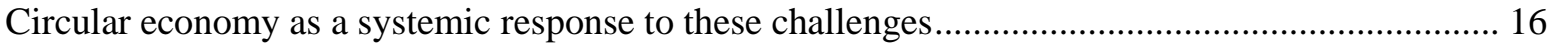

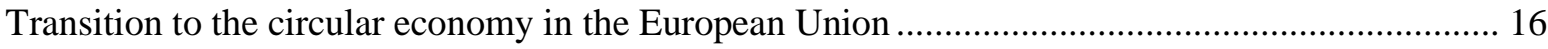

4. Rationale for transitioning to a circular economy in the Czech Republic .................................... 20

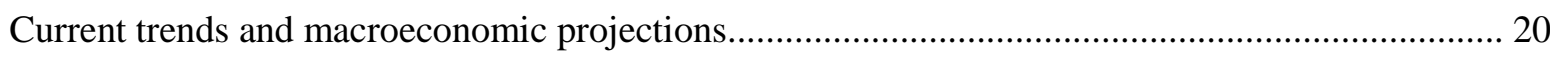

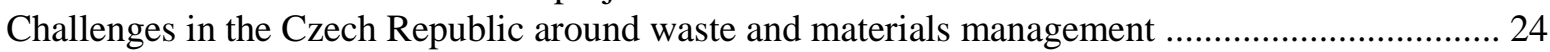

Existing policy landscape in the Czech Republic ......................................................................... 24

5. Direction of change towards Circular Czechia 2040 ...................................................................... 28

6. Priority areas and their circular potential ............................................................................................... 30

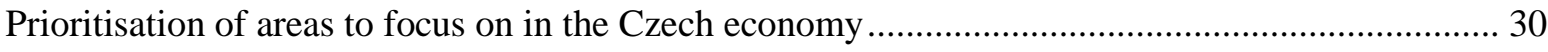

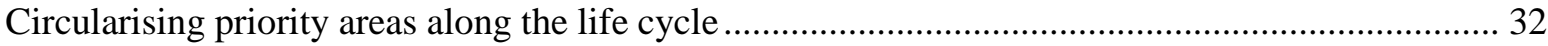

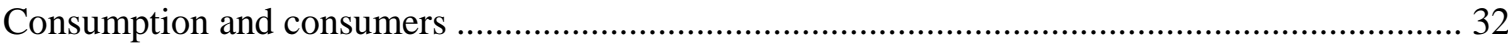

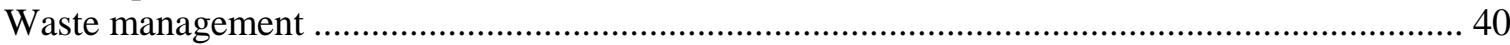

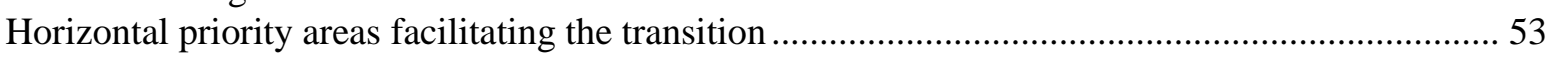

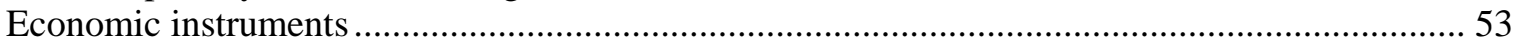

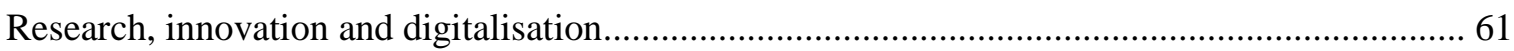

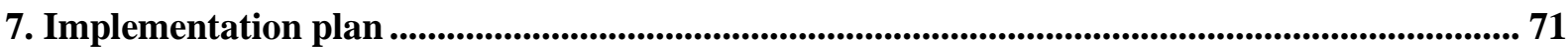

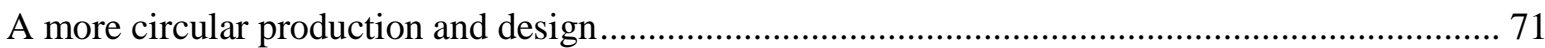

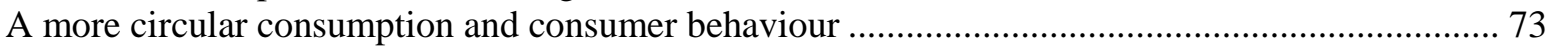

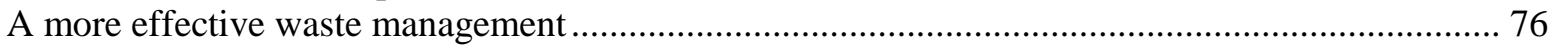

Research, innovation, and digitalisation for circular economy ...................................................... 79

Education and knowledge for circular economy ....................................................................... 82

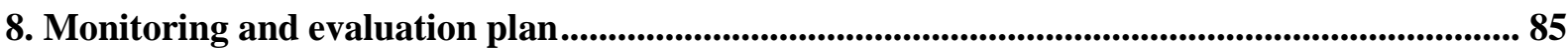

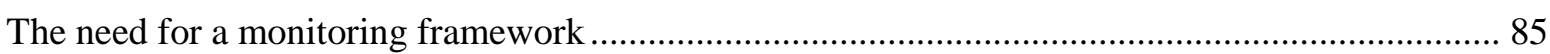

Current gaps in the circular economy monitoring frameworks and research needs ........................ 90

Monitoring framework for the circular economy in the Czech Republic ..................................... 92

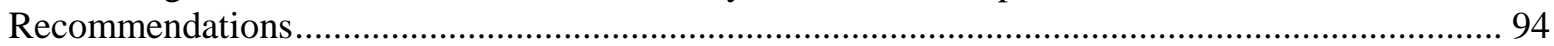

9. Communication plan .......................................................................................................................................... 97 


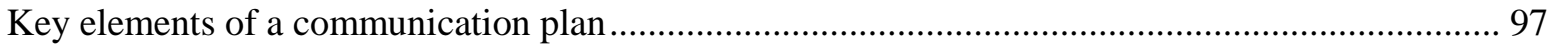

Guidance for developing the communication plan for the Circular Czechia 2030 strategy ............. 98

Calendar of events for communication to institutional stakeholders ............................................ 102

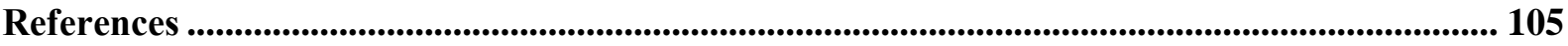

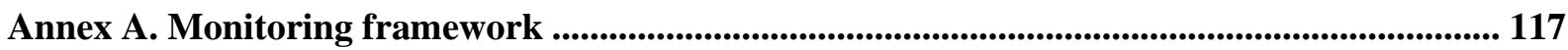

\section{Tables}

Table 6.1 Comparison of the price of landfill and incineration for combustible waste, various years 2012-14.

Table 6.2 Consumer product taxes relevant to the circular economy in EU Member States ................ 61

Table 8.1. Indicators in the EU's Circular Economy Monitoring Framework ..................................... 86

Table 8.2. Key advantages and disadvantages of using various types of indicators by policy makers

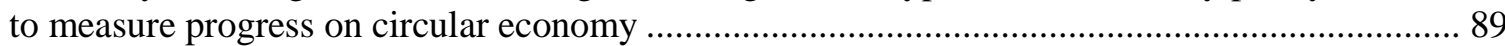

Table 9.1. Key elements for developing the Circular Czechia 2040 strategy communication plan... 100

Table 9.2. Proposed calendar of international events for the communication of the Circular Czechia

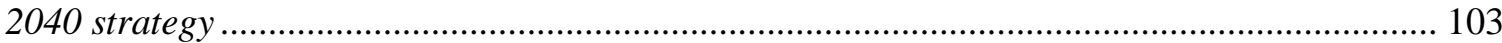

Table 9.3. Proposed draft calendar of national events for the communication of the Circular

Czechia 2040 strategy (to be completed by the Ministry of the Environment).....

Table A.1. Initial indicator set for monitoring CE in the Czech Republic (long-list)

\section{Figures}

Figure 3.1. Recent development and projections of material consumption globally and in the OECD countries

Figure 4.1. Projected raw materials use of the Czech Republic and its decomposition ....................... 21

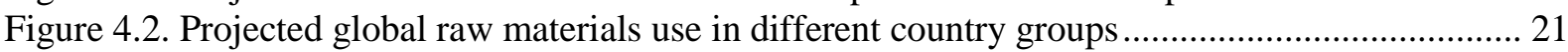

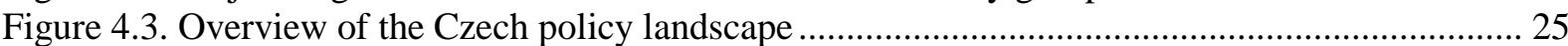

Figure 6.1. Priority areas to be targeted within the Circular Czechia 2040 strategy ........................... 31

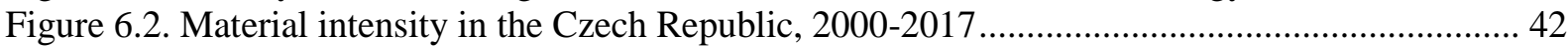

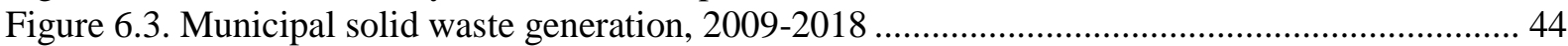

Figure 6.4. Landfill tax rates of MSW in OECD countries in 2018 and 2013 .................................... 49

\section{Boxes}

Box 3.1. Key development of the circular economy policy landscape in the European Union ............ 18

Box 4.1. Greening the COVID-19 recovery through circular economy............................................ 23

Box 4.2. Overview of relevant Czech policy initiatives for circular economy and resource

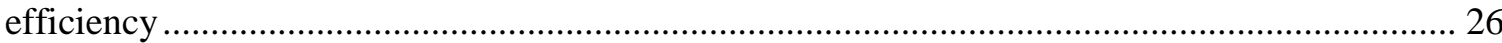

Box 6.1. International good practices in voluntary agreements and environmental taxes on plastic

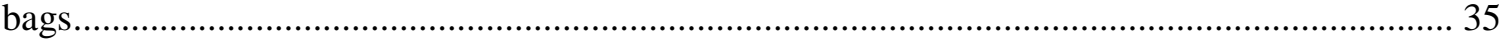

Box 6.2. Environmental education and awareness raising in the Czech Republic ............................... 36

Box 6.3. The current PAYT system in the Czech Republic and examples of good practices from

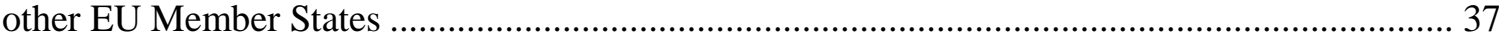


Box 6.4. Initiatives in the Czech Republic to support extension of the lifetime and reuse of products 39

Box 6.5. Reduced VAT for repair activities across the EU Member States......................................... 40

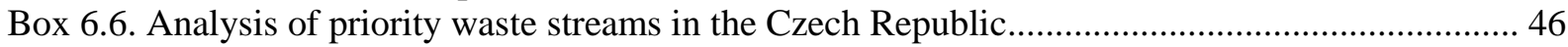

Box 6.7. Instruments directed to changing waste disposal practices.................................................... 48

Box 6.8. Examples of instruments for expanding policy mixes in the construction sector upstream in the Czech Republic and across other EU Member States ....................................................... 52

Box 6.9. Examples of Czech landfill taxes and relative prices of landfill and incineration in a

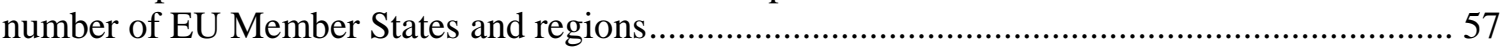

Box 6.10. EPR for packaging in the Czech Republic, and for textiles and clothing in France ............. 59

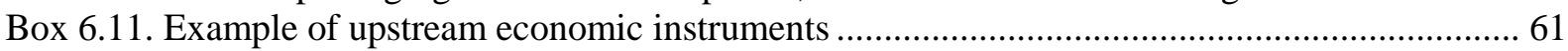

Box 6.12. The status of current R\&D\&I support in the Czech Republic .......................................... 65

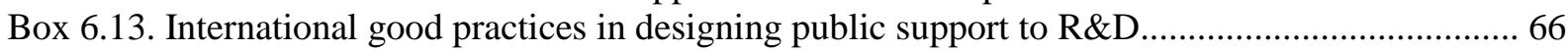

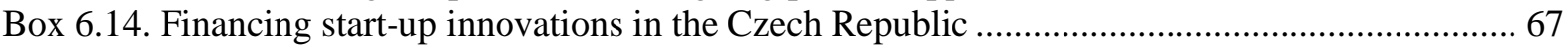

Box 6.15. International good practices of innovation funding instruments in the EU ......................... 67

Box 6.16. International good practices in mainstreaming digital innovation for the uptake of circular business models

Box 6.17. International good practices of using digital technologies to support the effective

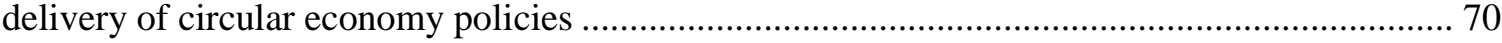

Box 8.1. EU's Circular Economy Monitoring Framework ............................................................. 85

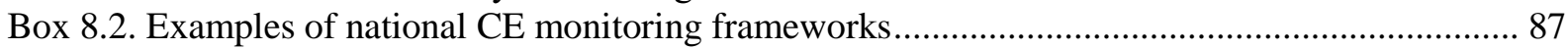

Box 8.3. Potential indicators for a circular economy in the Czech Republic ........................................ 93 


\section{Abbreviations and acronyms}

\begin{tabular}{|c|c|}
\hline $\mathrm{AI}$ & Artificial intelligence \\
\hline CDW & Construction and demolition waste \\
\hline $\mathrm{CE}$ & Circular Economy \\
\hline CENIA & Czech Environmental Information Agency \\
\hline CMU & Circular material use \\
\hline $\mathrm{CR}$ & Czech Republic \\
\hline $\mathrm{CZSO}$ & Czech Statistical Office \\
\hline $\mathrm{CZK}$ & Czech Koruna \\
\hline DG REFORM & Directorate General for Structural Reform Support \\
\hline $\mathrm{DMC}$ & Domestic Material Consumption \\
\hline DMI & Domestic material input \\
\hline DRS & Deposit Refund System \\
\hline DtD & Door-to-Door \\
\hline $\mathrm{EC}$ & European Commission \\
\hline EEA & European Environment Agency \\
\hline EEE & Electrical and Electronic Equipment \\
\hline EFSI & European Fund for Strategic Investments \\
\hline EI & Economic instrument \\
\hline EIB & European Investment Bank. \\
\hline EIR & Environmental Implementation Review \\
\hline ELV & End-of-life vehicles \\
\hline EMAS & Eco-Management and Audit Scheme \\
\hline EPR & Extended Producer Responsibility \\
\hline EU & European Union \\
\hline Expra & Extender Producer Responsibility Alliance \\
\hline G7 & Group of Seven \\
\hline $\mathrm{G} 20$ & Group of Twenty \\
\hline GDP & Gross Domestic Product \\
\hline GHG & Greenhouse gas \\
\hline GPP & Green Public Procurement \\
\hline Gt & Giga tonnes \\
\hline GVA & Gross Value Added \\
\hline ICT & Information and Communications Technology \\
\hline INCIEN & Institute of the Circular Economy in the CR \\
\hline IoT & Internet of Things \\
\hline ISO & International Standards Organisation \\
\hline ISOH & Waste Management Information System \\
\hline ISSAR & Information System of Statistics and Reporting \\
\hline JRC & Joint Research Centre \\
\hline $\mathrm{kg}$ & Kilogram \\
\hline LA & Local authorities \\
\hline LCA & Life Cycle Analysis \\
\hline $\mathrm{LCC}$ & Life Cycle Costing \\
\hline
\end{tabular}


$\mathrm{M} €$

MBT

$\mathrm{MoE}$

MSW

Mt

MW

NACE

NGO

OECD

OP

PAYT

PET

PRO

R\&D

$R \& D \& I$

RES

RMC

SDG

SME

SRM

SRSP

SUP

TACR

TMC

UK

VA

VAT

VISOH

WEEE

WMP

WPP

WtE

WWTP
Million euros

Mechanical biological treatment

Ministry of the Environment

Municipal Solid Waste

Million metric tonnes

Municipal Waste

Statistical Classification of Economic Activities

Non-governmental organisation

Organisation for Economic Co-operation and Development

Operational Programme

Pay-As-You-Throw

Polyethylene Terephthalate

Producer Responsibility Organisation

Research and Development

Research, Development and Innovation

Renewable Energy Sources

Raw Material Consumption

Sustainable Development Goal

Small and Medium sized Enterprises

Secondary raw materials

Structural Reform Support Programme

Single Use Plastics

Technology Agency of the Czech Republic

Total Material Consumption

United Kingdom

Voluntary Agreement

Value Added Tax

Publicly Available Part of the Waste Management Information System

Waste from Electrical and Electronic Equipment

Waste Management Plan

Waste Prevention Programme

Waste to Energy

Wastewater Treatment Plant 


\section{Executive summary}

1. Increasing consumption of materials and resources provokes negative environmental impacts and pressures. The global material consumption, and related environmental impacts, are projected by the OECD to at least double between 2018 and 2060 under the business-as-usual scenario. To reduce material resource consumption and offset the resulting environmental pressures, more stringent resource efficiency and circular economy policies are needed along the value chain, and linear business models need to be replaced by circular business models.

2. As a response to this challenge, the EU and its Member States, as well as other countries across the world, have adopted a number of circular economy strategies, action plans and legislation at different levels of governance. Within this context, the Czech Republic has committed to developing a national circular economy strategic framework towards 2040 (Circular Czechia 2040), and to implement significant changes and extensions to existing plans, policies and programmes. To support these efforts, the Directorate General for Structural Reform Support (DG REFORM) of the European Commission and the OECD are supporting the Czech Republic in the development of such a strategic framework.

3. This report discusses the rationale for transitioning to a circular economy in the Czech Republic, proposes a strategic vision, and provides an in-depth analysis of four priority areas that were identified by the stakeholder working group. The latter consisted of different parts of the Czech Government and representatives of industries and municipalities (including various associations and unions), as well as the civil society. The report also suggests 40 concrete policy measures to help implement the strategy, as well as a two-phased monitoring framework to measure the progress made, and an overview of the key elements of a communication plan.

In a business-as-usual scenario material consumption is projected to increase significantly in the coming decades

4. While the Czech Republic has made notable progress in decoupling environmental pressures from economic activity in the past decades, its economy remains among the most energy-, carbon- and resource-intensive in the OECD and the European Union, due to a strong industrial base and reliance on coal. As wealth increases and living standards in the Czech Republic converge towards the EU averages, the demand for resources and materials is projected to further increase. GDP per capita for the Czech Republic will likely grow faster than the OECD and EU averages, with a projected increase by over $2 \%$ between 2020 and 2050, driving an increased demand for resources. In particular, in sectors where the Czech Republic has a comparative advantage, such as motor vehicles, construction and non-metallic minerals sectors, further growth is expected to occur over the next decades.

5. Structural changes in the economy towards more servitisation will likely increase resource efficiency and lead to growth in services sectors, whilst material-intensive sectors will grow below average. Construction is the exception, where high infrastructure investments will maintain resource demand in the coming decades. Changes in production modes, such as the uptake of technological progress across sectors (e.g. ICT), digitalisation and the increased penetration of renewable energy will further increase resource efficiency 
of production. These will in turn enable to partially mitigate the rise in materials use driven by economic growth and increased consumption.

6. Taken together, these trends are projected to lead to overall materials consumption in the Czech Republic to increase by about one third by 2050 compared to 2017 levels (from $0.26 \mathrm{Gt}$ to $0.34 \mathrm{Gt}$ ). The rise in material use comes along with strong environmental consequences, among others triggering increases in GHG emissions, which might put the country at risk of missing important environmental goals (including the long-term emission reduction targets under the Paris Agreement). The largest increases in material consumption are projected to occur in the construction, manufacturing and food industries, which are amongst the most material intensive sectors. Modelling results also indicate that there is significant potential in strengthening the contribution to resource efficiency from technological change, indicating a need for an intensification of efforts in relevant research and development.

\section{There is a strong rationale for the Czech Republic to accelerate its transition towards a circular economy}

7. With this in mind, the forthcoming Circular Czechia 2040 and the circular economy transition that it will support, is envisaged to help the Czech Republic curb the business-as-usual trends described above and significantly improve environmental protection as a result. At the same time the strategy will strengthen the competitiveness and technological maturity of the economy, create new jobs, increase the security of raw material supply, and enable citizens in relevant sectors to acquire new skills and expertise.

\section{Circular Czechia 2040 proposes to target several priority areas}

8. The analysis in this report shows that the Czech Republic has a well-developed and fairly complete policy and legal framework related to waste and resources management. However, there are a number of areas where existing policy instruments could be strengthened or new ones introduced in order to accelerate the transition towards the circular economy.

9. The proposed strategy takes a life cycle perspective to identify policy recommendations, and particularly focuses on the product design and manufacturing stages, the consumption and the end-of-life management stages. In addition, it addresses horizontal measures cutting across the product life-cycle, in particular those of research, innovation and digitalisation; education and knowledge; and the use of economic policy instruments. Lastly, it also provides insights into specific sectors, with a focus on the bioeconomy and food; industry, raw materials, and construction; plastics; textiles; electronics; and household waste.

10. The following highlights some of the key insights and recommendations for strengthening circular economy incentives along the product life cycle.

\section{Incentives for circular product design and manufacturing need to be improved}

11. There is a large potential to improve circularity in product design and manufacturing in the Czech Republic, as the existing policy framework is significantly less developed in this upstream area than further down the value chain. Improved incentives in this field are crucial for maximising circularity opportunities, both up- and downstream of the value chain. For instance, product design measures can help to increase the effect of 
both, upstream waste prevention and downstream waste management measures, as more reusable and reparable products will remain in use for longer and better recyclability makes end-of life products easier and less costly to treat. There is a broad array of policies that can help to achieve these goals, including product level measures, as well as end-of-life interventions. Some of the key policies measures that could be taken in this field include:

- Increasing existing virgin materials taxes (extraction fees) to stimulate the use of secondary raw materials, especially for construction materials such as sand and gravel, which are not widely traded internationally;

- Considering the use of product taxes (excises) as an additional policy instrument, for products that are difficult to collect and recycle. This would render the production of such items more expensive and create incentives to manufacture alternatives;

- Improving and re-enforcing existing Extended Producer Responsibility (EPR) schemes, in particular for electronic waste, and possibly extending EPR to additional products, such as textiles and furniture.

\section{Consumers can prevent and sort waste better, and be encouraged to purchase circular products}

12. Consumer behaviour and resulting consumption patterns have a significant impact on resource efficiency of the economy, and changes here can play a fundamental role in reshaping the economy and in driving the transition towards a circular economy. Consumers play a key role through the consumption decisions that they make, as well as through the way they contribute to waste collection and sorting at the end-of-life stage. Some of the key policies measures that could be taken in this field include:

- Encouraging consumers to prevent waste by imposing taxes on environmentally harmful products, such as plastic bags;

- Promoting the uptake of second-hand, repaired, reused, refurbished, remanufactured and more generally ecolabelled products and services to shift consumer preferences towards more circularity and sustainability (with different types of instruments);

- Extending the use of pay-as-you-throw (PAYT) charging schemes for mixed municipal waste (while making enforcement policies to prevent illegal dumping more effective), and implementing nudges and a wider network of door-to-door collection for recyclables, in order to encourage consumers to sort more recyclable waste. Bio-waste and electronic waste hold particular potential for improvement.

\section{More material needs to be recovered from different waste streams in order to decrease landfilling and stimulate the use of secondary raw materials}

13. Waste and materials management have become an integral part of circular economy policy making, since they help strengthen the security of raw material supply and mitigate the negative environmental impacts from waste generation. While the policy and legislative frameworks in these areas are well-developed in the Czech Republic, there is still a large potential to improve waste and resources management. This reports suggests the following improvements, among others: 
- Increasing landfill taxes and improving their design in order to substantially decrease the relatively high landfill rate of municipal waste and support achievement of relevant EU waste targets. Landfill taxes would be more effective if the revenue they generate were not allocated to municipalities, and fees for the landfilling of hazardous waste were better enforced;

- Complementing landfill taxes with an incineration tax in the medium- to long-term, to help avoid shifting landfilled waste to incineration rather than recycling;

- Introducing additional tax incentives, such as value added tax (VAT)/ other tax deductions for products having a high recycled content to stimulate upcycling and demand for recyclables and secondary raw materials. Similar measures for repaired, refurbished and remanufactured goods and services could help encourage waste prevention efforts;

- Possibly expanding quality certification of reusable components, secondary raw materials and recyclable waste to help to build trust and increase demand for such products and materials.

\section{Synergies between research, innovation, digitalisation, and the circular economy transition need to be strengthened}

14. Innovation and technological development, including digitalisation, are important enabling factors in transitioning towards a circular economy, since much of the change that is required will depend on technological and organisational innovation taking place. The circular economy transition is facilitated by the introduction of new production processes and technologies, and by the emergence of innovative, circular business models. Some of the key policy measures that could be taken in this field include:

- Establishing a clear link between research, innovation, digitalisation and circular economy within a coherent strategy or programme;

- Improving coordination among the different public bodies and cooperation between the private sector and academia, to maximise synergies and accelerate the rate of innovation, including a focus on the use of digital technologies in this field;

- Strengthening financial support instruments for Research and Development (R\&D) through introduction of dedicated circular economy innovation instruments.

\section{Effective education and knowledge sharing helps accelerate the circular economy transition}

15. In addition to $\mathrm{R} \& \mathrm{D}$ and digitalisation, education and knowledge sharing can help to further accelerate the transition to a circular economy. The following information and capacity building tools could be developed:

- Expanding awareness raising campaigns for the public on waste prevention and the benefits of self-repair, green products, and the use and application of new circular business models (e.g. sharing schemes, reuse and repair centres);

- Mainstreaming the circular economy into education programmes in schools, vocational education and training and higher education;

- Supporting the adoption of advanced digital information technologies and digital data tracking tools in businesses and by policy makers. 


\section{Introduction}

\section{Context}

16. The Czech Republic, despite having relatively few natural resources and growth above the OECD average, has managed to decouple many environmental pressures from its economic growth. Nonetheless, the recent OECD Environmental Performance Review of the Czech Republic $\left(\mathrm{OECD}, 2018_{[1]}\right)$ identifies a number of challenges. While the Member State has well-developed and fairly complete policy and legal frameworks for waste and materials management, it faces challenges related to high shares of direct landfilling, lack of cost-efficiency in waste management, insufficient measures to minimise the environmental impact of waste and materials management over their life-cycle, and inadequate waste prevention and "upcycling" of waste into higher-value products. Additionally, the recent Environmental Implementation Review 2019 (European Commission, 2019 $\left.9_{[2]}\right)$ points to the fact that despite some encouraging policies being implemented in this field, the country has no specifically dedicated national circular economy strategy or roadmap yet. In the field of waste management, further efforts are needed to increase recycling, reduce landfill rates of municipal solid waste, and careful planning of additions to waste management infrastructure (such as waste-to-energy facilities or mechanical-biological treatment (MBT) facilities). The rate of circular use of materials in the Czech Republic is currently below that of the EU-28 average. The Member State also lags behind the EU average in resource productivity and eco-innovation performance.

\section{Objectives}

17. In order to achieve the 2030/2035 EU waste management targets, to align with the EU Strategy for Plastics in the Circular Economy, to prevent waste, and to transition towards a circular economy in line with the EU Action Plan for the Circular Economy (European Commission, 2020 $0_{[3]}$ ) and other relevant strategies related with circular economy, the Czech Republic is determined to implement significant changes and extensions to existing plans, policies and programmes. To support these efforts, the Directorate General for Structural Reform Support (DG REFORM) of the European Commission and the OECD have agreed to provide technical support to the Czech Republic in the development of a strategic framework for the transition towards a circular economy ${ }^{1}$.

\footnotetext{
${ }^{1}$ The mission of the Directorate General for Structural Reform Support (DG REFORM) of the European Commission is to provide support for the preparation and implementation of growthenhancing administrative and structural reforms by mobilising EU funds and technical expertise. The Czech Republic has requested support from the European Commission under Regulation (EU) 2017/825 on the establishment of the Structural Reform Support Programme ("SRSP Regulation"). The request has been analysed by the Commission in accordance with the criteria and principles referred to in Article 7(2) of the SRSP Regulation, following which the European Commission has agreed to provide support to the Czech Republic, together with the OECD in the area of circular economy and resource efficiency. The purpose of this support is to help the Member State to develop a strategic framework for the transition towards a circular economy under the conditions set in the Framework Grant Agreement SRSS/S2019/036.
} 
18. The overall outcome of this technical support is the adoption of a new national circular economy strategy (including new waste management strategy), which will complement and expand the existing waste management policy. The present report is the final output of this technical support, and outlines potential elements of the Czech national circular economy strategic framework (including elements for the new waste management strategy), along with recommendations for an implementation, and monitoring and evaluation plans. Communication plan is also included within this report.

19. It is expected that the Czech Republic, having been closely involved in the development of this report, will integrate these elements into its strategic framework, and adopt this through its internal mechanisms. Provided that the measures laid-out in the strategic framework will be implemented into the Czech Republic's regulatory framework, the outputs are expected to result in the following long-term impacts for the Czech economy:

- Improved strategic situation for support of circular economy;

- Improved institutional infrastructure/conditions for transitioning towards circular economy;

- Increased resource efficiency and improved waste management, including positive effects in attaining national climate and other environmental objectives;

- Improved material supply security and reduced reliance on material resources that have to be imported from outside of the EU; and

- Improved competitiveness of enterprises.

\section{Report structure}

20. The report is structured as followed: Chapter 3. provides insights into global trends of materials uses and their environmental implications, and how circular economy could provide a systemic response to the global challenges towards achieving sustainability. It also provides insights into the ongoing transition to circular economy within the EU. Chapter 4. discusses the rationale for transitioning to a circular economy in the Czech Republic, presenting the current trends and macroeconomic projections, highlighting challenges around waste and materials management, and reviewing the existing policy landscape in the Czech Republic. The direction of change towards Circular Czechia 2040 is presented in Chapter 5. This is further developed within Chapter 6. , which lays out the circular economy framework, provides in-depth analyses of selected priority areas, and identifies their circular potential and recommendations to strengthen existing and introduce new policy instruments, where needed. Chapters 7. , 8. and 9. outline the implementation, monitoring and evaluation, and communication plans, respectively. The report falls back on the analysis in several background reports, which were prepared within the context of this technical support project and whose findings feed into this report. 


\section{Circular economy as a systemic paradigm change towards achieving sustainability in face of global challenges}

\section{Global resource use and its environmental implications}

21. The past decades have witnessed unprecedented growth in demands for raw materials worldwide and the consumption of materials and resources is ever growing. Recent OECD modelling suggests that, in light of a growing world population and increasing affluence and living standards, materials use will further increase and more than double between 2018 and 2060 (from $76 \mathrm{Gt}$ to $167 \mathrm{Gt}$ ), if no further policy action is taken $\left(\mathrm{OECD}, 2019_{[4]}\right)$. Furthermore, Domestic Material Consumption $(\mathrm{DMC})^{2}$ is projected to further increase in the OECD countries, albeit at a slower rate (from around $25 \mathrm{Gt}$ in 2018 to around $39 \mathrm{Gt}$ in 2060) (Figure 3.1). More stringent resource efficiency and circular economy policies are thus needed to address this emerging issue and to decouple materials consumption and economic growth.

Figure 3.1. Recent development and projections of material consumption globally and in the OECD countries

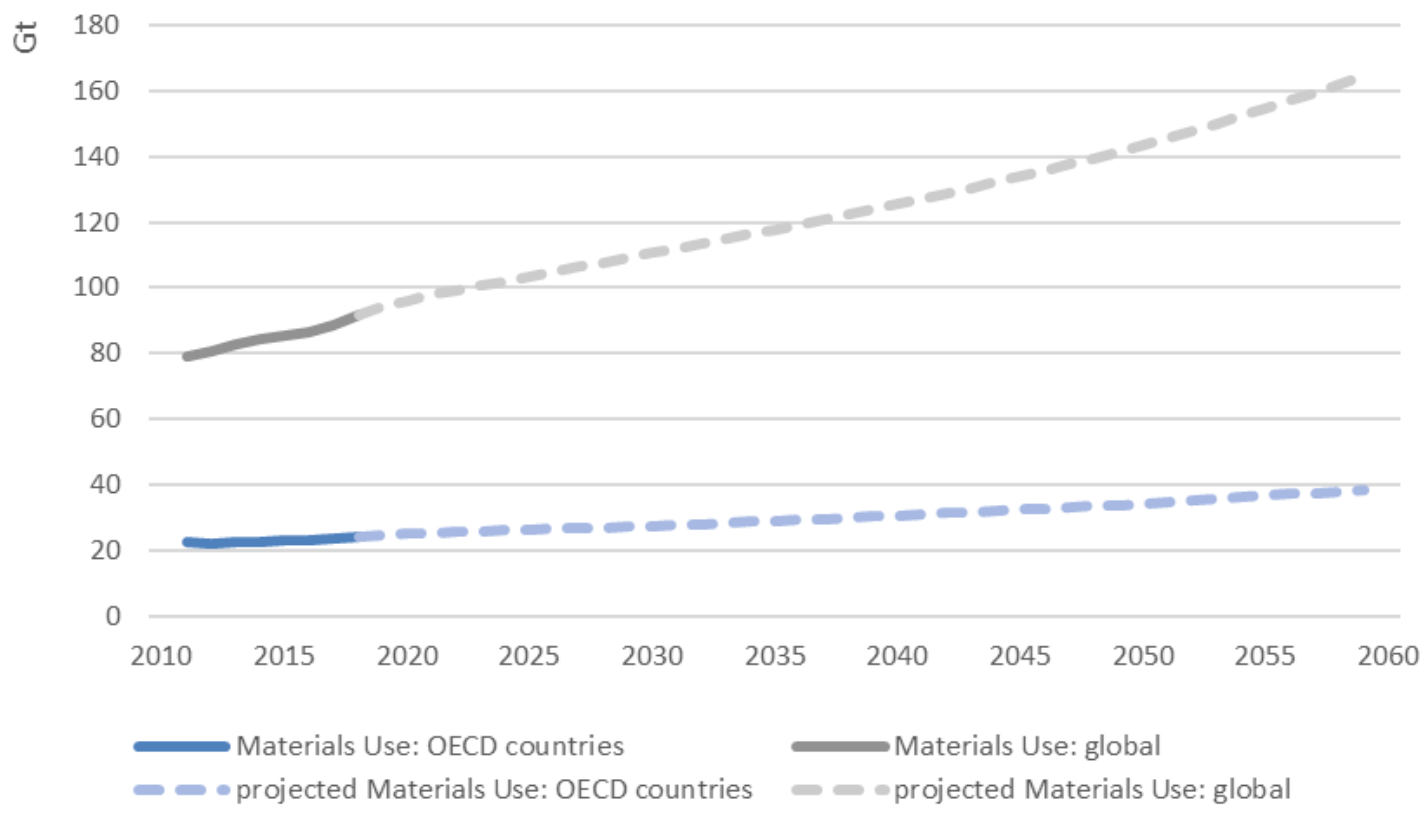

Source: OECD Global Materials Outlook to $2060\left(2019_{[4]}\right)$

22. The increasing use of non-renewable raw materials provokes a variety of environmental consequences and often irreversible ecological changes across all stages of the value chain. For instance, raw material extraction is energy intensive and can result in

\footnotetext{
${ }^{2}$ Domestic material consumption (DMC) measures the total amount of materials directly used by an economy, and is defined as the annual quantity of raw materials extracted from the domestic territory, plus all physical imports minus all physical exports.
} 
water shortages, soil degradation, biodiversity loss and pollution. Processing raw materials and distributing final products requires energy and water. At the end-of-life stage, dismantling and disposal of products can result in significant pollution and environmental pressures, if not handled properly. These will be further exacerbated if business-as-usual trends continue: along with growing material consumption, most global environmental impacts related to materials use are projected to at least double to 2060 (such as greenhouse gases caused by concrete production or human toxicity impacts from iron and copper) (OECD, 2019[4]).

\section{Circular economy as a systemic response to these challenges}

23. The traditional linear model of resource extraction, product ownership, and eventual disposal is unlikely to deliver the sustainable future wanted. A transition to a more circular economy - where materials and products are repaired, reused and recycled - can lead to substantial environmental benefits throughout the value chain. Resource-efficiency measures can reduce the resource demand per unit of production and thus decouple materials use and economic growth. Material circularity, through increased recycling and reuse can further reduce environmental impacts, as the environmental footprints associated with secondary materials are generally substantially lower than with primary materials. For example, recycling metals reduces most environmental impacts by one order of magnitude compared to primary production.

24. Achieving real progress will require that greener modes of production and consumption and circular business models gain a greater foothold in the economies (OECD, 2019 $\left.{ }_{[5]}\right)$. These business models can be classified into five groups:

- Circular supply models replace traditional material inputs derived from virgin resources with bio-based, renewable, or recovered materials;

- Resource recovery models recycle waste and scrap into secondary raw materials, diverting waste from final disposal while displacing demand for extraction and processing of virgin natural resources;

- Product life extension models, such as repair and remanufacturing, extend the use period of existing products, slow the flow of constituent materials through the economy, and reduce the rate of resource extraction and waste generation;

- Sharing models facilitate the sharing of under-utilised products, and reduce demand for new products; and

- Product service system models, where services rather than products are marketed, improve incentives for green product design and more efficient product use.

25. An uptake of these business models can not only contribute to environmental efficiencies, but also generate new economic growth and job opportunities ${ }^{3}$.

\section{Transition to the circular economy in the European Union}

26. In light of these challenges, the circular economy is receiving increasing attention worldwide. A number of high-profile multilateral and national initiatives have emerged in

\footnotetext{
${ }^{3}$ Changes to business models are expected to impact the employment in terms of both job creation and job displacement, as well as heightened labour productivity and widening skills gap.
} 
recent years, which affirms the importance of resource productivity, sustainable resource use and management, and the circular economy. In the G7 context, the G7 Alliance on Resource Efficiency was established at Schloss Elmau in 2015, and has been built upon by the adoption of the Toyama Framework on Material Cycles in 2016, and the Bologna Roadmap in 2017 (G7, 2017[6]). In 2017, G20 governments established the ongoing G20 Resource Efficiency Dialogue (G20, 2017 $[7])$.

27. In the European Union (EU), a Resource Efficiency Platform was established in 2012, and a Circular Economy Action Plan was adopted in 2015, accompanied by a Circular Economy Package (European Commission, 2015 $[8]$ ). Recently, as part of the European Green Deal, the 2020 "New Circular Economy Action Plan" encompasses bold initiatives along the entire life cycle of products, targeting among others their design, fostering sustainable consumption, and aiming to ensure that the resources used are kept in the EU economy for as long as possible (European Commission, 2020 ${ }_{[3]}$ ). For an overview of key developments in the EU circular economy policy landscape see Box 3.1.

28. On national and subnational levels, a large number of countries have developed circular economy strategic frameworks and roadmaps. Within the EU alone, more than 60 such frameworks at different levels (national, regional and municipal) have been developed in the past five years. The common aim of these strategic frameworks revolves around furthering the paradigm shift towards a circular economy along eight key building blocks:

- A vision of the desired future state;

- Qualitative goals the transition aims to achieve;

- Links to other policies and strategies;

- An indication of interest groups involved;

- A selection of priority areas;

- Quantitative targets;

- Implementation measures and monitoring; and

- Evaluation and communication plans.

29. Despite the shared goal of developing tools to address circular economy transition, a great diversity of approaches to strategic framework development exists. These largely depend on local context, existing challenges and potential benefits, as well as on the underlying drivers and stakeholder commitment/involvement in the development and implementation of circular economy related policy actions and strategies. The overview of good practices identified is discussed in detail within the Background report on the EU national circular economy strategies. These are largely guiding the development of the elements of the strategic framework for Circular Czechia 2040 contained within this report. 


\section{Box 3.1. Key development of the circular economy policy landscape in the European Union}

Elements of resource efficiency and the circular economy have now been on the European policy agenda for several years. First policy initiatives were outlined in the first EU Action Plan for the Circular Economy: 'Closing the loop' (European Commission, 2015 $\left.{ }_{[8]}\right]$. The Circular Economy Package also contained proposals to amend the EU legislative framework on waste.

In 2018, the European Commission proposed the second Circular Economy Package consisting of an EU Strategy for Plastics (European Commission, $2018_{[9]}$ ), along with a proposal for a Directive to reduce the impact of certain plastic products (European Commission, 2018 ${ }_{[10]}$ ), a Communication on the Interface between chemicals, products and waste legislation (European Commission, 2018 $[11]$ ), a Monitoring framework for the circular economy (European Commission, $2018_{[12]}$ ) and a report on Critical Raw Materials (European Commission, 2018 ${ }_{[13]}$ ). The revised legislative framework for waste was also adopted in 2018.

In 2019, a third Circular Economy Package featured a report on the full implementation of the Circular Economy Action Plan (European Commission, 2019 ${ }_{[14]}$ ), as well as a Staff Working Document on Sustainable Products in a Circular Economy - Towards an EU Product Policy Framework (European Commission, 2019 $[15]$ ).

A number of sector-specific policy packages and legislation were adopted and revised to implement the policy vision set in the 2015 Circular Economy Action Plan:

- Revised EU waste legislative framework:

- Six EU waste directives were revised within the context of the 2015 Circular Economy Package: Directive (EU) 2018/851 amending Directive 2008/98/EC on waste, Directive (EU) 2018/850 amending Directive 1999/31/EC on the landfill of waste, Directive (EU) 2018/852 amending Directive 94/62/EC packaging and packaging waste, and Directive (EU) 2018/849 amending Directives 2000/53/EC on end-of-life vehicles (ELV), 2006/66/EC on batteries and accumulators and waste batteries and accumulators, and 2012/19/EU on waste electrical and electronic equipment (WEEE).

- Revised eco-design and product labelling requirements:

- The eco-design framework directive (Directive 2009/125/EC) is implemented through product-specific implementing and delegated regulations. In 2019, 10 eco-design implementing regulations were adopted by the European Commission (eight revisions and two new product group introductions). These regulations set energy efficiency and other product design requirements, including aspects on reparability, recyclability, durability and water consumption.

- The energy labelling regulation (Regulation (EU) 2017/1369) requires an energy label for 15 product groups sold in the EU.

- The EU Ecolabel regulation provides voluntary labelling scheme for a number of products (Regulation (EC) No 66/2010).

- Introduced EU Fertilising Products regulation:

○ The new EU Fertilising Products Regulation (EU) 2019/1009 introduces harmonised rules for organic fertilisers manufactured from secondary raw materials, such as agricultural by-products and recovered bio-waste.

- Introduced a legislative proposal on Single-Use Plastics

- The new Single Use Plastics Directive (Directive (EU) 2019/904) aims to reduce certain plastic waste, such as marine plastic litter. It covers the single-use plastic 
items, products made from oxo-degradable plastic and fishing gear-containing plastic. It introduces a number of targets as well as a ban on certain single use plastic products for which an alternative exists (e.g. cutlery, plates, straws, cotton bud sticks).

- Chemicals legislation

- The REACH Regulation (EC 1907/2006) aims to protect human health and environment by obliging companies to identify and manage risks related to chemical substances they produce and sell.

In March 2020, the New Circular Economy Action Plan was released, as part of the European Green Deal, in which Circular Economy is considered a key pillar for the EU environmental policy (European Commission, 2020 ${ }_{[3]}$ ). The New Circular Economy Action Plan specifies future-oriented agenda for the transition to a circular economy, including 35 legislative and non-legislative proposals (European Commission, 2020 $0_{[3]}$ ). This includes measures to stimulate sustainable production, empower consumers and public buyers, reduce waste and make circularity work for people, regions and cities, just to name a few. The Action Plan also focuses on a number of strategic product value chains, such as electronics, plastics, or textiles.

The aim of the European Green Deal, incorporating this Action Plan as one of its main building blocks, is to transform the European Union into a modern, resource efficient and competitive economy, which is carbon neutral by 2050, and where economic growth is decoupled from resource use (European Commission, 2019 [16]). 


\section{Rationale for transitioning to a circular economy in the Czech Republic}

\section{Current trends and macroeconomic projections}

30. The Czech Republic has made notable progress in decoupling environmental pressures from economic activity in the past decades. However, its economy remains among the most energy-, carbon- and resource-intensive in the OECD and the European Union, due to a strong industrial base and reliance on coal (OECD, 2018 $\left.{ }_{[1]}\right)$.

31. As wealth increases and living standards in the Czech Republic converge towards the EU averages, the demand for resources and materials is projected to further increase. GDP per capita for the Czech Republic will likely grow faster than the OECD and EU averages, with a projected increase by over $2 \%$ between 2020 and 2050 driving the increased demand for resources. In particular, in sectors where the Czech Republic has a comparative advantage, such as motor vehicles, construction and non-metallic minerals sectors, further growth is expected to occur over the next decades.

32. Structural changes in the economy towards more servitisation will likely increase resource efficiency and lead to growth in services sectors, whilst material-intensive sectors will grow below average. Construction is the exception, where high infrastructure investments will maintain resource demand in the upcoming decades. Changes in production modes, such as the uptake of technological progress across sectors (e.g. ICT), digitalisation and the increased penetration of renewable energy will further increase resource efficiency of production. These will in turn enable to partially mitigate the rise in materials use driven by economic growth and increased consumption.

33. Yet, despite the decoupling trends through structural ${ }^{4}$ and technological changes ${ }^{5}$, overall materials consumption in the Czech Republic is still projected to increase by about one third by 2050 compared to 2017 levels (from $0.26 \mathrm{Gt}$ to $0.34 \mathrm{Gt}$ ). This development will generate significant pressures on the environment, putting the Member State at risk of missing important environmental goals (Figure 4.1).

34. Especially non-metallic minerals (such as construction sand, gravel and crushed rock) are projected to increase at a faster rate than the other EU and OECD averages, due to a gradual ramp-up of infrastructure investments (

35. Figure 4.2). This increase in materials use is likely to have large associated environmental impacts (notably high acidification, increased greenhouse gas emissions which in turn lead to rising temperatures, sea level rise, extreme weather events - and increased cumulative energy demand from combustion of fossil fuels).

\footnotetext{
${ }^{4}$ Shift activity away from material intensive sectors but construction.

${ }^{5}$ Change in production modes, for instance the growing importance of recycling and secondary metals.
} 
Figure 4.1. Projected raw materials use of the Czech Republic and its decomposition

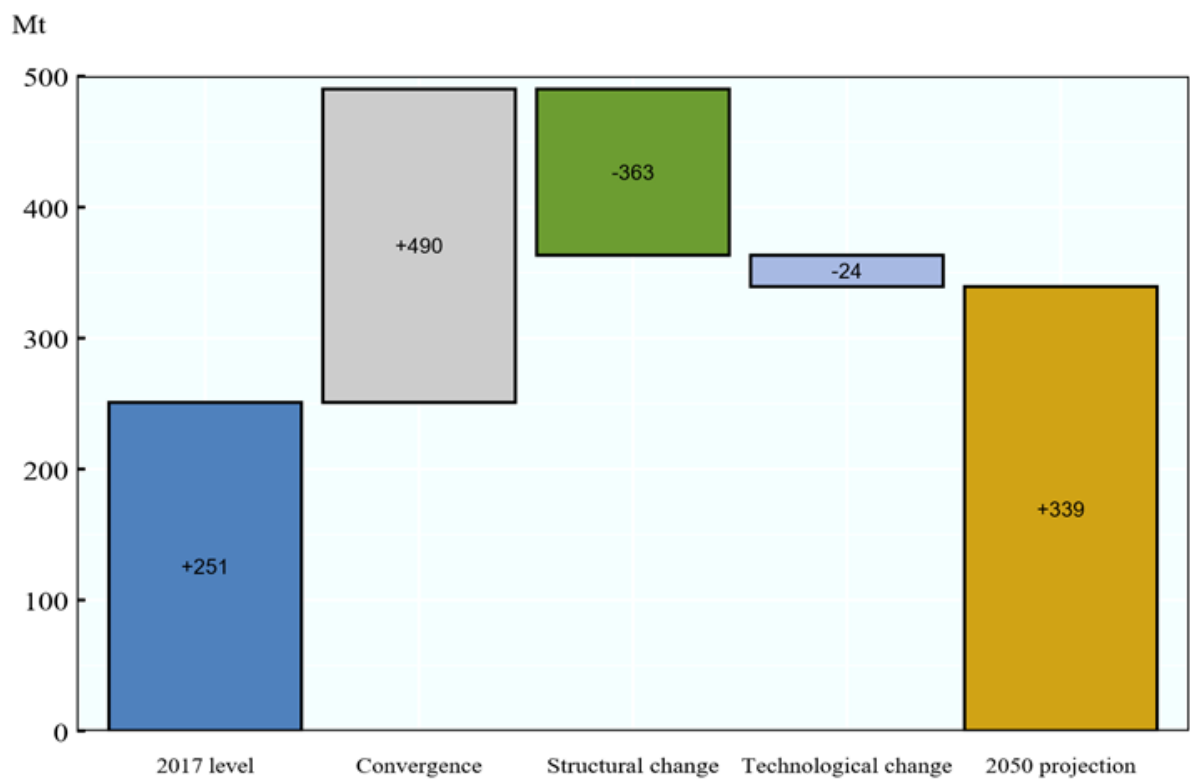

Source: ENV-Linkages model.

Figure 4.2. Projected global raw materials use in different country groups

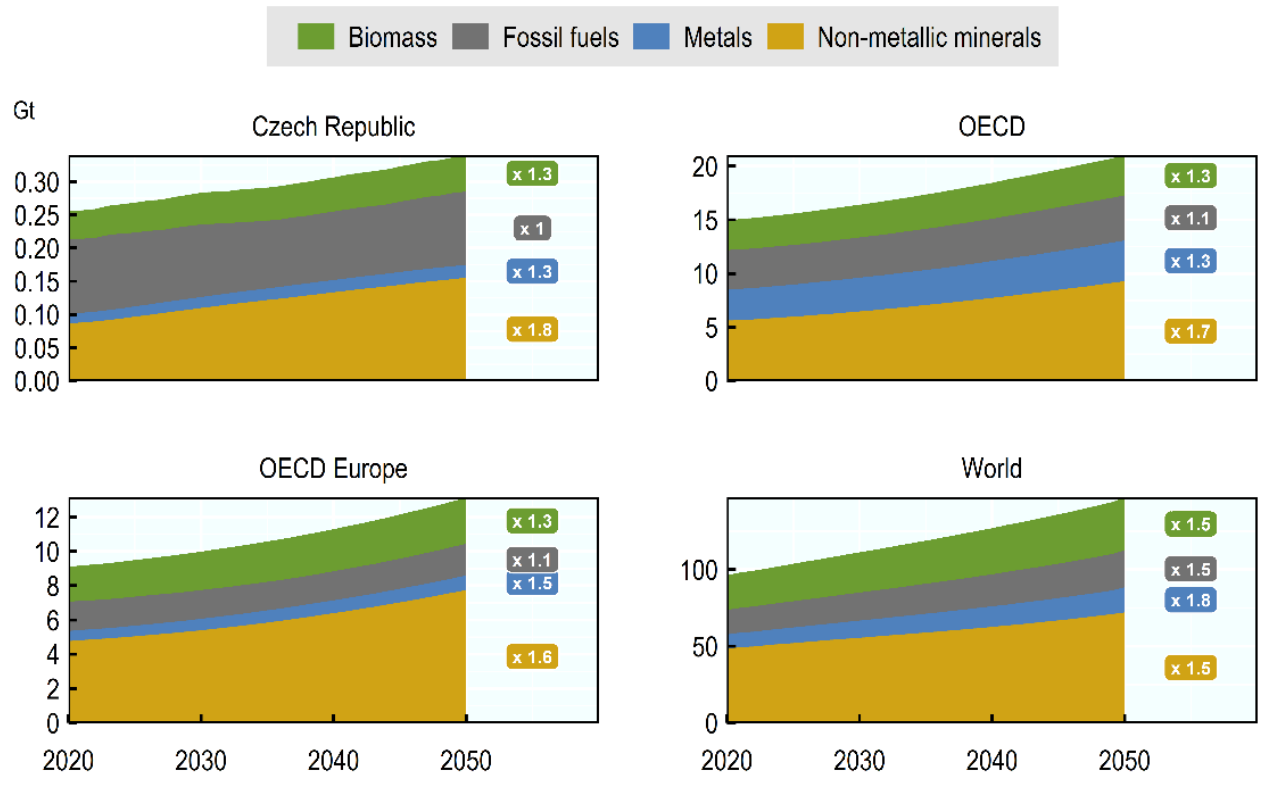

Source: ENV-Linkages model.

36. Additional policies are thus needed to achieve stronger decoupling of material use from economic growth and from greenhouse gas emissions by supporting more structural and technological changes. These drivers are projected to slow down the growth in materials use, but are not sufficient to reach absolute decoupling of material consumption 
from GDP. The potential for increased technological change appears particularly large, given its small contribution towards decoupling in the baseline scenario.

37. The national circular economy strategy could also help focus policies on manufacturing, construction and the food industry, which are among the most material intensive, and thus provide significant potential for cost-effective resource efficiency improvements. Considering the high environmental footprint of metals, circular policies would need to foster innovative changes in production modes in the manufacturing sector towards using more recyclables and secondary metals, and improving resource efficiency. Strengthened efforts to reduce food loss and waste would help improving resource efficiency in the food sector. Decoupling construction materials from economic growth may be more challenging, as the development of the sector often follows economic growth. Nevertheless, resource efficiency improvements are feasible and necessary in this area as well. 


\section{Box 4.1. Greening the COVID-19 recovery through circular economy}

\section{Role of circular economy in COVID-19 recovery}

The COVID-19 pandemic has evolved from a major sanitary crisis to become a major socioeconomic crisis spanning beyond 2020. From an environmental perspective, the pandemic is closely intertwined with climate change, biodiversity loss, pollution, and waste management, both in terms of its origin and the implications for environmental outcomes (OECD, 2020 [17]]). Addressing global environmental issues, while seeking to rebuild the economies and enhancing resilience against future shocks, therefore becomes more important than ever.

Circular economy has a key role to play in the recovery from the global pandemic, and is one of the means to "building back better". As a channel to decouple economic growth from resource use and its environmental impact, it opens up a way for resilience and green growth in the long term, generating new circular business opportunities and providing social and environmental benefits (Ellen MacArthur Foundation, 2020 $\left.0_{[18]}\right)$.

\section{COVID-19 recovery in Europe}

A key means to deliver the European Green Deal, circular economy is also considered to play an essential role in rebuilding the post-COVID-19 Europe into a greener, more digital and more resilient economy. As much as a third of the EU's multiannual financial framework 2021-2027 and the temporary recovery instrument NextGenerationEU (adding up to EUR 1.8 trillion) is planned to be channelled into fighting climate change (European Commission, 2020 ${ }_{[19]}$ ), part of which includes allocations for natural resources and environment, and thereby also circular economy measures.

The core initiatives will focus on massive renovation of buildings and infrastructure and a more circular economy, rolling out renewable energy projects and kick-starting clean hydrogen economy, on cleaner transport and logistics, and on strengthening the Just Transition Fund supporting reskilling for business to create new economic opportunities, to name a few (European Commission, $\left.2020_{[19]}\right)$.

\section{Greening the COVID-19 recovery in the Czech Republic}

In order to green investment opportunities and extract their environmental benefits, to increase resilience of the Czech economy, and to facilitate the transition towards circular economy and climate neutrality, the Czech Republic's Recovery and Resilience Plan (RRP) needs to include policy measures that integrate social and environmental concerns. The EU funding offers an opportunity for the Czech Republic to finance a package of reforms and public investment projects, which would address country-specific challenges and COVID-19 recovery priorities.

According to the working draft of the recovery plan proposal (Euractiv, 2020 [20]; Zachová et al., $2020_{[21]}$ ), the Czech Republic intends to spend a substantial proportion of the funds on Physical Infrastructure and Green Transition, directing investments into transportation and the transition to a low-carbon economy. While targeting the uptake of renewable energy technologies is important (especially those further from the market, such as energy storage), measures to improve resource efficiency and the transition towards a more circular economy through investments supporting reparability, reusability, remanufacturing and recycling should not be neglected either (Agrawala, Dussaux and Monti, 2020[22]). To reap the environmental, economic and social benefits of the circular economy transition in the post-COVID-19 world, the Czech Republic might consider including such considerations into the process of developing its RRP. 


\section{Challenges in the Czech Republic around waste and materials management}

38. Both upstream (at the material consumption stage) and downstream (at the waste generation stage) growing environmental pressures require action. Economically efficient and environmentally sound waste management represent a challenge for the Member State, and more effort is needed to comply with the EU recycling targets for the post-2020 period.

39. High shares of direct landfilling, low resource recovery rates, cost inefficiencies in waste management and insufficient waste prevention have been identified as some of the challenges in recent environmental reviews by the OECD (OECD, 2018 ${ }_{[1]}$ ) and the European Commission (European Commission, 2019 ${ }_{[2]}$ ). With municipal waste recycling rates ranging from $34 \%$ (Eurostat, 2020 ${ }_{[23]}$ ) to $39 \%$ (Ministry of the Environment of the Czech Republic, 2019 ${ }_{\text {[24] }}$ ) in 2018 (including composting and digestion), these are among the lowest of the OECD and the EU-Member States. ${ }^{6}$ At the same time, landfilling remains the main treatment option accounting for $46 \%$ (Ministry of the Environment of the Czech Republic, 2019 [24]) and 49\% (Eurostat, 2020 ${ }_{[23]}$ ) in the same year. ${ }^{7}$

40. Increasing recycling, diverting waste from landfilling, promoting waste prevention and improving the environmental and economic efficiency of waste management are the key challenges that require more policy action. To respond to these, it has been recommended to invest in recycling infrastructure, to improve separate collection of waste, to increase landfill taxes, to develop markets for secondary raw materials, to improve transparency and the functioning of extended producer responsibility (EPR) systems, and to strengthen the institutional framework establishing a broader cooperation between relevant stakeholders (OECD, 2018 ${ }_{[1]}$; European Commission, 2019 $[2]$ ). Additionally, discrepancies between the two data information reporting systems on waste statistics (by the Ministry of the Environment and the Czech Statistical Office) will require reconciliation and harmonisation, in order to enable more consistent policy planning and monitoring.

\section{Existing policy landscape in the Czech Republic}

41. There is a well-developed and fairly complete policy and legal framework related to waste, resources and enabling policy landscape in the Czech Republic (CR). The Czech Republic also has an overarching sustainable development Strategic Framework 2030 and the State Environmental Policy to 2020 (currently being updated), both including the notions of circular economy. Moreover, policy frameworks on waste, raw materials and the bioeconomy provide relevant policy guidance, and jointly constitute the core of the circular economy policy landscape in the Czech Republic ${ }^{8}$ (see Box 4.2 and refer to the inner circle in Figure 4.3).

\footnotetext{
${ }^{6}$ The recycling rate of materials from municipal waste was $27 \%$ by weight in 2018 , slightly below the EU average of $30 \%$, and $7 \%$ by weight recycling rate from composting and digestion, compared to $17 \%$ for the EU average (Eurostat, $2020_{[23]}$ ).

${ }^{7}$ For more information on the two information systems for waste management please refer to footnote 19 .

${ }^{8}$ Defined as policies focusing largely on circular economy or on at least one of its core principles.
} 
42. Regarding directly related policies to circular economy, ${ }^{9}$ the Czech Republic has paid a lot of attention to the digital economy transformation agenda, which is strongly relevant to the development of innovative circular economy business models. In addition, there is an innovation related policy framework, which further supports the transition to a circular economy. Other directly related policies are in the areas of energy and climate, agriculture, transport, regional development, environment and consumer protection (refer to the outer circle in Figure 4.3).

Figure 4.3. Overview of the Czech policy landscape

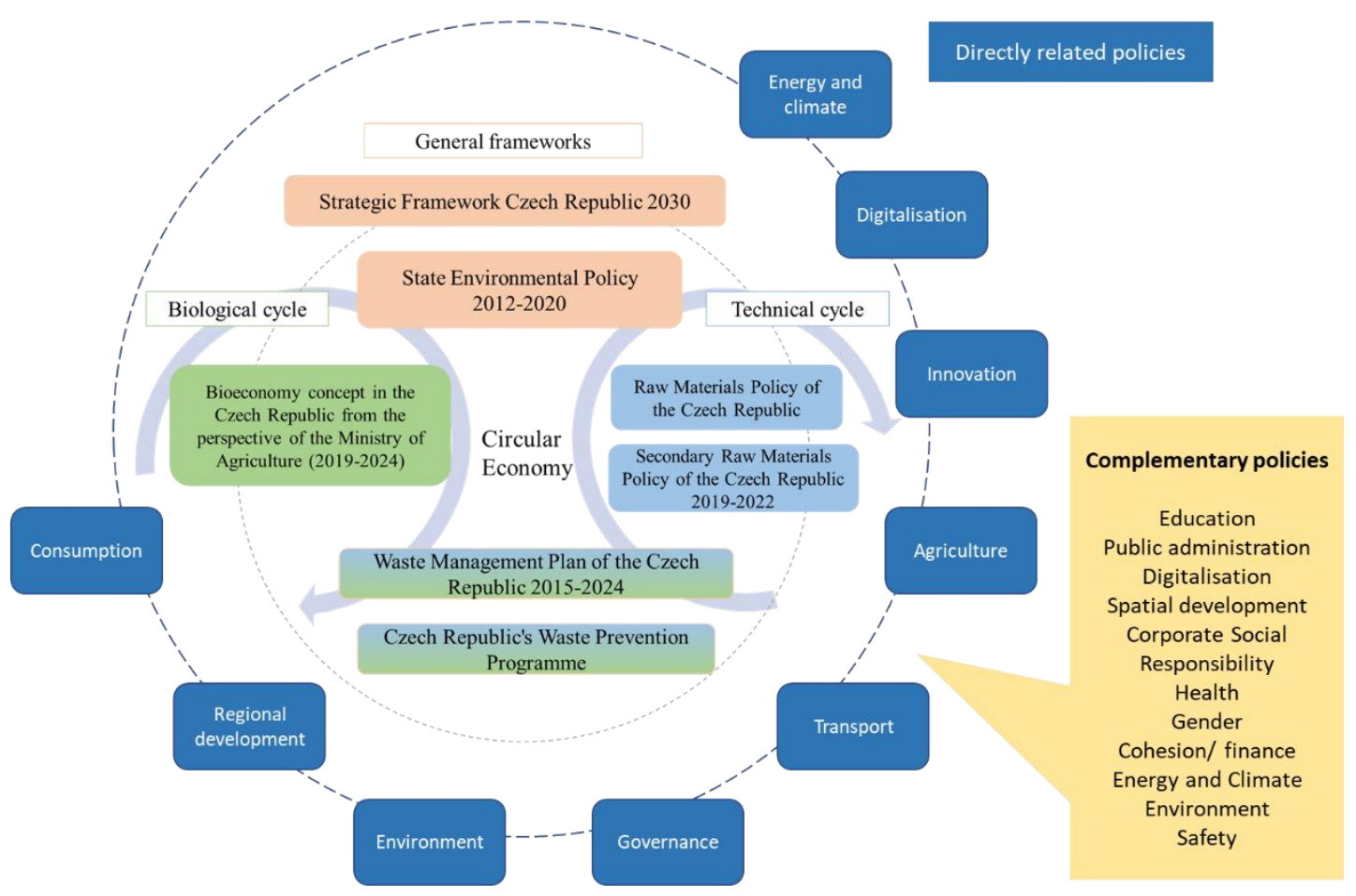

Source: Own elaboration.

43. Nonetheless, to date, the Czech Republic does not have a separate strategic framework that provides a comprehensive and coherent roadmap for implementing circular economy measures across the different sectors and policy areas. Often, policy packages are also missing more operational guidance and concrete targets.

\footnotetext{
${ }^{9}$ Defined as policies directly relevant to one of the circular economy sectors or principles, however, which go beyond them in scope. Such policies apply to a wider range of areas besides circular economy. Additionally, a group of policies with less direct links to circular economy, and going beyond it in their scope, have been identified as complementary (refer to the yellow callout in Figure 4.3). The policies often act as an enabling factor to the circular economy, but can be applied to a wide range of areas. The Background report on the Czech policy landscape includes the full list and titles of all policy documents reviewed.
} 


\section{Box 4.2. Overview of relevant Czech policy initiatives for circular economy and resource efficiency}

The Strategic Framework Czech Republic 2030 and the State Environmental Policy 2012-2020 provide a general basis for a national environmental strategy. Circular economy and resource efficiency are in parts addressed in these high-level frameworks. In addition, the Czech policy landscape includes a number of sector-specific policy initiatives relevant to resource efficiency and circular economy.

Waste related core policy documents

- The Waste Management Plan 2015-2024 (WMP) (currently being updated) outlines the CR strategy on waste management for a ten-year period, establishing objectives, policies and measures for waste management in the Czech Republic. It is also the defining document for the development of waste management plans of the regions. Besides binding objectives and targets it stipulates non-binding waste management priorities for the next ten years.

- Linked to the WMP is the Waste Prevention Programme (WPP), the main strategic document for waste prevention.

Raw materials related policy documents

- The Secondary Raw Materials Policy of the CR 2019-2022 includes circular economy in its vision. The policy sets out strategic goals for the extraction, processing and use of secondary raw materials from domestic and imported sources, with a focus on ten priority commodities.

- The Raw Materials Policy of CR addresses energy and non-energy raw materials, ore and non-ore commodities, including energy, construction and high-tech mineral resources. The strategy's main goal is the security of supply of raw materials.

Bioeconomy related policy document

- The Bioeconomy concept in the Czech Republic from the perspective of the Ministry of Agriculture 2019-2024 links the biological cycle to the circular economy, including aspects of ecosystem and ecosystem services, rural areas, economy, food, innovation and research. The policy document provides a high-level vision on bioeconomy in the Czech Republic, which might be followed by a more concrete bioeconomy strategy, if this shows to be needed.

44. Besides lacking an overall comprehensive strategy, there are gaps in certain areas in the existing circular economy relevant policy frameworks. In these areas, policy coverage is less systematic and comprehensive across individual sectors and/or lacks operational guidance with concrete measures to implement their objectives. The five areas where this is most apparent include: (1) product eco-design; (2) economic and financial instruments; (3) consumer information and behaviour; (4) innovation and research; and (5) reverse logistics.

- Product eco-design is very well covered by the Secondary Raw Materials Policy of the CR 2019-2022 and the Industry 4.0 initiative, however, these policy documents apply only to their respective areas of scope. An overall approach to circular product design needs to be explored, which also covers product modularisation, design for disassembly and assembly, durability, and use of bio-based materials, among others. 
- There is a gap of an adequate and comprehensive system of economic and financial instruments. Existing economic and financial instruments cover waste management (e.g. landfill taxes, local charges on municipal waste), resources (e.g. resource fees for extraction of materials) and provide incentives for circular economy projects and initiatives (e.g. the EU and national grants and loans programme). However, some of the existing economic instruments need to be strengthened and some new instruments should be introduced.

- Whilst policies around consumer safety and protection on consumer online platforms exist, and overall approach to consumer information and behaviour is lacking. New measures are needed, for example, the provision of information on durability and reparability of products at the point of sale, environmental labelling, measures or incentives to stimulate circular-conscious consumption.

- The current research and innovation policy framework is rather general and misses specific links to the circular economy. Moreover, a fragmented R\&D policy and funding framework seems to be hampering the development of eco-innovation (OECD, 2018 $\left.{ }_{[1]}\right)$.

- Lastly, reverse logistics is an important aspect of a circular economy, and may need to be addressed more explicitly. These include aspects around collecting, aggregating and transporting products and materials from users back to the manufacturers for remanufacturing, repair and reuse. While reverse logistics for waste is well covered by the waste management policy in the Czech Republic, the collection of by-products and used goods - which are suitable for reuse, repair, refurbishment and remanufacturing - as well as logistics infrastructure supporting biomass and bio-based products reuse and processing could be further explored. 


\section{Direction of change towards Circular Czechia 2040}

45. The circular economy vision spells out the big picture individual countries wish to achieve by embarking on the path to a circular economy transition. Being positioned within the current context of country's sectoral trends, its political priorities, and the international context (i.e. climate, development, and trade policies), such vision is ideally linked with the existing national and international strategies, and takes equal account of economic, natural and social capital (Weber and Stuchtey, 2019 ${ }_{[25]}$ ). Moreover, for a vision to be compelling, it is crucial for it to develop a narrative that makes the transition to circular economy relevant to all stakeholders involved.

46. The Ministry of the Environment has developed the following vision for the circular economy strategic framework towards 2040 (Circular Czechia 2040): In 2040, the circular economy brings significant environmental, economic and social benefits to the Czech Republic. Through implementing policy measures, the Czech Republic shows a systematic support to the circular economy as a model for improving environmental protection, strengthening competitiveness and technological maturity of the economy, creating new jobs, increasing the security of raw material supply, and enabling citizens in relevant sectors to acquire new skills and expertise.

47. In this vision, the circular economy is seen as a new model of economic, environmental and social development, which shall help to reach the goal of "generating less waste and more value added for the Czech Republic". It shall be operationalised through the following strategic goals:

- Improving environmental protection;

- Reducing waste generation and better waste management;

- Strengthening competitiveness;

- Creating new jobs;

- Increasing supply security of raw materials, efficiency of natural resources management, and share of renewables;

- Improving technological maturity and innovation;

- Promotion of innovative forms of consumption;

- Acquiring new competences, knowledge and skills;

- Creating an environment free of toxic substances and protecting the health of the population; and

- Expanding circular economy to regional and municipal levels.

48. In order to make the vision more specific and actionable on the level of individual priority areas, this report formulates separate visions for individual priority areas within the Czech economy. These are building on the Czech-specific context and the visions from related Czech policies, such as the Strategic Framework 2030, the State Environmental Policy 2020-2030 up to 2050, and the Secondary Raw Materials policy 2019-2022. 
- Raw materials: Raw materials are optimally deployed by 2040 in the Czech Republic, secondary raw materials are used by default in the economy, and virgin raw materials are used only where absolutely necessary.

- Production and consumption: Czech firms implement new production methods using state-of-the-art technologies to design and manufacture products in a sustainable way. Circular business models are promoted in production and consumption of products and services in the Czech Republic.

- Waste management: Waste is reduced where possible, recycling and reuse is maximised, and energy recovery is opted for only when waste cannot be prevented, recycled or reused. Landfilling is only used as a last resort. By 2040, the Czech Republic aims to increase the recycling of all waste types to the maximum possible levels, to significantly decrease waste generation per capita, and to reduce landfilling rate to below the EU target.

- Research, innovation and digitalisation: Czech firms are involved in high-end services in the value chain related to engineering and $R \& D$. Part of the state $R \& D$ funding is earmarked specifically for circular economy related projects and R\&D programmes. The use of digital technologies is wide-spread in the Czech Republic.

- Industry and competitiveness: Czech firms are competing in eco-innovation and digital technologies on global markets. By investing into circular economy, Czech industries increase their competitiveness and reduce their resource dependence and costs.

- Employment and education: By transitioning to a circular economy, 50 thousand jobs (around 1\% of current employment) are created by 2040. Circular economy as a concept is incorporated in the entire educational system. 


\section{Priority areas and their circular potential}

\section{Prioritisation of areas to focus on in the Czech economy}

49. In order to fulfil the vision for Circular Czechia 2040, and to achieve the qualitative goals for operationalising this vision, the systemic paradigm change in the Czech economy should focus on certain number of priority areas. As shown by international experience, the selection of priority areas shall be guided by either strategic considerations or the results of a quantitative analysis. Depending on the prioritisation approach, the focus areas are either selected from across different sectors/systems, or from along the value chain stages, or as a combination of the two. Additionally, overarching horizontal measures are often included.

50. Informed by the good practices from across the EU Member State circular economy strategies, the selection of priority areas for circularising the Czech economy is an outcome taking into account the results of the macroeconomic projections and policy landscape analysis (as reported in the background reports to the project), coupled with the strategic considerations formulated by the Czech Government:

- As shown by the projections of the macroeconomic analysis (section on Current trends and macroeconomic projections), in order to speed up the decoupling trend, new policies need to be implemented to facilitate structural and technological change targeting the most material intensive sectors, such as manufacturing, construction and food sectors ${ }^{10}$.

- Furthermore, the outcome of the Czech policy landscape analysis (section on Existing policy landscape in the Czech Republic) points to policy gaps in product eco-design, economic and financial instruments, consumer information and behaviour, innovation and research, and reverse logistics.

- Finally, a prioritisation along the strategic importance of individual focus areas has been proposed by the Circular Czechia 2040 project working group ${ }^{11}$. In particular, 10 priority areas have been identified, covering both sectors/systems, horizontal initiatives, and value chain stages as follows:

- Value chain: Products and design; consumption and consumers; waste management;

○ Sectors/systems: Industry, raw materials, construction, energy; bioeconomy and food; water management; smart cities, smart regions, infrastructure;

\footnotetext{
${ }^{10}$ In addition to these, circular policies could help reduce material uses accelerating changes in production and uses along the value chains of motor vehicles and electronics (of which the Czech Republic will remain an exporter) and textiles (where demand for imported products in increasing over time).

${ }^{11}$ This is a stakeholder working group, set-up by the Ministry of Environment and including experts of the Ministries of Environment, Industry and Trade, as well as any other Ministries, state agencies and offices, and stakeholders from industrial associations, NGOs related to circular economy and academia.
} 
- Horizontal initiatives: Research, innovation and digitalisation; education and knowledge; economic instruments.

51. In light of the outcomes of different prioritisation exercises, and drawing on the evidence and insights gathered from international good practices for prioritisation approaches and priority area selections, the Circular Czechia 2040 strategic framework developed in this report:

- Adopts a life cycle approach, identifying circular potential and policy recommendations for the individual stages of the value chain, in particular on production and design; consumption and consumers; and waste management;

- Addresses horizontal measures that advance the transition to a circular economy across multiple sectors and systems, in particular those of research, innovation and digitalisation; economic instruments; and education and knowledge;

- Provides insights into specific sectors through the lens of their environmental/resource use implications, and examples of good practices, focusing on bioeconomy and food; industry, raw materials, and construction; plastics; textiles; electronics; and household waste.

52. Adopting such three-pronged approach to prioritisation and priority area selection, the design of the strategic framework aims at conveying a holistic perspective on circularising the Czech economy. Note that this report develops insights into most, but not all, of the proposed priority areas of the Czech circular economy strategic framework. The results presented in this report are intended to feed into, and extend the analysis of, the Circular Czechia 2040 strategic framework drafted by the Ministry of Environment. The circular economy framework, and its individual elements, are illustrated in Figure 6.1.

Figure 6.1. Priority areas to be targeted within the Circular Czechia 2040 strategy

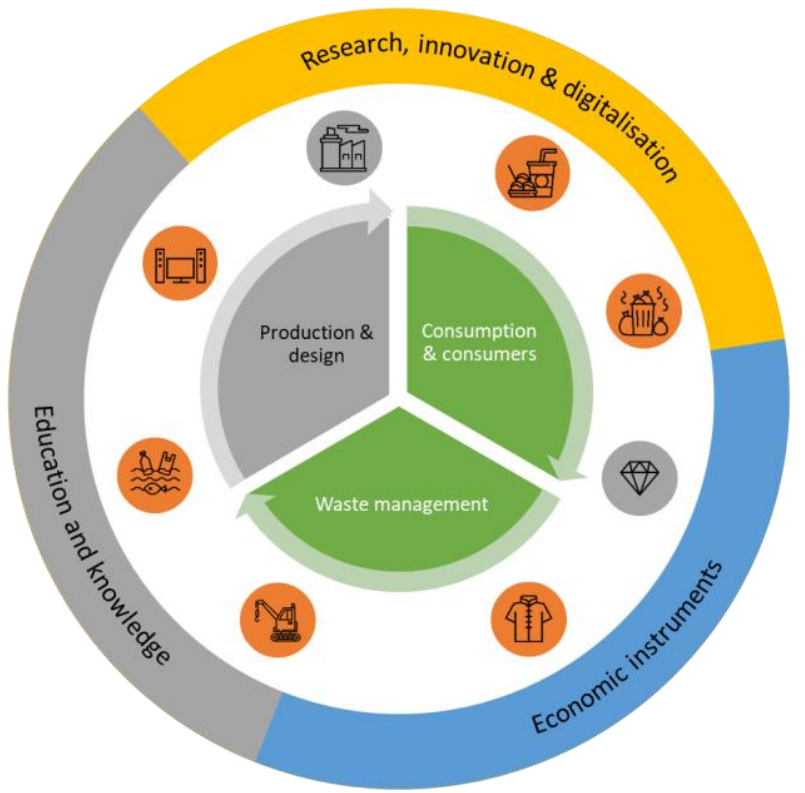

Note: This figure illustrates the priority areas to be included into the circular economy strategic framework for Circular Czechia 2040, as drafted by the Ministry of Environment. Note that the grey shaded areas have not been addressed within this report, but might be included within the final strategy by the Czech Government. Source: Own elaboration. 
53. The prioritisation approach and priority areas selection described above, also directly inform the structure of the forthcoming sections. These provide a discussion of the status quo and the opportunities in the individual areas covered within this report, as follows:

- The status quo and high-level policy recommendations along the two stages of the value chain;

- Two overarching horizontal measures; and

- Both illustrated with insights from across six sectors.

\section{Circularising priority areas along the life cycle}

\section{Consumption and consumers}

\section{Role of consumer behaviour and consumption patterns for the circular economy}

54. Changes in consumption patterns and consumption behaviour play a fundamental role in reshaping the economy. Even if not directly involved in the production processes, consumers' behaviour can strongly influence the former through changes in demand patterns. This has now also been acknowledged and reflected in the sustainable product policy framework of the new EU Circular Economy Action Plan (European Commission, $2020_{[3]}$ ).

55. To drive the transition towards a circular economy, consumers need guidance for a more circular behaviour. Preventing food waste, separating household waste, purchasing products that are recyclable, repairable, reusable, avoiding single-use products, and opting for durable goods with high-quality and extended warranty, are examples of circular consumption patterns. Despite the fact that consumers across the EU declare their willingness to be involved in circular consumption practices, their engagement rate is in reality quite low ${ }^{12}$.

56. Policy instruments need to be introduced to positively shape circular consumer choices and behaviour. On the level of the EU, sectoral and horizontal policies furthering circular economy have been historically focusing on plastics, food waste, critical raw materials, construction and demolition, biomass and bio-based products (European Commission, 2015 $[8]$ ), and later also on the textile sector (European Commission, 2019 $9_{[15]}$ ). The new Circular Economy Action Plan extends this list to include electronics, batteries and vehicles, food, water and nutrients, packaging, plastics, and construction and buildings value chains (European Commission, 2020[3] $)$.

\section{Evidence on consumer behaviour and attitudes towards the circular economy in the Czech Republic}

57. In the Czech Republic, the key priority areas, in terms of their relevance from the perspective of consumer behaviour, are food and municipal bio-waste, plastics, textiles, and electrical and electronic equipment (EEE). In these sectors, more than anywhere else,

\footnotetext{
${ }^{12}$ Almost $90 \%$ of consumers have never bought second-hand products or rented, leased and shared any item or service, and around $36 \%$ have never repaired their products in the past (LE Europe et al., $\left.2018_{[136]}\right)$.
} 
the consumer behaviour patterns and their choices are crucial in influencing the product design, use, and end-of-life stages.

58. There are different ways in which the current linear consumption patterns influence these sectors. For instance, in the textiles sector, the demand for and production of fast fashion has been dramatically reducing the average lifetime of clothes, with significant adverse impacts on the environment ${ }^{13}$. The increasing production and consumption of EEE coupled with the growing variety and complexity of products, negatively impact their repair and collection through take-back schemes, and waste generation. Similarly, the production of plastics has been increasing at a staggering rate, with direct impact on the generation of plastic waste. Last but not least, the relatively high proportion of bio-waste ending up in mixed municipal waste (around 50\% of municipal solid waste over the past years compared to around an EU average of 30-40\%) implies that sorting of waste from markets and shops and bio-waste from residential buildings (among others) seems still to be a challenge in the Czech Republic (European Environmental Agency, 2013 [26]; Czech Statistical Office, $\left.2019_{[27]}\right)$.

59. In contrast with the impacts of their behaviour, the reported Czech citizens' attitudes and behaviour towards waste prevention and reduction can generally been seen as fairly positive. For instance, a consumer survey showed that $85 \%$ of Czech consumers sort at least occasionally waste of electrical and electronic equipment (WEEE), while as many as $96 \%$ of Czech citizens (among the highest share in surveyed EU Member States) waste less than $15 \%$ of the food they buy (European Commission and TNS Political \& Social, $\left.2014_{[28]}\right)$. When it comes to sorting and recycling of packaging waste, more than $90 \%$ of Czech citizens sort at least occasionally paper, cardboard and beverage cartons, plastic bottles and other plastic materials, and glass (European Commission and TNS Political \& Social, $\left.2014_{[28]}\right)$. With regards to textiles, there are no statistics collected yet ${ }^{14}$.

\section{Consumer oriented circular economy legislation in the Czech Republic}

60. In light of the above evidence, there are several pieces of circular economy related legislation in the Czech Republic, which establishes instruments whose primary or secondary aim is to create incentives for consumers to behave in a more resource efficient and circular fashion. These largely relate to waste prevention, reduction, recycling and packaging. The current Waste Act (No. 185/2001 Coll.) regulates the local charges on municipal waste (also regulated by the Local Charges Act) and the EPR schemes for a variety of end-of-life products, as well as their sorting by consumers and separate collection by municipalities. The Packaging Law (No. 477/2001 Coll.) regulates the introduction of deposit refund systems (DRS) for packaging, as well as the EPR obligations for companies introducing packaging or packaged products onto the market. The level of deposits for the across-the-board DRS system for a selection of glass bottles is stipulated in the Government Decree No. 111/2002 Coll. Even though unrelated in their scope to circular economy, still other policies and legal frameworks regulate matters impacting the circular behaviour of

13 The textiles and clothing production and consumption models exacerbate environmental implications on land, water, energy, and resource uses, while also emitting greenhouse gases and generating packaging waste (Wencke Gwozdz/Kristian Steensen Nielsen/Tina Müller, 2017 ${ }_{\text {[137] }}$ ) (Koszewska, 2018 ${ }_{[138]}$ ) (Šajn, 2019 ${ }_{[139]}$ ) (WRAP, 2012 $\left.[140]\right)$.

${ }^{14}$ In general the textiles sector has not received much attention, since for the moment there is no legal obligation to report on such waste, nor are there any targets set. 
consumers, such as local municipal waste charges, value added tax (VAT) of some goods and services, consumer protection, product labelling, and food regulation.

61. More specifically, the above legal frameworks and related policies include 12 policy instruments relevant for circular economy and consumers. These can be categorised into six broad categories.

- Economic instruments: Environmental tax (local charge on municipal waste PAYT), tax reduction (VAT reduction for municipal waste collection, treatment and disposal services);

- Regulatory instruments: EPR (for packaging and WEEE), DRS (for certain glass bottles), separate collection of municipal waste (mandatory for bio-waste and hazardous waste, as well as for plastics, paper, glass and metals; voluntary for textiles, furniture and bulky waste), support to online platforms stimulating sharing and repair;

- Voluntary agreements: Enough of Plastics initiative;

- Information instruments: Awareness raising initiatives by the Ministry of the Environment, EKO-KOM (the collective system for packaging EPR) and NGOs, ecolabelling (Czech and EU ecolabels), product labelling (sale of used products);

- Education and capacity building: National Programme of Environmental Education, Awareness Raising and Environmental Consulting 2016-2025 and its Action Plan for 2019-2021;

- Cooperation: Cooperation by Ministry of the Environment with charities and NGOs to support extension of the lifetime and reuse of products.

62. In December 2019, a new waste package was approved by the Czech Government, whose main aim is to increase sorting and recycling of waste, to decrease landfilling, and to transpose and fulfil the recent EU waste legislation and targets (Ministry of the Environment of the Czech Republic, 2019 ${ }_{[29]}$ ). This waste package includes a proposal for an updated Waste Act, Packaging Law and End-of-Life Products Law, and includes proposals for instruments, such as mandatory separate collection points for textiles as of 2025, incentives for wider introduction of pay-as-you-throw (PAYT) system for households, and strengthened obligations for producers/importers to inform the consumers on take-back, collection, reuse, recovery or disposal of certain end-of-life products (e.g. packaging, end-of-life vehicles (ELV), batteries and accumulators, tyres and EEE).

\section{Policy recommendations for a more circular consumption}

63. The majority of Czech policy instruments have implicitly or explicitly waste prevention as their goal, followed by recycling, and then reuse. Some of these instruments provide adequate incentives for consumers to engage in circular consumption behaviour (such as the DRS for glass bottles and EPR for packaging ${ }^{15}$, as well as the National Programme for Environmental Education and Awareness Raising). However, for other instruments it seems to be less so. The below discussion identifies how those could be strengthened within the existing Czech policy framework. The specific implementation actions are listed in the Implementation plan in chapter 7. of this report.

\footnotetext{
${ }^{15}$ In particular, the EPR for packaging has been evaluated as one of the most cost-effective EPR schemes for packaging in Europe (European Commission, 2014 ${ }_{[132]}$ ).
} 


\section{Strengthen waste prevention efforts for food, plastics and packaging waste}

64. Although several existing and planned initiatives to avoid waste generation are already in place in the Czech Republic, there is significant room for more effective incentives for waste prevention in the areas of food, plastics and packaging. In particular, the initiatives in place include regulatory instruments for food waste prevention (linked to food banks and charities, rather than to circular economy and consumers), voluntary agreements and regulation in the plastic sector (the initiative \#dostbyloplastu primarily targeting companies and organisations in the fast food sector; the recently introduced obligation to make plastic carrier bags available to the consumers for a price corresponding to at least the cost of their purchase, however with very lightweight bags being exempt), and door-to-door collection schemes (which have a limited scope). Strengthening these waste prevention efforts therefore requires the introduction of new instruments, which would better reflect the environmental impacts, incorporate the waste treatment and disposal costs, and thereby discourage the consumption of specific products (refer to Box $6.1)$.

\section{Box 6.1. International good practices in voluntary agreements and environmental taxes on plastic bags}

In order to discourage consumption of specific items (for instance plastic bags), new instruments could be introduced, which would reflect the environmental impacts and incorporate waste treatment/disposal costs. These could be alternative or complementary to existing EPR schemes, and may take the form of voluntary agreements (including reduction targets) or environmental taxes and bans.

An example is the voluntary agreement signed in 2009 between the regional Government of Catalonia and all distribution and manufacturing organisations. The aim of the Pacte per la Bossa (Bag Pact) was to reduce the consumption of single-use plastic bags by $50 \%$ in 2012 . In reality, consumption had declined to 156 bags per capita in 2012 (down from 327 bags in 2007), what represents a reduction of $54 \%$ (i.e. slightly above the original goal of the agreement) (Agència de Residus de Catalunya, 2020[30]).

An example of environmental tax is the Irish plastic bag tax. Plastic bags were one of the main objects found in litter in Ireland. As a result the Irish Government decided to introduce an environmental levy on them, in order to discourage their consumption, encourage the use of reusable bags, and help change attitudes to litter and pollution. The levy was introduced at EUR 0.15/bag in 2002, and further increased to EUR $0.22 /$ bag in 2007. The result has been a $90 \%$ decrease in the use of plastic bags (Irish Environment, 2015 [31]). Plastic bags are currently at $0.13 \%$ of Irish litter pollution, which means a severe reduction in its proportion compared to the year of introduction of the levy.

65. Another measure is linked to supporting the establishment of public-private collaborations among different stakeholders along the product life cycle, in order to facilitate the development of logistics for distributing surplus food and the valorisation of discarded organic material. In terms of information instruments, various national awareness raising campaigns, school campaigns, as well as online and leaflet campaigns are in place already. Some educational programmes exist too (refer to Box 6.2). However, a stronger cooperation with the Ministry of Education is required for mainstreaming the topic of circular economy into the curricula more effectively. Besides education, it is also recommended to step up information instruments to further foster food waste reduction at all levels. 
Box 6.2. Environmental education and awareness raising in the Czech Republic

The Ministry of Environment is the principal guarantor for the coordination of environmental education and awareness raising in the Czech Republic. The main policy documents in this area are the National Programme of Environmental Education, public education and environmental consulting 2016-2025 and its Action Plan for 2019-2021. Furthermore, one of the objectives of the Waste Prevention Programme is to provide informational support on waste prevention (including integration into school curricula and other educational activities), and on voluntary instruments, both having impact on the consumer.

Activities that have taken place by the Ministry of Environment include workshops, conferences, leaflets, guidelines for citizens, aiming to support waste prevention objectives in the areas of food waste, WEEE, textile, furniture and packaging (Ministry of the Environment of the Czech Republic, n.d.[32]); as well as awareness raising and education campaigns funded through the State Environmental Fund and the State grants for NGOs (which gave rise to platforms such as Portál Třetí ruka, Bezobalu, Potraviny nejsou odpad, and Zachran̆ jídlo).

Other consumer awareness campaigns, educational activities, and dialogues with public authorities have been rolled out by the Institute of the Circular Economy (INCIEN) and EKO-KOM (producer responsibility organisation (PRO) for packaging and packaging waste). These initiatives focus on dialogue with public authorities at local, regional and national level (INCIEN, 2020 [33]), and consumer awareness campaigns and educational activities for children and adults (EKO-KOM, $\left.2018_{[34]}\right)$, respectively.

\section{Strengthen waste separation at source and material recovery for municipal solid waste, bio-waste, and WEEE}

66. Increasing the waste separation of municipal solid waste and reducing the content of impurities in sorted waste fractions call for strengthening the existing policy instruments. Sorting and source separation of municipal solid waste and material recovery in the Czech Republic are currently implemented through national EPR systems (some of which would benefit from more efficiency, see discussion in the section on Economic instruments), municipal bring systems (mandatory only for bio-waste and e-waste), PAYT schemes (with a rather small penetration), and door-to-door collection (limited to some areas). Although these initiatives encourage consumers to separate waste at source, their effectiveness is currently insufficient, with around half of municipal waste still remaining unsorted (Czech Statistical Office, 2019 $9_{[27]}$ ). It is therefore recommended to stimulate a wider implementation of door-to-door collection of recyclables with low collection frequencies (such as WEEE, bio-waste and textiles), so as to induce citizens to separate more. This could further be accompanied by awareness raising campaigns about environmental benefits and good practices related to household waste sorting, so as to familiarise citizens with new collection systems. Furthermore, the waste sorting rate and quality of recyclables could be improved through the introduction of system nudges (such as free bins for recycling, transparent bags, decreased distance to containers, and changing the size of the lids of containers). In terms of municipal waste charges, it is suggested to extend the coverage of PAYT schemes (refer to Box 6.3 and section on Economic instruments). As an accompanying measure contributing to the achievement of collection targets, it is recommended to reassess the potential extension of DRS to PET beverage bottles, and to evaluate the introduction of EPR schemes for textiles. 


\section{Box 6.3. The current PAYT system in the Czech Republic and examples of good practices from other EU Member States}

Even though the Waste Act No. 185/2001 Coll. allows for the introduction of a PAYT system by municipalities, in 2009 only around $10-15 \%$ of municipalities used such a system (OECD, $\left.2018_{[1]}\right)$. Most of these municipalities are small and medium-sized (Šauer, Pař́zková and Hadrabová, $\left.2008_{[35]}\right)$. Moreover, PAYT as currently designed in the Czech Republic (i.e. a fee based on the expected costs of waste management related to the number and volume of containers per building), is imperfect in itself as it does not properly reflect the actual generation of municipal waste per household. Neither does it reflect the actual costs of municipal solid waste management and treatment (Ministry of the Interior of the Czech Republic, 2018[36]). More specifically, around 30\% of costs of municipal waste treatment is not covered and has to come from the municipal budget (OECD, 2018 $[1])$.

In terms of the effectiveness, a survey conducted among Czech municipalities in 2003 confirmed that in municipalities that apply the PAYT charging system, citizens separate more waste and produce less residual waste (Šauer, Pařízková and Hadrabová, 2008 ${ }_{[35]}$ ). The study also found that the most important factors influencing consumer behaviour to reduce and sort more waste include: technical conditions for waste separation in the kitchen; availability of containers for separated waste; and level of awareness of proper waste separation methods.

Although the new Waste Act (expected to be in force from 2021) sets incentives for municipalities to introduce PAYT systems more widely, the actual adoption rate remains to be seen (since the adoption of such a system has not been made mandatory under the new proposed legislation).

Several examples of successful adoption of PAYT schemes can be identified at the level of other EU Member States.

- In low density areas such schemes have been set up as pay-per-bag charges in Bergamo (Italy). These function based on compulsory purchasing of special bags for residual waste using a smart card associated to each household. Over time, they helped increasing the separate collection levels in the province of Bergamo to 57\% (up from 42.5\%) (Provincia di Bergamo, 2020 $0_{[37]}$ ). Berlin (Germany) introduced pay-per-bin charges with different collection fees applied to the different bins: EUR 55.45/year for 60 litres residual waste bin; EUR 25.06/year for 60 litres bio-waste bin; recycling bins being free of charge; and an extra cost charged for additional "grey sacks" for residual waste.

- An example of PAYT scheme in high density areas are chamber systems with smart containers operated by personal ID cards introduced in Schwerin (Germany). Here, an individual billing system was set up, defined as a flat rate plus a variable fee depending on the number of uses of the residual waste containers. Overall, the residual waste in the area with this chamber system was reduced by almost $90 \%$, from 40 to 4 litres per inhabitant per week (Stadt Schwerin, 2000 $[38]$ ).

67. In the specific case of household bio-waste, existing policy instruments supporting better sorting require a wider adoption and strengthening. The fact that about a quarter of all household unsorted waste is bio-waste (EKO-KOM, 2019 [39]) points to the lack of efficiency in operating the current bio-waste collection system (based on bring banks and a few door-to-door initiatives by NGOs). The diversion of household bio-waste from public waste collection systems on the one hand, and the increased quantity and quality of home composted bio-waste on the other, could therefore be achieved by enforcing Czech Republic-wide compulsory sorting of bio-waste, in combination with increased landfill and incineration taxes. Additionally, fostering home composting through reduced waste charges (as part of the PAYT schemes), and providing citizens with training, support and 
infrastructure, might further enhance sustainable bio-waste management, and thereby also contribute to the overall recycling targets for municipal waste.

68. Overcoming the obstacles to WEEE separation require modifying the current setup of the respective EPR scheme. Compared to the EPR on packaging, the latter has been found to lack efficiency and transparency (OECD, 2018 $[1]$ ), partly due to the fact that currently 16 producer responsibility organisations (PROs) in WEEE operate on the Czech market. This large number makes it difficult to monitor their cost-effectiveness and functioning, and to assess the potential for eco-modulation fees imposed by each of them. The design of the scheme could therefore be improved by setting a recycling and recovery target at the level of the PROs/industry (rather than having a separate collection obligation applicable only on the state level). This would help creating a coordination mechanism for better monitoring and effectiveness of all the PROs, as well as increasing the density and effectiveness of take-back and separate collection points for WEEE. Additionally, it could be reinforced by introducing eco-modulated fees, which would vary according to the impact the specific products have on the environment. The latter has already been proposed within the new waste legislation package.

\section{Shift consumer preferences towards green and more circular products and services}

69. There is a lot of scope in the Czech Republic to promote green products ${ }^{16}$ and to make more wide spread use of environmental product labels and information. The presently insufficient set of instruments has led to a steady decline in the use of the ecolabels certified under the auspices of the Czech Ministry of the Environment (both in terms of the number of licence holders and of product groups licensed). The main policy recommendation in face of insufficient market shares and lack of awareness of and confidence in logos and labels, is therefore to strengthen the awareness raising about the environmental benefits of green products, their logo and labels on the one hand, and to reduce the complexity of the existing ecolabels on the other. This can be accompanied with stepping up the requirements for information instruments, and the provision of trustworthy and relevant information on products at the point of sale (e.g. on durability and reparability). Additionally, the introduction of new ecolabelled products of daily use and their increased penetration in local markets may accelerate the recognition of logos and labels by consumers, and ultimately also lead to increased customers' demand. At the same time, the uptake of ecolabelling of products and services could be also furthered by green public procurement.

70. At the end-of-life stage, encouraging repair and promoting reused, refurbished and remanufactured products can further strengthen the consumption of circular products and services. Today, some awareness raising initiatives by the Ministry of the Environment in cooperation with NGOs and charities exist, along with some local initiatives at municipal level (refer to Box 6.4). However, as indicated by consumer surveys, a declared lack of

16 There is no universally agreed definition of green products. A comprehensive review of the different conceptual understandings proposes the following definition: "Green is a product (tangible or intangible) that minimises its environmental impact (direct and indirect) during its whole lifecycle, subject to the present technological and scientific status" (Sdrolia and Zarotiadis, 2018 ${ }_{[143]}$ ). In contrast with green products, there is a complete lack of definition for circular products. Bocken et al. $\left(2016_{[141]}\right)$ discuss the different circular product design strategies, which yield such products. Based on these, circular products might be understood to have the following characteristics: longlife through durability and reparability; extended life enabled by reuse, maintenance, repair, technical upgrading, and combination of these; made of "technical nutrients" that can be recycled into new materials/products, or of "biological nutrients" that can be biodegraded or composted. 
consumer confidence in repair activities persists in the Czech Republic (European Commission and TNS Political \& Social, $\left.2014_{[28]}\right)$. This is further aggravated by missing certificates or warranties for repaired products, as well as the inexistent planned obsolescence law (which could indirectly promote the reparability of products). The key recommendation is therefore to strengthen the awareness raising campaigns, information instruments, and education programmes on the quality and safety of products and their environmental benefits on waste prevention on the one hand, and to promote and support the establishment of repair cafés to increase consumer's repair knowledge and their awareness about financial and environmental benefits to repairing on the other.

\section{Box 6.4. Initiatives in the Czech Republic to support extension of the lifetime and reuse of products}

The Ministry of Environment supports repair and use of reused, refurbished and remanufactured products by co-financing projects through its State support to NGOs, Operational Programme (OP) Environment, and promoting such projects within its communication activities (website, workshops, conferences) and reports (e.g. monitoring and evaluation of implementation of the Waste Prevention Programme of the Czech Republic) (Ministry of the Environment of the Czech Republic, 2014 [40] $)$.

In terms of practical initiatives at the local level, some municipal projects have been introduced by the city of Brno. In particular, the project REUSE "Second Life" supports the collection and sale of items, while the project $R E-N A B$ supports the reuse of old furniture and creates a furniture bank for socially vulnerable citizens (Ministry of the Environment of the Czech Republic, 2017 [41]). One of the actions of the Circular Economy Strategy of Prague has as for objective to create circular Reuse Hubs to support reuse and repair among Prague citizens (Circle Economy and INCIEN, 2019[42]). The creation of such Hubs includes a number of activities: creating a network of decentralised Reuse Hubs, upgrading existing municipal collection yards into reuse hubs, providing education and repair services in ReUse Labs, and collaboration between ReUse activities.

71. Additionally, the uptake of the demand for such products can be stimulated by creating dedicated spaces for second-hand and exchange markets. These products can be further made affordable and competitive by reducing the VAT for their reparation, refurbishing and reuse (refer to Box 6.5). From a products design perspective, the introduction of quality standards for reused products could boost the market for secondhand, refurbished and remanufactured consumer goods further. Last but not least, the extension of legal warranties or the establishment of warranty duration according to the expected lifespan of the specific product, can be an important innovative measure to foster products' durability and to improve their reparability.

72. To accelerate the adoption of circular activities in the Czech Republic, it is crucial to introduce policies in support of innovative consumer-related circular business models. Today, such platforms are not systematically supported by policy. Examples of two successful online platforms that were to some extent supported by policy in the Czech Republic and which promote product-as-a-service business models are Rekola - a bike sharing scheme (Rekola, n.d.[43]), and Opravarna - a repair platform (Opravarna, n.d.[44]). Moreover, it has been evidenced by consumer surveys that renting and leasing are not popular among the Czech consumers. Consequently, the introduction of regulatory instruments to foster a sharing economy ${ }^{17}$, powered by digital technologies, could not only

17 Different countries define the concept of sharing economy (also referred to as collaborative economy) differently (OECD, 2019 $\left.{ }_{[142]}\right)$. In Greece the sharing economy is defined as "any model 
accelerate the sharing of existing (and often underutilised) assets, but could also help the Czech citizens to reap benefits from it and to dematerialise the Czech economy. It is however important to carefully balance the uptake of such models with consumer protection, in order to minimise the potential unintended consequences of the fast expansion of sharing business models (e.g. clogged pavements and entrances to underground stations by deposited shared bicycles and scooters in some cities). Additionally, the support of national/regional circular economy hubs could facilitate the promotion of circular economy along entire value chains, encouraging cooperation between public and private actors, improving the efficient use of available resources and decreasing waste generation.

\section{Box 6.5. Reduced VAT for repair activities across the EU Member States}

A VAT reduction may be an incentive to make preparation for reuse (repairing, refurnishing and remanufacturing) more affordable and competitive. At the same time, this can also have indirect positive impacts on creating new jobs, reducing virgin materials use in the production of new items, and preventing waste generation by goods that otherwise might be cheaper to discard and replace than to repair.

Several EU Member States have opted for reducing VAT to repairing activities. In the case of Sweden, on 1st January 2017 VAT was cut from $25 \%$ to $12 \%$ on the repair of bicycles, shoes, clothes and other textiles. In addition, 50\% of the labour costs of repairing large appliances are deductible from the personal income tax. Reduced VAT for repair activities is also in place in Ireland (13.5\%), Malta (5\%), Luxembourg (8\%), the Netherlands (9\%), Poland (8\%), Portugal (6\%), Slovenia (9.5\%) and Belgium (6\%) (Rreuse, 2020 [45] $)$.

As of 1 May 2020, a reduced VAT rate of 10\% (instead of 21\%) applies to certain repair services (e.g. repair of footwear and leather products, repairs and adjustments of clothing and textile products) also in the Czech Republic.

Additionally, in France, the collection and sales of used goods carried out by social enterprises are exempt from VAT, because their activities are linked to the employment of disadvantaged and disabled people. This is a charity-oriented initiative that, however, contributes to waste prevention (Rreuse, 2020 $[45]$ ).

\section{Waste management}

\section{Role of waste and material management for the circular economy}

73. Transitioning to a circular economy is critical for strengthening the security of raw material supply (through maximising the value of materials that circulate and minimising the virgin material consumption) and for mitigating the environmental externalities from waste management (through preventing waste from being generated and reducing hazardous substances in waste and products). These in turn help addressing the challenges of specific materials and waste flows (such as plastics, food, and EEE), and thereby boosting the competitiveness and sustainability of the economy (by reducing plastics

where digital platforms create an open market for the temporary use of goods or services which are often provided by individuals". In Norway the sharing economy is seen as "economic activity enabled or facilitated via digital platforms that coordinate the provision of a service or the exchange of services, skills, assets, property, resources or capital without transferring ownership and primarily between private individuals". 
leakage into the environment, better management of municipal solid waste, remanufacturing of EEE parts, and introducing sharing schemes for cars).

74. Accordingly, waste and material management have now become an integral part of circular economy policy making at the EU level. The Circular Economy Package sets ambitious targets in the field of waste separation, recycling, landfilling and extended producer responsibility (e.g. recycling target of $60 \%$ of municipal waste and $70 \%$ of all packaging waste by 2030 ; landfill rate of a maximum of $10 \%$ of municipal waste generated by 2035; and differentiated recycling targets for different packaging materials). Besides these, individual Member States have established specific material intensity and resource productivity targets $(\mathrm{OECD}, 2021$ forthcoming $[46]){ }^{18}$

\section{Evidence on waste, materials management and circular economy in the Czech Republic}

75. The economy of the Czech Republic is significantly reliant on industrial production. At the same time, its domestic raw material base is limited, making the economy dependent on foreign imports (mainly fuel and metals). The efficient materials and waste management are therefore crucial to keep resources circulating within, rather than throughout, the Czech economy.

76. On the upstream, the total amount of materials used within the economy per person has been decreasing over time, down to half of the 1990s levels. However, since 2013 the trend has been slightly increasing again, driven by the country's strong industrial base. For the same period, the material intensity of the Czech economy has been steadily decreasing (by almost $42 \%$ since 2000), indicating decoupling of materials consumption from economic growth (see Figure 6.2).

77. The resource productivity in the Czech Republic, measuring the efficiency with which the economy uses material resources to produce wealth, lags significantly behind the EU average. Although its performance has improved over the last decade (with EUR $1.20 / \mathrm{kg}$ in 2018), this represents approximately the half of the EU average (EUR 2.24/kg in 2018) (Eurostat, 2020 $0_{[47]}$ ). Similarly, the circular material use rate (despite having increased to $8.1 \%$ in 2017) ranks the Czech Republic well below the EU average (at $11.7 \%$ in 2017) (Eurostat, 2020 [47]).

\footnotetext{
${ }^{18}$ Across most countries, targets for material intensity and resource productivity are expressed as the DMC/GDP, with the exception of Germany that includes total raw material productivity (TMC/GDP) too. DMC represents the annual amount of raw materials extracted from the domestic territory, plus imports, minus exports, while TMC in addition takes into account "hidden flows" (unused extraction and indirect flows).
} 
Figure 6.2. Material intensity in the Czech Republic, 2000-2017

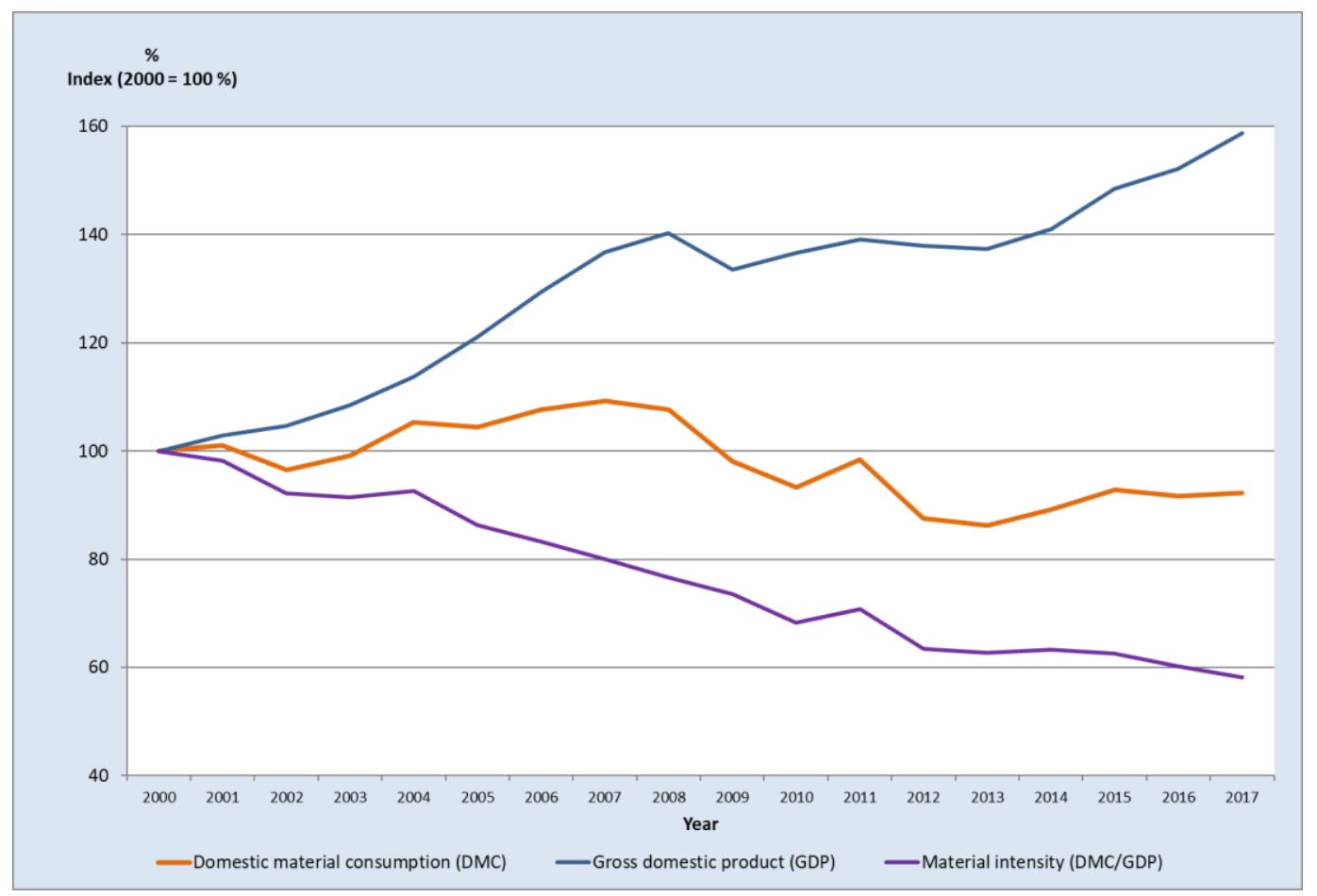

Source: Own elaboration based on data from Information System for Statistics and Reporting (CENIA, $\left.2020_{[48]}\right)$. Data in line with the statistics reported by the Eurostat.

78. On the downstream, the total waste generation in the Czech Republic was ranging between 27.9 million tonnes and 37.8 million tonnes in 2018, corresponding to rates of 2.63 and 3.56 tonnes of waste per capita, according to the statistics reported by the Eurostat $\left(2020_{[49]}\right)$ and the data information system of the Ministry of Environment (CENIA, $2019_{[50]}$ ), respectively ${ }^{19}$. Of this, construction and demolition waste made up over $60 \%$ (23.7 million tonnes) according to CENIA ${ }^{20}$, while municipal waste accounted for another

${ }^{19}$ In the Czech Republic, two information systems with differing data sets coexist: the Waste Management Information System - ISOH used by the Ministry of Environment (MoE) and the waste statistics managed by the Czech Statistical Office (CZSO). While the latter is used to report to Eurostat under the EU Waste Statistics Regulation, the former is used to develop the Waste Management Plans at all levels (national, regional, municipal), monitor their implementation and report on EU waste policy objectives as well as to develop and monitor the Operational Programme Environment (OECD, 2018 $[1]$; European Commission, 2019 $9_{[2]}$ ). The waste management section of this report uses waste management data produced by the information system of the Ministry of Environment (ISOH) where available, next to the Eurostat data for consistency reasons. The two information systems produce different data points on the amount of waste generated and treated in the Czech Republic, however both information systems provide similar data in relation to relative indicators and trends, and thus lead to similar results and conclusions in this analysis.

${ }^{20}$ It is not possible to compare in a straightforward manner construction and demolition waste as reported by Eurostat and CENIA, because Eurostat reports data on Mineral waste from construction and demolition (4.3 million tonnes in 2018), while CENIA reports data on Construction and demolition waste, including excavated soil from contaminated sites (23.7 million tonnes in 2018). 
$13 \%$ (i.e. 3.73 million tonnes) to $15 \%$ (i.e. 5.78 million tonnes), according to Eurostat $\left(2020_{[49]} ; 2020_{[23]}\right)$ and CENIA $\left(2019_{[50]}\right)$, respectively. The decreasing trend in waste generation achieved by 2012 has over time been reversed, recording an increase of $20 \%$ and $26 \%$ between 2012 and 2018, based on the data reported by the Eurostat $\left(2020_{[49]}\right)$ and the Ministry of the Environment of the Czech Republic (2019[24]) respectively. This has been primarily driven by the rising generation of non-hazardous waste (although the generation of hazardous waste has been growing too since 2016). When it comes to the treatment of waste, material recovery represents the prevailing method of waste treatment (covering $76 \%$ to $83 \%$ of waste generated in 2018 , based on the data reported by the Eurostat and the Ministry of the Environment of the Czech Republic, respectively ${ }^{21}$. While energy recovery remains largely stable in 2018 (at 3\% according to the Ministry of the Environment of the Czech Republic, and 5\% according to Eurostat), landfilling has been decreasing (down to 9\% according to the Ministry of the Environment of the Czech Republic, and 19\% according to Eurostat in 2018) (Ministry of the Environment of the Czech Republic, 2019 [24]; Eurostat, 2020 [51]).

79. In terms of municipal waste, the Czech Republic produced 5.78 million tonnes in 2018 (corresponding to $544 \mathrm{~kg} / \mathrm{inh}$ abitant) as reported by the Ministry of the Environment of the Czech, and 3.73 million tonnes (corresponding to $351 \mathrm{~kg} / \mathrm{inh}$ abitant) as reported by the Eurostat (CENIA, 2019 [50]; Eurostat, 2020 ${ }_{[23]}$ ). Of this, 2.81 million tonnes were mixed municipal waste (corresponding to $264 \mathrm{~kg} /$ inhabitant) (CENIA, 2019 $\left.9_{[50]}\right)^{22}$. Although the generation of municipal waste has increased during the past decade, the generation of mixed municipal waste has been decreasing. This points to the improvement of primary sorting of municipal waste. Nevertheless, as indicated by the trend in Figure 6.3, the pace of the decrease has been slowing down. Municipal waste management still poses a big challenge, since landfilling remains the most common method of treatment (at 46\% according to the Ministry of the Environment of the Czech Republic and 49\% according to the Eurostat in 2018). This trend has been decreasing in favour of recycling, including composting and digestion (which increased to 39\% according to the Ministry of the Environment of the Czech Republic data and 34\% according to the Eurostat data in 2018). The proportion of energy recovery remains stable (at roughly $11 \%$ and $16 \%$ according to the Ministry of the Environment of the Czech Republic and the Eurostat, respectively) (Ministry of the Environment of the Czech Republic, 2019 [24]; Eurostat,

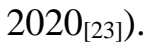

\footnotetext{
${ }^{21}$ Note that currently a substantial part of this recovery is made up of downcycling (for instance using waste for land reclaiming or landscaping). According to some estimates, as much as $29 \%$ of waste is being backfilled in the Czech Republic, compared to the EU average of 9.9\% in 2016 (Eurostat, 2019 $\left.{ }_{[133]}\right)$ (European Commission, 2018 $\left.{ }_{[134]}\right]$. In 2018, backfilling constituted 26\% of the total waste treatment in the Czech Republic (Eurostat, 2020 [51]). This undermines the higher value of recycling resources.

${ }^{22}$ The Eurostat database does not report the corresponding statistics for mixed MSW, nor does it define how mixed municipal waste could be calculated from the available municipal waste treatment options.
} 
Figure 6.3. Municipal solid waste generation, 2009-2018

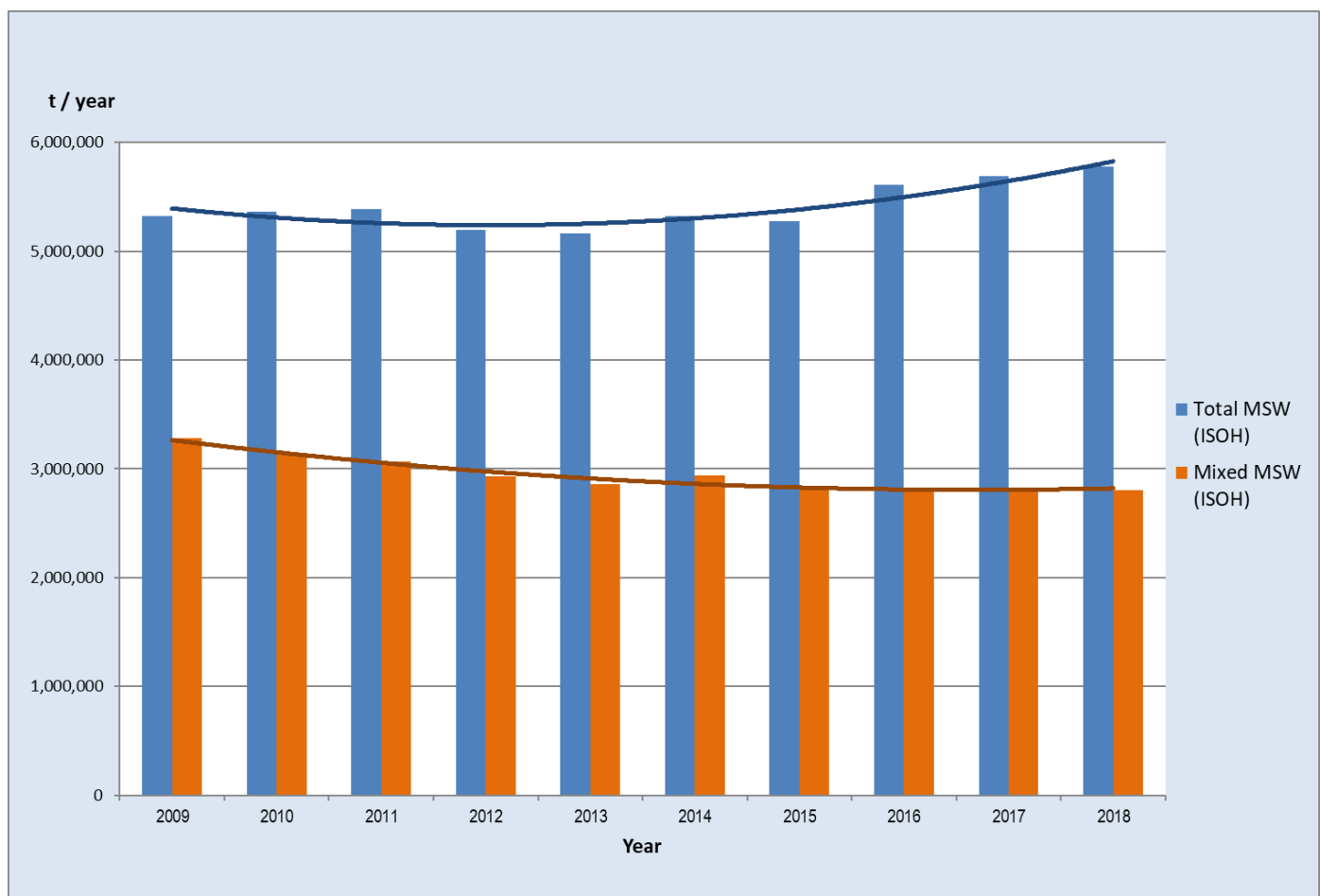

Note: The figure is based on data from the Waste Management Information System - ISOH used by the Ministry of Environment. The Eurostat database does not report the corresponding statistics for mixed MSW.

Source: Own elaboration based on data from Environmental Statistical Yearbook 2018 (CENIA, 2019[50]).

Resources and waste management related circular economy legislation in the Czech Republic

80. The Czech Republic has made a great progress towards introducing new waste legislation (still under discussion), which promotes the waste management hierarchy and builds on the principles of a circular economy. The main current waste legislation is contained within the aforementioned Waste Act (No. 185/2001 Coll.) regulating the landfill tax, the local charges on municipal waste (also regulated by the Local Charges Act), the EPR for a variety of end-of-life products, as well as the waste collection and management obligations of municipalities and companies, among others. The Packaging Law (No. 477/2001 Coll.) regulates the management of packaging and packing waste in the Czech Republic. Extraction of minerals is regulated by the Mining Law (No. 89/2016 Coll.) and the related secondary legislation.

81. Besides these main legal acts, there are a number of relevant key policy documents, including the Waste Management Plan 2015-2024 (currently being updated) (Ministry of the Environment of the Czech Republic, 2014 $4_{[52]}$ ), the Waste Prevention Programme (Ministry of the Environment of the Czech Republic, 2014 $[40]$ ), as well as the Secondary Raw Materials Policy of the CR 2019-2022 (Ministry of Industry and Trade of the Czech Republic, 2019 $9_{[53]}$ ) and the Raw Materials Policy of Czech Republic (Ministry of Industry

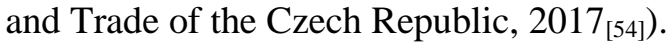

82. The Waste Management Plan (WMP) outlines the Czech Republic's strategy on waste management and sets binding objectives, targets, and measures, as well as policies and priorities for a ten-year period on national, regional, and municipal levels. The Waste 
Prevention Programme is the main strategic document for waste prevention in the Czech Republic and is included within the WMP. In terms of resource management, the Secondary Raw Materials Policy sets out strategic goals for the extraction, processing and use of secondary raw materials from domestic and foreign sources (i.e. imported products). Its main goal is to ensure effective and sustainable security of supply and use of ore, nonore, energy, construction as well as non-traditional high-tech mineral resources to the benefit of the population and a competitive national economy.

83. In terms of specific waste streams management, these are regulated within the Decree No. 321/2014 Coll., on the extent and method of provision of separate collection of components of municipal wastes. In particular, municipalities are obliged to provide for separate collection of paper, plastic, glass and metal waste, as well as hazardous waste, biodegradable waste, and edible oils and fats. Additionally in several municipalities, some other types of waste are collected separately, such as multi-layer beverages packaging and kitchen waste. Hazardous waste from households is generally accepted at household waste recycling centres that are well distributed throughout the Member State. Moreover, extended producer responsibility schemes currently in place include packaging waste, WEEE, waste batteries and accumulators, end-of-life vehicles and tyres. Additionally, medicines can be returned to pharmacies. Although the separation of textile waste is not regulated yet, a system of used clothes collection operates through municipal collection spots, collection spots operated by waste management companies or by non-profit and charity organisations.

84. More specifically, the above legal frameworks and related policies include a number of waste and resources related policy instruments, some of which have already been mentioned in the Consumption and consumers section:

- Economic instruments: Environmental taxes (landfill tax, local charge on municipal waste - PAYT), waste-related fees charged for ELV collection, processing, recovery and disposal, fines for non-compliance, tax reduction (VAT reduction for municipal waste collection, treatment and disposal services), subsidies for recovery operations and for waste transport and collection, grants and loans for R\&D, support programmes for businesses and grants for remediation of environmental damage, investment in waste treatment and recycling facilities;

- Regulatory instruments: EPR (for a number of products), DRS (for certain glass bottles), separate collection requirements and mandatory recycling targets for recyclable materials, ban on provision of free plastic bags, green public procurement;

- Voluntary agreements: Enough of Plastics initiative, environmental management certification;

- Information instruments: Awareness raising initiatives about the importance of waste reduction and recycling and environmentally sound management, information campaigns to stimulate separate collection and recycling of selected waste streams, ecolabelling (Czech and EU ecolabels).

- Education and capacity building: National Programme of Environmental Education, Awareness Raising and Environmental Consulting 2016-2025 and its Action Plan for 2019-2021; 


\section{Policy recommendations for a more effective waste management}

85. Although the Czech Republic has a fairly complete policy framework for waste and materials, a mature extended producer responsibility system for packaging waste, and an established recovery and recycling with separate collection of municipal waste, it has not yet succeeded in exploiting the raw material potential of its waste (OECD, $\left.2018_{[1]}\right)$. The below discussion identifies how existing policy instruments could be strengthened within the existing Czech policy framework, focusing on the five priority waste streams: residual municipal solid waste; plastics; construction and demolition waste; organic waste (including food waste and used oils); and hazardous waste (see Box 6.6). A more detailed discussion for other waste streams is provided within the Background report on waste management, and the specific implementation actions are listed in the Implementation plan in chapter 7. of this report.

\section{Box 6.6. Analysis of priority waste streams in the Czech Republic}

The prioritisation of waste streams for the analysis within this report is based on the approach adopted by the Waste Management Plan of the Czech Republic 2014-2025, the Waste Prevention Programme of the Czech Republic, and the Secondary Raw Materials Policy of the Czech Republic 2019-2022. Based on these policy documents, a set of 15 specific waste streams has been identified, classified, and later prioritised against three criteria: waste stream intensity (i.e. proportion on the total waste generation), environmental impact (i.e. impact and potential risks for the environment water, air, soil, environmental accidents, etc.), and potential for improvement (i.e. potential for prevention, preparation for reuse, recycling, recovery and circularity) in the Czech Republic. ${ }^{23}$ The result of this exercise is the prioritisation of five waste streams for the circularising the waste management in the Czech Republic:

- Residual municipal solid waste: The generation of residual MSW has been largely stable over the past five years (with 4\% reduction of mixed MSW between 2014 and 2018 ${ }^{24}$ ), in spite of the significant increase in recycling of MSW, including composting and digestion (to about $39 \%$ and $34 \%$ according to the data by the Ministry of the Environment and the Eurostat, respectively) coupled with an increase in direct energy recovery (to about $12 \%$ and $16 \%$ according to the data by the Ministry of the Environment and the Eurostat, respectively) (CENIA, 2019 [50]; Eurostat, 2020[23]). Furthermore, the increasing trend in total MSW generation (the major component of which is residual MSW) is expected to continue into the future, coinciding with the wave of long-term economic growth phase.

${ }^{23}$ For the majority of these waste streams the primary focus is on waste from settlements (covering municipal and packaging waste), while for some (e.g. construction and demolition waste - CDW) the whole economy is covered, as follows: (1) Residual municipal solid waste (mixed and bulky waste); (2) Paper (municipal and packaging waste); (3) Plastics (municipal and packaging waste); (4) Glass (municipal and packaging waste); (5) Metals (municipal and packaging waste); (6) Wood (municipal and packaging waste); (7) Construction and demolition waste; (8) Organic waste, including food waste and used oils (in particular green organic waste, food waste from kitchens and canteens, food waste from households, used cooking oils); (9) Textile (municipal waste); (10) Waste electric and electronic equipment (subject to extended producer responsibility); (11) Batteries and accumulators (subject to extended producer responsibility); (12) End-of-life vehicles (subject to extended producer responsibility); (13) Tyres (subject to extended producer responsibility); (15) Sludge from municipal wastewater treatment plant (WWTP); and (15) Hazardous waste (municipal waste).

24 The Eurostat database does not report the corresponding statistics for residual and mixed MSW. 
- Plastics: Plastics are contained in all types of products, from consumer goods, through vehicles, to buildings and infrastructure. Besides the municipal plastic waste (which amounted to 154 thousand tonnes in 2018), the packaging plastic waste (representing 267 thousand tonnes in 2018) constitutes an important opportunity for a more circular plastics waste management (Ministry of Environment of the Czech Republic, 2019 [55]; CENIA, 2019[50]). The large proportion of plastics waste within the mixed MSW (EKO-KOM, 2019[56]), along with the targets set within the Act on Packaging, point to the large scope for improvement of plastics separation and recycling.

- Construction and demolition waste: According to the official waste management data, 20.8 million tonnes of CDW were generated in 2018, which constitutes more than half of total waste generation reported in the Czech Republic (55.2\%) (Ministry of the Environment of the Czech Republic, 2019 [57]).

- Organic waste (including food waste and used oils): The total generation of separately collected municipal biodegradable waste was 690 thousand tonnes in 2018, with an increasing trend over time (Ministry of the Environment of the Czech Republic, 2019[57]). Additionally, the organic waste recycling has also been growing on importance in the Czech Republic, with increasing financial support for separate waste collection and composting, as well as tighter regulations.

- Hazardous waste: The trend in generation of municipal hazardous waste has been rather ambiguous over the past decade (CENIA, 2019 [50]). On the one hand, the stagnation may suggest that the effort to increase separation is not very effective. On the other hand, it may also be a sign of declining of hazardous component in MSW. This may result from high efficiency of take-back systems for WEEE and batteries and accumulators, as well as from widely spread knowledge that waste medicines should be returned to pharmacies.

\section{Strengthen downstream policy instruments}

86. As mentioned above, the Czech Government has recently (in December 2019) introduced a set of new legislative proposals on waste, packaging and end-of-life products, which are expected to lead to considerable improvements in municipal waste treatment, and to help achieve the EU waste targets for 2030 and beyond. To this end, several instruments are envisaged to be newly introduced or strengthened, such as increased landfill tax (fee), strengthened PAYT system, and a ban on landfilling of recyclable/recoverable waste by 2030, in line with EU legislation.

87. Although the plans and programmes on waste management and prevention, along with the new Waste Management Act currently under adoption, create incentives to follow the waste management hierarchy, essential steps still need to be taken to further strengthen the principles of a circular economy downstream. This is particularly relevant for diverting waste from landfilling and increasing the investment to strengthen the recycling market and infrastructure. More specifically, while the Czech Republic is on track to meeting the EU's 2020 recycling target, much more effort is needed to comply with the recycling targets for the post-2020 period (European Commission, 2019 $9_{[2]}$ ). Moreover, landfilling remains the most common method of municipal waste treatment in the Czech Republic ${ }^{25}$. In order to

25 In 2018, 48\% of MSW and 46\% of biodegradable municipal waste were disposed in landfills (CENIA, 2019 ${ }_{[50]}$ ) (Ministry of the Environment of the Czech Republic, 2019 ${ }_{[57]}$ ). Although several measures have been implemented to promote composting and biodegradable waste utilisation (including financial support), it is questionable whether achieving the target of $35 \%$ of the 1995 levels by 2020 is actually feasible. 
encourage a stronger shift in waste disposal towards less environmentally-damaging options (for instance towards incineration with energy recovery, and recycling), the Czech Republic would benefit from progressively increasing the landfill tax (as is being proposed in the new Waste Act) and strengthening some of its design considerations (such as removing or decreasing the share of proceeds from the landfill tax to municipalities on whose territory the landfill site operates - so as to divert incentives from landfilling to more sorting - and enforcing fees for landfilling of the hazardous waste). For more details, see the section on Economic instruments. This would not only help diverting reusable, recyclable and recoverable waste more quickly from landfilling, it could potentially also enable earmarking the revenues to support circular solutions. Additionally, this progressive increase in landfill taxes to the level reflecting the marginal cost of waste treatment (to the levels required by the EU targets) could be accompanied by supporting measures, such as landfill ban for specific waste types and introduction of incineration taxes (see Box 6.7). From a longer term perspective, in order to leverage the future potential of waste prevention and opportunities for reuse and recycling, it is also essential to carefully plan the waste-toenergy (WtE) capacities so as to not to over-dimension them.

88. Furthermore, in order to stimulate the recycling market (and revert the decreasing trend in recycling of packaging waste, for example $)^{26}$ and the upcycling of waste into highquality high-value materials and products, the Czech Republic could consider introducing fiscal incentives for decentralised reuse, recycling and processing capacities. Such capacities could be designed in cooperation with different levels of public governance, and reflect the requirements for particular waste flows. At the same time, recycling could be facilitated through the optimisation of the waste collection system for recyclables, including just-in-time waste collection (to prevent overfilling of containers and minimise waste collection costs), bringing recyclables collection points to the same walking distance as mixed MSW collection points, and door-to-door collection of recyclables with lower frequencies of mixed MSW collection (for more detail on these refer to the section on Consumption and consumers). Finally, incentives and measures strengthening the markets for secondary raw materials and recyclable waste, and encouraging the use of these materials and waste, could comprise the introduction of standards and ecolabels for secondary materials and recyclable waste, commodity exchanges, and tax deductions. Some of these instruments are discussed in the section on Economic instruments.

\section{Box 6.7. Instruments directed to changing waste disposal practices}

Of the most widely used instruments directed to encouraging a shift to alternative forms of waste disposal are:

- Landfill taxes: Landfill taxes provide an incentive to reduce the tonnage of waste landfilled. As illustrated in Figure 6.4, the level of taxes levied by the Czech Republic is well below the average of that of the EU Member States. In terms of the progression over time, landfill taxes have increased over the past five years in the Czech Republic, however the rate of increase remains below that of the other OECD countries and regions. Introducing high landfill taxes, countries tend to have lower landfill rates. Some have managed to decrease landfill rates for MSW to below 1\%, such as Belgium, Denmark, Finland, Sweden, Switzerland and the Netherlands (OECD, 2019 ${ }_{[58]}$ ). It should be noted that complementary to economic instruments, several OECD countries and the EU have implemented landfill

${ }^{26}$ Rates of most types of packaging waste (including the total rate) have decreased since 2015; all of them decreased in between 2017 and 2018. 
bans, which have also contributed to a reduction in landfill taxes (OECD, 2021 forthcoming $[46])$.

- Incineration taxes: Some countries levy incineration taxes in order disincentivise incineration of MSW. Incineration with energy recovery is still environmentally preferable to landfilling in the waste hierarchy, which is why incineration taxes - if existent - are significantly lower than landfill taxes. For instance, the Italian waste law (549/95) defines that incineration tax without energy recovery should amount to $20 \%$ of the landfill tax in each region (Italian Ministry of Economy and Finance, 1996 ${ }_{\text {[59] }}$ ). Catalonia's tax design stands out, as generated tax revenues are earmarked for Waste Management Funds. The Danish incineration tax was converted in 2010 from a weight-based tax to one based on energy and $\mathrm{CO}_{2}$ content. The new system aims to provide a stronger incentive to recycle the most energy intensive waste, such as plastics (OECD, 2021 forthcoming $\left.{ }_{[46]}\right)$. A comprehensive study on landfill and incineration taxes indicates mixed results in incineration of municipal waste across countries, namely: a decreased rate in Denmark (from $61 \%$ in 2004 to $54 \%$ in 2014; with incineration taxes implemented in 1987), a stable rate in Catalonia and France (at $24 \%$ and 34\%, respectively; with both tax rates implemented in 2009), and an increased rate in Austria (from 30\% in 2004 to $38 \%$ in 2014; with incineration tax introduced in 2006) and Wallonia (Belgium) (from 30\% in 2004 to $48 \%$ in 2014, with the incineration rate since 2008) (ADEME, 2017 [60]). Note however, that the total price of landfill is superior to the total price of incineration in Austria and Wallonia, while the opposite is true for Catalonia and France. The comparison of the price of landfill and incineration for combustible waste across countries is also reported in Box 6.9 (section on Economic instruments).

Figure 6.4. Landfill tax rates of MSW in OECD countries in 2018 and 2013

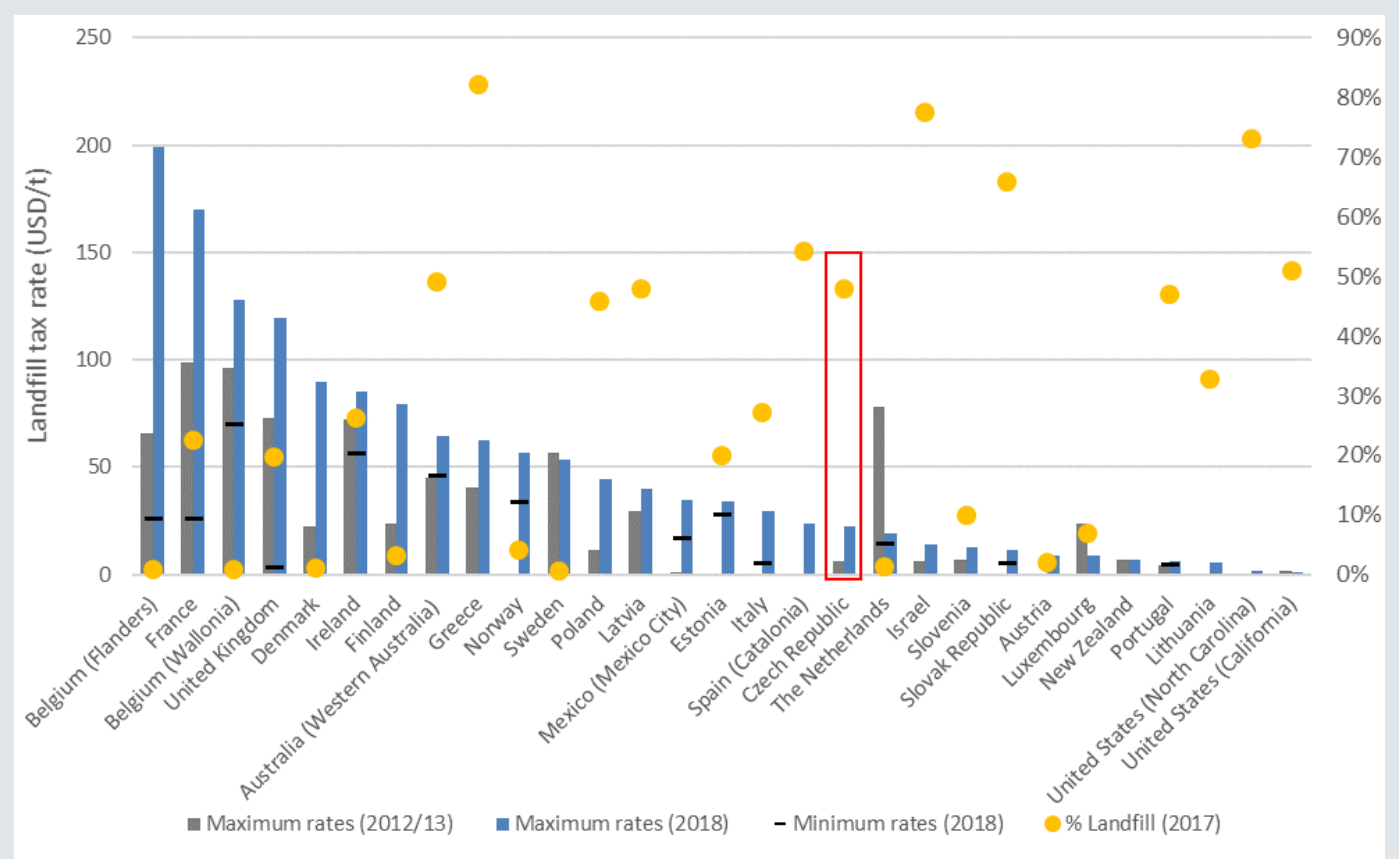

Note: The Netherlands abolished their landfill tax in 2012 and reintroduced a different model in 2015 , hence the two values may not be comparable. Landfill tax rates can vary depending on type of waste, hence the range between minimum and maximum values in some countries.

Source: Progress report on the implementation of the Recommendation of the Council on Resource Productivity (OECD, 2021 forthcoming $[46])$. 


\section{Expand policy mixes upstream}

89. Besides strengthening the measures downstream, waste prevention and improvements upstream in the value chain will also require more attention in the policy making (OECD, 2018 ${ }_{[1]}$; European Commission, 2019 ${ }_{[2]}$ ). The Czech Republic has already implemented some upstream measures to target producer responsibility, such as the implementation of the Secondary Raw Materials Policy of CR 2019-2022 and its action plan on self-sufficiency, the introduction of government-approved national programmes (including the cleaner production and the ecolabel programmes) and voluntary instruments (including certified environmental management systems under ISO and EMAS, along with ecolabels), and the establishment of a new EPR scheme covering tyres (Ministry of the Environment of the Czech Republic, 2019 ${ }_{[57]}$; Ministry of the Environment of the Czech Republic, 2017 $7_{[61]}$; OECD, 2018 ${ }_{[1]}$. Although current plans and programmes on waste management and prevention, and secondary raw materials, eco-innovation and cleaner production facilitate the transition towards a circular economy, more extensive policy mixes need to be introduced in order to achieve a reduction in the environmental impact of products throughout their life cycle - including impacts inherent in the selection of materials for the products, impacts from design and manufacturers' production process itself, and impacts from the use and disposal of the products. The recommendations for expanding the policy mixes upstream are discussed along the individual stages of the product life cycle.

90. To start with the material production stage, the uptake of secondary raw material uses could be encouraged by introducing virgin materials taxes at a sustainable level ${ }^{27}$. These would help internalising the externalities of their production and use on the environment and incentivise the shift towards the use of secondary raw materials, especially for aggregates used in the construction sector (such as stones, gravel, and sand). Many of these are not traded internationally, and would therefore not threaten the competitiveness of domestic producers. At the same time, the income generated could be earmarked for the development of circular construction systems or financing the establishment of regional and local recycling and reuse centres. Furthermore, in the specific case of the building sector, reviewing the building code/standards that prevent the reuse of secondary materials appears to be important. An additional consideration could be to explore taxes on plastics (both virgin plastics and plastic packaging, possibly with a focus on non-recyclable plastics packaging as a first step) and potentially a fertiliser tax (Sud, $\left.2020_{[62]}\right)$. Similar to virgin material taxes, these too would help to internalise the externalities of their production and use. Moreover, they would also induce the use of recycled plastics (or renewable and more durable alternatives) and stimulate the production and use of compost in agriculture, respectively.

91. The positive effects of design and production stages on the environment and on conservation of natural resources could be reinforced through the introduction of ecomodulation within EPR schemes based on life cycle analysis (LCA) and life cycle costing (LCC). These would allow reflecting the impact of specific raw materials, products, their quality and lifetime on the environment throughout their life cycle, and encouraging the

\footnotetext{
${ }^{27}$ Note that fees for the use of land for mining and, in particular, for the extraction of raw materials already exist in the Czech Republic. These have the potential for development into more powerful economic instruments, capable of incentivising the use of secondary materials. The model for this could be the virgin materials taxes, typically taking the form of an excise tax per tonne of raw materials mined or quarried.
} 
use of higher rates of recycled content, higher quality and longer lifetime materials in manufacturing. Strengthening the EPR impacts upstream would also require the design of EPR schemes for additional products (i.e. introducing regulation regarding the single use plastic products ${ }^{28}$, as well as textiles, furniture and other products as discussed in Box $6.10)^{29}$. Finally, strengthening the regulation around the use of hazardous materials would help limiting their uses as raw materials and product components (and thereby ultimately also reduce the amount of generated hazardous substances in recovered materials). In this respect, it is suggested for the Czech Republic to take an active role and work with the European institutions in order to help accelerate the changes within the REACH regulation.

92. On the demand side, green public procurement might further strengthen the uptake of green and circular products and designs, through introducing criteria and additional incentives for "circular/green procurement". In the future, this could be further strengthened with mandating minimum recycled content standards for the producers, coupled with relevant economic instruments (such as trade compliance certificates or high fees for non-compliance, discussed in more detail in the section on Economic instruments). On the consumers side, the introduction of standards and ecolabels for reusable components and products, coupled with boosting the trade in recyclables and simultaneously removing fiscal and regulatory impediments for such trade (discussed in more detail in the section on Economic instruments), could help increasing their demand for further use (as secondhand, refurbished, remanufactured and upcycled products, instead of new ones). From the product use and post-consumer phases perspective, a more effective implementation and enforcement of take-back obligations might be beneficial for further strengthening the upstream impacts of the EPR schemes (in particular the design of the EPR for WEEE discussed in more detail in the section on Economic instruments and Box 6.10). These would also facilitate catching up with missed targets for utilisation and recycling downstream (e.g. of particular EEE categories such as vending machines) and preparing to reach the future targets (e.g. target set in the WEEE Directive for 2021).

\footnotetext{
${ }^{28}$ The Single Use Plastics Directive requirements are not included in the new waste legislation, but are envisaged to be transposed by a separate Act currently under preparation.

${ }^{29}$ Introducing new EPR schemes in the Czech Republic could target some of the 614 thousand tonnes of bulky waste (almost 18\% of total residual MSW in 2018) (CENIA, 2019 [50]) and at least a part of the approximately 200 thousand tonnes of textile and clothing waste (which makes up an estimated $6 \%$ of municipal waste). The actual impact of the EPR schemes would depend on the effectiveness of their design, and on alternative waste disposal practices in place (e.g. through textile collection spots).
} 


\section{Box 6.8. Examples of instruments for expanding policy mixes in the construction sector upstream in the Czech Republic and across other EU Member States}

Some concrete examples of used instruments directed to encouraging a shift to more circular initiatives preventing waste generation upstream are:

- Virgin material taxes: When used in construction, taxes on virgin raw materials have been found to reduce the amount of resources used, and thereby reducing the environmental damage (associate with extraction of raw materials and manufacturing of products made of these) and encouraging the use of less harmful and recycled materials. Evidence is available from several Member States. Sweden has introduced a tax on natural gravel in 1996, with the purpose of promoting the use of crushed rock and recycled materials, in response to the increasingly limited supplies in certain parts of the Member State. In Denmark, the combination of virgin material taxes introduced in 1990 (on sand, gravel, stones, peat, clay and limestone) with waste taxes, drew the demand for recycled substitutes from only $12 \%$ of CDW to be recycled in 1985 to $94 \%$ in 2004 . Although aggregate taxes have reduced the use of natural resources and to some extent encouraged the use of substitute materials, greater incentives to waste recycling are needed, couple with other waste management instruments to reinforce the latter (e.g. sorting of wastes) (European Commission, 2011 [63]).

- Regulation - definition of waste: Reclassification of some of the construction and demolition waste into construction material further extends the opportunities for secondary material uses. In 2015, the Netherlands introduced ministerial regulations on end-of-waste status of recycling granulate and on the conditions for the by-product status of the substance glycerine (Dutch Ministry of Infrastructure and the Environment, 2016 $6_{[64]}$ ). Since then, legal rulings and information campaigns have been put in place to encourage businesses and governments to start applying the concepts of "by-product" and "end-of-waste". Further refining of the definition of the concepts of "waste", "by-product" and "end-of-waste" has been done within the third National Waste Management Plan (LAP3).

- Collaboration: Rijkswaterstaat in the Netherlands has started exploring the first strategy steps towards a digital circular construction sector. In order to create a consensus on the concept of a Circular Building sector, Rijkswaterstaat has established a public private discussion platform together with the National real estate company and the National Standardisation body (PLATFORM CB'23, 2020 ${ }_{[65]}$ ). Over hundred stakeholders have been engaged in discussions on how to measure circularity and what type of information material passports standards need to contain, to achieve the goals. The guides 'Core method for measuring circularity in the construction sector' and 'Passports for the construction sector' have been drawn up. How this information and data exchange should be organised in practice is currently under debate among the coalition aiming to professionalise the digital construction sector (DigiDealGO, 2020[66]).

\section{Stimulate capacity building, innovation, and collaboration}

93. Environmental education and awareness raising are fairly well developed in the Czech Republic (for an overview see Box 6.2). However, awareness among businesses about the benefits of waste prevention and a circular economy seems rather low (OECD, $\left.2018_{[1]}\right)$.

94. At the heart of making the waste management more circular is a systematic and digitalised information monitoring and reporting of selected materials flowing through the economy. In order to provide a better understanding of the physical resources that enter the economy and subsequently undergo transformations throughout their lifecycle, as well as an understanding the potential for their circularisation, reporting on quality, quantity and 
respective uses of selected material flows is indispensable and should be made compulsory, systematic, and digitalised. This will allow standardised collection of data and linking the data collected at different levels (macro, meso, micro) across databases. An effective and efficient management of selected material flows requires an information system, which would be building on existing information systems on the one hand, and would enable working with big data on the other.

95. On another level, and as already highlighted in the section on Consumption and consumers, there is a need to strengthen the support of awareness raising and educational programmes, by mainstreaming the topic of circular economy into the educational curricula and by scaling up information instruments targeting waste reduction. More specifically, the dialogue and cooperation among all stakeholders should be widely supported, so as to encourage mutual learning along the value chain. In education, it is recommended to develop circular modules for different levels of the educational system (schools, vocational education and training, and higher education), and to support voluntary activities by students and schools. To better target initiatives by citizens, NGOs and businesses, the deployment and uptake of bottom-up circular initiatives requires support from across all the levels of government. Local sharing economy strategies, education and information campaigns are some of the instruments for capacity building to support new business models, such as sharing schemes, second-hand shops, re-use centres and repair shops. In addition to these, information awareness campaigns for entrepreneurs and investors about business opportunities of new circular digital models are discussed in the section on Research, innovation and digitalisation. In terms of more sector-specific instruments for capacity building, food waste minimisation can be facilitated through educational and awareness raising campaigns as well as voluntary agreements. Several initiatives already exist in the Czech Republic, as detailed within Box 6.2. In construction, the recommendation is to start with improving the framework conditions for promoting circularity throughout the industry. Part of this could entail creation of a platform for circular innovation and investments, which would allow bringing together major stakeholders. Such platform could steer the transition to a circular economy in construction industry throughout the life cycle of buildings and promote investment choices based on circularity. The optimisation of individual phases of the construction works life cycle could further be reinforced through digitalisation of construction projects (by linking waste data and accounting data, passportisation of buildings, and a wide-scale implementation of building information modelling (BIM) processes).

\section{Horizontal priority areas facilitating the transition}

\section{Economic instruments}

\section{Role of economic instruments for the circular economy}

96. Economic instruments offer the prospect of achieving a given level of environmental improvement at lower economic cost than through more rigid and inflexible forms of regulation. Firms or individuals are encouraged to change their behaviour in a desired direction that reduces environmental damage by the presence of a price charged for undesired behaviour, such as a tax or the price they must pay for tradeable permits. Steering polluters through a price, rather than an outright ban, offers flexibility, allowing polluters to pay the price when they would otherwise incur excessive costs of compliance. Environmental benefits are achieved when polluters respond to the price by changing 
behaviour, and excessive economic costs are avoided when polluters choose to pay the price instead.

97. Economic instruments such as landfill taxes, packaging taxes, deposit-refund systems, extended producer responsibility, and taxes on virgin materials (some of which have been touched upon already earlier in the report) have become an established and effective part of the waste and materials management policy landscape in EU Member States over the past four decades. These instruments have the potential to encourage a deeper and more rapid transition towards a more circular pattern of economic activity, without burdening the economy with excessive costs or unrealistic rapid adjustments. There is considerable scope for further development and applications of such economic instruments as part of circular economy strategies. They can help to re-shape the "grain" of the economy towards a circular pattern of recovery, re-use and recycling, while avoiding an excessive economic burden and adverse effects on economic performance.

\section{Policy and legal frameworks in the Czech Republic containing economic instruments for the circular economy}

98. Economic instruments are stipulated in the national legislation. The most important circular economy related legislation containing relevant economic instruments includes the legislation on waste (Waste Act No 185/2001 Coll.), packaging (Packaging Law 477/2001 Coll.), extraction of minerals (Mining Law No. 89/2016 Coll.) and water management (Water management Act No. 254/2001). This primary legislation complemented by secondary law specifies the taxes, charges and fees to be paid, beneficiaries of these revenues and cost bearers. There is also other legislation stipulating economic instruments to support the circular economy transition with a more general application, such as the Local Charges Act No. 565/ 1990 Coll. specifying local charges on municipal waste, and the Law No. 235/2004 on Value Added Tax which establishes conditions for a VAT reduction for some environmental goods and services, including waste treatment and water supply management.

99. In addition to the taxes and charges supporting the transition to a circular economy, the Czech Republic also makes use of EU and national funding in form of grants and/or loans. For example, the Act No. 130/2002 on State support for R\&D includes provisions related to the national grants for $\mathrm{R} \& \mathrm{D}$ projects, some of which are relevant to the circular economy. These grants and loans support circular economy projects in a number of sectors and areas. However, such funding is not exclusive to circular economy but covers a wider range of areas, such as for example, environmental and research projects in general.

100. As mentioned already earlier in the report, on 9 December 2019 a new waste package was approved by the Government in the Czech Republic, including a proposal for an updated Waste Law, an amendment to the Packaging Law and a proposal for an Endof-Life Products Law. This new waste package includes changes with regard to the design and level of landfill tax, increasing substantially the landfill tax for recyclable and otherwise recoverable waste from the current CZK 500 per tonne (EUR 18.50) to CZK 1850 per tonne (EUR 73) by 2030. In addition, to motivate municipalities to sort their municipal waste better and to introduce PAYT system more widely, a discount rate on the landfill tax is introduced for municipalities when they sort their waste above certain thresholds. Eco-modulation fees within the EPR schemes are also expected to be introduced as part of this package. 
Current use of economic instruments for the circular economy in the Czech Republic

101. The aforementioned legislative and policy frameworks include 22 economic instruments for the circular economy identified in the Czech Republic ${ }^{30}$. As economic instruments are a horizontal measure, these have application across the different priority areas, such as the aforementioned consumption and consumers, and waste management priority areas. The identified instruments can be classified into eight categories:

- Taxes and charges: landfill fee, local charge on municipal waste (including PAYT system), packaging registration and evidence fees, resource fees (extraction of minerals, payments for the use of the mining area, groundwater withdrawal);

- Product taxes: reduced VAT for environmentally friendly goods and services;

- EPR take-back schemes: for packaging, WEEE, ELVs, tyres, batteries and accumulators;

- Deposit-refund system: for certain glass bottles;

- Advance disposal fees: second-hand car registration fee;

- Incentive subsidies: EU (European Structural Funds, Horizon 2020, LIFE, Interreg Europe) and national grants (for R\&D, NGOs, car wreck collection);

- Loans: EU (EIB/EFSI) and national loan programmes (State Environmental Fund, National Programme for the environment grants and loans); and

- Voluntary agreements: National programme for environmental labelling, Enough of plastics initiative (these are not economic instruments as such but they contain features of economic instruments).

\section{Policy recommendations to support the use of economic instruments for the circular} economy

102. While existing economic instruments for the circular economy in the Czech Republic provide incentives for relevant actors to adopt circular economy practices, there is scope for enhancing their effectiveness, and in particular to sharpen the incentives that they establish to steer activity in desired directions. In addition, a number of additional economic instruments could be introduced to strengthen the circular transition. These suggestions are based on international best practices and academic research. A more detailed discussion is provided within the Background report on economic instruments, and the specific implementation actions are listed across the different stages of the value chain in the Implementation plan in chapter 7. of this report.

\section{Strengthen economic instruments for waste management, namely landfill taxes}

103. It has already been recognised that the landfill tax needs to rise significantly in order to reduce the Czech Republic's high rate of landfill use, and recent legislation approved by the Government which should enter into force from 2021 is an important move

\footnotetext{
${ }^{30}$ For a more detailed analysis of the Czech policy landscape and these instruments refer to the Background report on the Czech policy landscape.
} 
in this direction. However, there is scope for further and faster reform in this area, and for significant supporting measures.

104. First, a significant part of the revenue from the landfill tax is assigned to the municipality in whose territory the landfill is based (currently the revenues from the basic component, the new Waste Act specifies the shares of revenues to the municipality for each component, and those which go in favour of the State Environmental Fund). This may be seen as giving appropriate compensation to the local community for accepting the various risks associated with living near a landfill site. However, it also decreases the cost of landfill sites for these municipalities and weakens the incentive effect of the landfill tax. Decreasing or removing the proceeds from the landfill tax to municipalities could be further strengthened. The new Waste Act goes in the right direction but more could be done.

105. Another issue is landfilling hazardous waste, which is landfilled at a very high cost even by comparison with other EU Member States. The new Waste Act decreases the landfill fee for hazardous waste to CZK 2000 per tonne. Furthermore, the 2018 OECD Environmental Performance Review highlights that there appear to be important loopholes in the application of this fee, especially the provisions for exemption from the risk fee for material - that can include hazardous material - used for backfilling landfill sites (OECD, $\left.2018_{[1]}\right)$. This means that a substantial fraction of hazardous waste appears to be landfilled for "free". The long-term solution to this must be found in more effective control and enforcement of the waste stream, rather than in limiting the application of financial incentives such as the landfill tax.

106. Lastly, increasing the landfill tax might also have an unintended consequence of diverting waste from landfilling to incineration. To guard against an undesirable boom in incineration, fuelled simply by the absence of any environmental tax on incineration (as is the case in the Czech Republic), it would be desirable to establish an incineration tax. While this currently does not appear necessary in the Czech Republic, it might be the case in the future. As landfill costs and tax rates rise, incineration may begin to look more attractive from a financial point of view. Such a tax could be levied at rates which reflect the relative environmental harm caused by landfill and by incineration. This would imply lower rates on incineration with energy recovery, and higher rates on incineration without energy recovery. Such a tax is employed in a number of OECD countries (see Box 6.9). 


\section{Box 6.9. Examples of Czech landfill taxes and relative prices of landfill and incineration in a number of EU Member States and regions}

\section{The price of landfill in the Czech Republic}

The landfill tax has currently two components: basic and risk with the following prices.

- $\quad$ Basic unit (Municipal and other waste) = CZK 500 per tonne (= EUR 18.50);

- $\quad$ Basic unit (Hazardous waste) = CZK 1700 per tonne (= EUR 62.88); and

- $\quad$ Risk unit - Hazardous waste = CZK 4500 per tonne (= EUR 166.50).

The beneficiaries from these proceeds are municipalities on whose territory the landfill site operates (revenues from the basic component) and the State Environmental Fund (revenues from the risk component).

Under the proposed new Waste Act, the rates for the basic component will split into two categories: recyclable/ recoverable waste and residual waste, where the prices for the recyclable/ residual was will increase by more than threefold, to CZK 1850 per tonne (EUR 73) by 2030. There is currently no incineration tax applied in the Czech Republic.

\section{The price of landfill and incineration in various countries and regions}

The price of landfill and incineration for combustible waste in a number of countries and regions can be seen in Table 6.1.

Table 6.1 Comparison of the price of landfill and incineration for combustible waste, various years 2012-14

\begin{tabular}{|c|c|c|c|c|c|c|c|}
\hline & \multicolumn{2}{|c|}{$\begin{array}{l}\text { Landfill } \\
\text { (€/tonne) }\end{array}$} & \multirow[b]{2}{*}{ Total } & \multicolumn{3}{|c|}{ Incineration (€/tonne) } & \multirow{2}{*}{$\begin{array}{c}\text { After-tax cost } \\
\text { differential } \\
\text { (incineration as \% o } \\
\text { landfill) }\end{array}$} \\
\hline & Cost & Tax & & Cost & Tax & Total & \\
\hline France & 65 & 16 & 81 & 117 & 4 & 121 & 149 \\
\hline Catalonia (Spain) & 34 & 12 & 46 & 50 & 9 & 59 & 128 \\
\hline Netherlands & 20 & 17 & 37 & 71 & 13 & 84 & 227 \\
\hline England (UK) & 26 & 101 & 127 & 109 & 0 & 109 & 86 \\
\hline Austria & 70 & 87 & 157 & 125 & 8 & 133 & 85 \\
\hline Sweden & 114 & 54 & 168 & 59 & 0 & 59 & 35 \\
\hline Wallonia (Belgium) & 70 & 76 & 146 & 70 & 10 & 80 & 55 \\
\hline
\end{tabular}

Source: Calculated from data on page 95 of the Comparative study of the taxation of waste disposal in Europe

(ADEME, 2017 [60]).

\section{Strengthen economic instruments for household waste}

107. The key to progress is getting more waste sorted. Around $50 \%$ of municipal waste in the Czech Republic is mixed waste, a lot of which is currently collected without sorting. Local authorities (LAs) have little interest in changing this because using landfill is so cheap, they are allowed to levy a very low fixed charge for waste collection. This is aggravated by the fact that the markets for collected recyclables are underdeveloped, as 
already discussed above. Increasing the rates of separate collection of recyclables requires widespread changes in household behaviour, as well as in waste management. The proportion of recyclables collected might be also increased by making more use of household collection of recyclables (a door-to-door system) instead of bring facilities. This is already being done to some extent in the Czech Republic where the set-up of door-todoor systems are being financially supported by the EU structural funds.

108. Economic instruments can support such changes in addition to consumer behaviour related approaches, such as information and educational tools. Most importantly, an appropriate volume-related system of charging for waste disposal (PAYT), while recyclables are collected free, can provide a financial incentive to sort waste and to reduce the quantity of charged waste. This system is applied by Czech municipalities to its residents only marginally (around 10-15\% of municipalities use a form of such a system) and mostly in the form of a subscription charge for a waste container of a particular size. The effectiveness of such a system can be increased if the size of the container is small enough relative to the amount of unsorted waste thrown away, or if there is a range of subscription options for containers of different sizes or different collection frequencies, with sharply differentiated subscription fees (large containers/ higher frequency resulting in substantially higher prices). These higher charges are further enhanced if implemented together with door-to-door separate collection of certain recyclables, such as bio-waste, paper and glass.

109. In addition, the coverage of PAYT system for waste collection needs to be extended. At the same time, in order to minimise the potential for illegal diversion of waste, consider making the enforcement policies more effective where necessary. Options for extending PAYT and enhancing its effectiveness include a financial penalty on LAs that operate a non-PAYT regime, mandating PAYT and/or incentivising the most efficient forms of PAYT, and making disposal of unsorted waste so costly that LAs would want to sort. It is acknowledged that not all of these policy options are likely to be possible in the present context of the Czech Republic, in particular, due to the large number of municipalities (6 250). In the longer term it may be desirable to accelerate the trend towards consortia of municipalities jointly operating waste collection and management facilities to benefit from the cost savings that come from economies of scale, while also permitting the use of more sophisticated and costly technologies, including PAYT.

110. For more details on the current PAYT system in the Czech Republic and examples of good practices from other EU Member States see Box 6.3.

\section{Improve the effectiveness of some of the current EPR systems}

111. While the packaging EPR system in the Czech Republic works well, the effectiveness of some of the other EPR systems needs to be addressed, in particular the one for WEEE. The 2018 Environmental Performance Review urged a consolidation of the 16 separate WEEE EPR systems, together with regular monitoring and an appropriate clearing mechanisms to ensure transparency and equitable financing (OECD, 2018 $\left.{ }_{[1]}\right)$. Issues both of transparency and effectiveness need to be addressed to ensure effective functioning, allowing rigorous external audit of performance and financing. In the long-run, effectiveness of EPR will also require attention to be paid to the appropriate design of the tariff for products imposing different EPR cost burdens. The system should incentivise long-term waste-cost-reducing innovation, and ensure that the financing rules of the system are treating all firms equitably. If the institutional arrangements for EPR cannot be reformed in a way that delivers the required outcomes, it would be appropriate to legislate 
for more effective mechanisms to achieve the goals of EPR, through the establishment of mandatory DRS in the underperforming EPR sectors.

\section{Box 6.10. EPR for packaging in the Czech Republic, and for textiles and clothing in France}

\section{EPR for packaging in the Czech Republic}

The recycling data show that the EPR system for packaging and packaging waste works well in the Czech Republic, and consumers sort well their packaging waste. For the moment, there is only a single PRO operating on the market, EKO-KOM, covering 93\% of all packaging waste in the Czech Republic and $84 \%$ of packaging introduced onto the market in the Czech Republic is by clients participating in the EKO-KOM system (EKO-KOM, 2019[39]). In comparison to other countries, EKO-KOM has been attaining high degree of recycling packaging waste and being cost-effective regarding separation and recycling per inhabitant per year (OECD, 2018 $\left.{ }_{[1]}\right)$.

\section{EPR for textiles and clothing in France}

France has EPR schemes covering around 20 different sectors. One of these is an EPR scheme for textiles and clothing, a sector not covered by EPR elsewhere. This placed obligations on firms in the textiles and clothing sector in France to ensure a given standard of recovery and recycling. Firms could achieve this directly, through their own actions, or by contributing to an accredited PRO. In practice a single non-profit PRO, Eco-TLC (Eco-organisme du textiles, du linge et de la chaussure), has emerged as the sole vehicle for collective action in this sector. Member contributions are based on the previous year's sales of items in four size categories of clothing, and two categories of footwear. Reduced contribution rates ("eco-modulation") apply to producers of hard-wearing and sustainable products, and to producers that can demonstrate a content of recycled fibres in their production (Bukhari, Carrasco-Gallego and Ponce-Cueto, 2018 $[67]$ ).

Some 240 thousand tonnes of clothing were collected and processed through the system in 2018, equivalent to about $38 \%$ of clothing sales during the same period. Of the total collected, about $59 \%$ is re-used. Nearly all of the remainder is used for recycling (in particular, processed into insulation materials) and energy recovery, and less than $1 \%$ is discarded in landfill (Eco-TLC, 2019 [68]).

\section{Increase the incentive mechanism of virgin materials taxes}

112. The existing fees for the use of land for mining and, in particular, for the extraction of raw materials have the potential for development into more powerful economic instruments, capable of incentivising the use of secondary materials. This could be relevant in the Czech context especially the recycling of CDW for use as aggregates in road construction. The model for this could be the virgin materials taxes (see Box 6.8), typically taking the form of an excise tax per tonne of raw materials mined or quarried, which have been employed by some countries, including Sweden, Denmark and the UK, to incentivise changes in the use of rock, gravel and other construction aggregates. They take the form of a significant charge per tonne of material quarried, however, without taking account of the environmental performance of individual quarrying operations. Consequently, they provide little incentive for operators to improve their environmental performance. Moreover, the experience shows that such taxes are confined to commodities with relatively limited international trade due to the high transport costs of construction materials relative to their value. Lastly, considerations should be also given to ensure that domestic industry is not disrupted due to higher costs burden imposed for materials. 


\section{Support wider application and use of upstream economic incentives}

113. The use of upstream economic incentives capable of steering the economy towards circular patterns of activity remains work in progress across most OECD countries in general and in the Czech Republic in particular (OECD, 2018 $\left.8_{[1]}\right)$. Hence, there is scope for introducing some new initiatives in this area.

114. One such initiative includes a wider use of product taxes (excises) to act as advance disposal fees for commodities which will result in end-of-life wastes, which are costly to collect and/or difficult to recycle. By making disposable or hard-to-recycle products more expensive, these excises can help to shift consumer purchasing and production towards more sustainable alternatives. Examples include disposable tableware or clothing made of certain composite fibres, but there is no consensus on the products which should be discouraged in this way (refer to Box 6.11). For products covered by EPR, and if EPR works effectively, there is no need also to impose additional excises. Similar for products, which will be covered by the EU's Single-Use Plastics Directive (SUP Directive), which was proposed in May 2018 as part of the European Strategy for Plastics in a Circular Economy.

115. Another initiative includes introducing a systematic programme to identify and implement fiscal measures to facilitate upcycling and reuse, including the identification and removal of current fiscal impediments to these circular activities. Such fiscal measures could be selective tax reductions (e.g. reductions in VAT) for repair services, refurbished or upcycled products or specific VAT treatment of second-hand goods. As mentioned above, a reduced VAT rate of $10 \%$ (instead of $21 \%$ ) will apply to repair of footwear and leather products, repairs and adjustments of clothing and textile products also in the Czech Republic from 1 May 2020. This practices has been already introduced in for example Sweden, where the VAT for repair services is levied at half the standard VAT rate (see Box 6.5 for examples in other countries). In parallel with the reduction of VAT, Sweden has also introduced provisions to cut the labour income tax rate levied on the provision of certain types of repair services by small traders (as labour income taxes are high in Sweden). Similar VAT reduction instrument could be explored also for the processing and resale of repaired, refurbished and upcycled products (such as clothing, furniture and electrical equipment). Regarding the sale of second-hand goods, the Czech Republic permits trade in second-hand goods to be taxed on the basis of a "margin scheme", rather than the standard VAT mechanism. This means that VAT is applied to the margin earned by the trader, in the sense of the difference between the selling price of the good and its purchase price, rather than applied to the full value of the sale, with provision to recover VAT paid on the initial purchase. Similar mechanism could be explored also for less highprofile second-hand commodities (e.g. repair-and-resale "upcycling" activities) where the resulting tax reduction is large enough to reflect the benefits on the environment for example.

116. Lastly, as already discussed in Waste management section, a wider programme to strengthen incentives for the use of recycled materials should be explored. As in many other European countries (and globally), the markets for recycled materials are limited in certain areas. While focus has been so far on achieving a high rate of separately collected materials and commodities from households, ensuring adequate demand for such recyclables is crucial to ensuring the sustainability of the circular economy. Economic instruments can play an important role in this process. These could include financial incentives and subsidies of various sorts, either paid directly or in the form of selective tax reductions, to encourage $\mathrm{R} \& \mathrm{D}$, demonstration projects and recycled product marketing efforts. An 
innovative economic instrument that could be considered to encourage the use of more recycled materials in manufacturing of certain products would be to mandate minimum recycled content standards to be met by all producers. For this instrument to have the benefits of an economic instrument, it would have to be coupled with provisions to introduce some economic flexibility in the application of such standards. For example, to meet their compliance requirements, firms could trade compliance with other firms, or there could be a safety valve of a reasonably high fee for non-compliance. Alternatively, EPR system could be used to encourage higher rates of recycled content in manufacturing. A model for this might, for example, be the French EPR system for textiles and clothing recovery.

\section{Box 6.11. Example of upstream economic instruments}

\section{Product taxes}

Some examples of consumer product taxes relevant to the circular economy are given in Table 6.2.

Table 6.2 Consumer product taxes relevant to the circular economy in EU Member States

\begin{tabular}{|c|c|}
\hline Product & Member States applying environmental tax \\
\hline Household batteries & $\begin{array}{c}\text { Croatia, Denmark, Hungary, Italy, Poland, Portugal, Slovakia, } \\
\text { Sweden }\end{array}$ \\
\hline Disposable tableware & Belgium, Denmark, Latvia \\
\hline Disposable cameras & Belgium \\
\hline Aluminium foil & Belgium \\
\hline Plastic carrier bags & Belgium, Denmark, Hungary, Ireland \\
\hline Electric light bulbs & Denmark, Latvia, Slovakia \\
\hline Motor vehicle batteries & Bulgaria, Latvia, Lithuania, Poland, Portugal, Sweden \\
\hline Car tyres & $\begin{array}{c}\text { Bulgaria, Croatia, Denmark, Finland, Hungary, Latvia, Lithuania, } \\
\text { Malta, Portugal, Slovakia }\end{array}$ \\
\hline Paint, other solvent-containing products & Belgium \\
\hline Ozone-depleting substances & Czech Republic, Poland \\
\hline Pesticides & Denmark \\
\hline Vehicle oils and lubricants & Croatia, Finland \\
\hline Textiles & France, Denmark \\
\hline Consumer electrical products & Hungary, Italy, Malta, Poland, Portugal, Slovakia \\
\hline
\end{tabular}

Source: OECD/EEA Economic Instruments Database

117. In each of these three areas, the scope for policy measures will need to be assessed in detail to ensure that they are appropriately targeted, consistent with both EU legislation and the objectives of fiscal policy in the Czech Republic, and capable of achieving beneficial outcomes sufficient to justify the costs that would be involved.

\section{Research, innovation and digitalisation}

\section{Role of research, innovation and digitalisation for the circular economy}

118. Innovation and technological development, including digitalisation, are important factors in transitioning towards a circular economy. In particular, circular economy is facilitated by the introduction of new production processes and technologies, and by the design of innovative business models, which bring about new ways of more efficient 
resource uses. The uptake of circular business models in turn is facilitated by digital transformation, which reinforces the shifts in consumption and production models, for instance by reducing transaction costs and risks associated with sharing models, facilitating product service systems through real time monitoring of product performance, and dematerialising products $\left(\mathrm{OECD}, 2021\right.$ forthcoming $\left.{ }_{[69]}\right)$. Additionally, a change in entire systems is needed, accompanied by cooperation between researchers, technology centres, industry, SMEs, primary sector, entrepreneurs, users, governments and civil society (European Commission, 2017[70]).

\section{Evidence on the research, innovation and digitalisation for the circular economy in} the Czech Republic

119. The Czech Republic ranked $13^{\text {th }}$ in the 2018 European Innovation Scoreboard, and $18^{\text {th }}$ for its eco-innovation performance in the 2017 Eco-innovation scoreboard (European Commission, $\left.2019_{[2]}\right)$. Over the past years, new programmes to finance innovation and development, and more initiatives by agencies and ministries are supporting stakeholders in eco-innovation for transitioning towards a circular economy. Among the main targeted areas are energy efficiency and renewable energy, sustainable transport, waste management, material and resource efficiency, innovative technologies, and bio- and nanotechnologies (European Commission, 2019 ${ }_{[2]}$ ).

120. The review of the Czech regulatory framework, of relevant literature on the Czech research, development and innovation (R\&D\&I), and of data on R\&D spending show that the importance of science, research, innovation and digitalisation has been growing in the Czech Republic (Eco-innovation observatory, 2018 ${ }_{[71]}$; Czech Statistical Office, 2019 ${ }_{[72]}$; OECD, 2018 $8_{[1]}$; Research Development and Innovation Council, 2019 [73]). For instance, the direct state subsidies to R\&D in 2018 amounted to CZK 33.4 billion (EUR 1.2 billion), out of which around $10.6 \%$ went to industry production and technology, and around $2 \%$ to the protection of the environment (Czech Statistical Office, 2019 $9_{[72]}$ ). Coupled with this, for the period 2014-2020, around EUR 1.34 billion is allocated to the promotion of R\&D\&I from the European Structural and Investment Funds, and its Operational Programmes (OP) Environment, Enterprise and Innovation for Competitiveness, of which some of the funding supports specifically eco-innovation and digitalisation (Ministry of Industry and Trade of the Czech Republic, 2015 [74]). On another level, of the indirect public support measures in form of tax incentives for R\&D and start-ups, the tax deduction support to R\&D amounted to around CZK 2.5 billion (EUR 91.5 million) in 2017, or around $0.2 \%$ of state budget (Czech Statistical Office, 2019[75]).

121. From a more longer term perspective, the Innovation Strategy of the Czech Republic for the period 2019-2030 includes a target to strengthen R\&D funding to $2.5 \%$ by 2025 and $3 \%$ of GDP by 2030, accompanied by several other goals and tools to strengthen R\&D\&I in the Czech Republic (Research Development and Innovation Council, $\left.2019_{[73]}\right)$. Even though a concrete link to the circular economy is not made in this strategy, a part of the dedicated R\&D funding and other planned incentive schemes might be available to innovation projects related to the circular economy.

\section{Research, innovation and digitalisation oriented circular economy legislation in the Czech Republic}

122. The most recent strategic document on digital economy and society in the Czech Republic is the Digital Czechia - Government Programme 2018+ (Office of the Government of the Czech Republic, 2018 $\left.{ }_{[76]}\right)$. This includes all previous umbrella 
documents on digitalisation, such as the Action Plan for Society 4.0 and the Industry 4.0, and coordinates between the sectoral documents. Industry 4.0 covers innovations in production and industry, including reduced energy and material intensity of production, increased productivity in production, or optimisation of logistics routes, which are all innovations relevant for the transition to a circular economy. The Industry 4.0 also supports research and development that aims to strengthen the Czech Republic's position in artificial intelligence and the digitalisation of branches of the economy, and is one of the nine strategic priorities of the Innovation Strategy of the Czech Republic for the period 20192030 (Research Development and Innovation Council, 2019 [77] $)$.

123. The innovation and technological development related policies in the Czech Republic include the most recent Innovation Strategy of the Czech Republic for the period 2019-2030 (Research Development and Innovation Council, 2019 $9_{[77]}$ ) and the older National Research, Development and Innovation Policy of the Czech Republic for the period 2016-2020 (Office of the Government of the Czech Republic, 2015 ${ }_{[78]}$ ), both of which aim at creating conditions for the development of knowledge and to actively use it in innovation. The most relevant innovation policy document to circular economy is the National Priorities of Oriented Research, Experimental Development and Innovations, which has a specific focus on sustainable production, resource efficiency and critical raw materials (Ministry of Education Youth and Sports; Research Development and Innovation Council, 2012[79]). It reviews the goals and activities of the older research, development and innovation policy, and proposes new priorities in applied research, many of which directly link to circular economy, such as biotechnologies or decreasing material demand of the economy. However, with regard to eco-innovation and circular economy specifically, there is no national policy outlining a coherent approach on innovation or digitalisation for the circular economy $\left(\mathrm{OECD}, 2018_{[1]}\right)$.

124. The main policy instruments stimulating research, innovation and digitalisation in circular economy in the Czech Republic have been economic and financial instruments. In particular, these are incentive subsidies (also known as direct public support to R\&D) to support research and innovation in general, which researchers and businesses can apply for (some of them have been mentioned already as part of Economic instruments section):

- European grants: The European Structural and Investment Funds (Operational Programmes (OP) Environment, Enterprise and Innovation for Competitiveness, Research, Development and Education), Horizon 2020, LIFE Programme and Interreg Europe supporting transnational collaboration on a wide range of $R \& D$, demonstration or other innovation related projects, including innovation and digitalisation related to the circular economy, development of R\&D infrastructure, and many more.

- National grants: National R\&D support in form of direct subsidies through the Act No. 130/2002 on State support for R\&D projects and innovative business models, disbursed through specific programmes by the Technology Agency of the Czech Republic (TACR) (e.g. programmes EPSILON, TRIO and ALFA for applied R\&D\&I, and the ZETA programme for cooperation between academia and industry), the State Environmental Fund, and several R\&D funding programmes provided by the Czech Science Foundation.

125. The secondary policy instrument in the Czech Republic supporting R\&D (and thereby also eco-innovation) are fiscal measures in the form of tax incentives for R\&D and start-ups (known as indirect public support to R\&D). The Income Tax Act No. 586/1992 provides a possibility for corporate taxpayers to deduct eligible costs of their own R\&D 
activities (as well as expenditures on $R \& D$ projects covering services related to their realisation) from their income tax base.

126. Additionally, Czech research, innovation and digitalisation companies can apply for European loan programmes such as those offered through a joint initiative between the European Commission and the European Investment Bank (EIB), the so-called Juncker Plan, or the European Fund for Strategic Investments (EFSI). In particular, this funding supports projects in several relevant sectors to circular economy, such as bioeconomy, environment and resource efficiency, R\&D\&I, digital, energy, transport, regional development, social and smaller companies.

127. Besides economic and financial instruments, there are also regulatory instruments and standards steering industry towards innovation and digitalisation in circular economy. These instruments, even though not all fully effective, include EPR schemes for packaging, batteries and accumulators, WEEE, end-of-life vehicles and tyres, emission limit values for pollution sources, technical requirements for operating equipment, as well as some product standards and quotas and targets (e.g. waste management targets - recycling rates, landfill rates, and others).

128. Voluntary agreements negotiated between the industry and the government can also serve as an incentive to innovate. In fact, when certain practices or standards are agreed on, the industry needs to adopt new practices, products or business models to reach these standards (e.g. "Enough of Plastics" initiative (Ministry of the Environment of the Czech Republic, n.d. $[80]))$.

129. Information instruments to raise awareness on the importance of innovation and digitalisation in circular economy among citizens also exist and include the "Waste as a resource" initiative (INCIEN, 2019 $9_{[81]}$ ) and the Prague Circular Hub (Cirkulární Hub Praha, n.d. $[82])$.

130. Education and capacity building instruments include tailored training courses for companies and entrepreneurs (e.g. Enterprise Europe Network for the Czech Republic, Technology Centre ASCR, TACR, Brno Innovation Centre, South Moravian Innovation Centre), as well as advice/consulting for start-ups, companies and entrepreneurs (e.g. CzechInvest, CzechTrade, and many more) (Eco-innovation observatory, 2018 ${ }_{[71]}$ ). The Czech's digitalisation agenda also aims to adjust school education programmes and the training of teachers in order to cope with new challenges, such as digital education.

\section{Policy recommendations for research, innovation and digitalisation to support a transition towards a circular economy}

131. Despite the recent developments in the policy area and in the funding of R\&D, ecoinnovation and digitalisation for circular economy in the Czech Republic is still an emerging area (Eco-innovation observatory, $2018_{[71]}$ ), and an area which faces similar challenges as the general research and innovation agenda. More specifically, these challenges have been identified as: weak outcomes of R\&D activities, limited co-operation between academia and business, lack of human resources, a fragmented R\&D policy, lack of targeted funding for circular economy and eco-innovation, high dependence on the activities of foreign-owned companies, and inefficiency in the business environment (Ecoinnovation observatory, 2018 [71]; OECD, 2018 $8_{[1]}$; European Commission, 2019 $\left.{ }_{[83]}\right)$. 
Establish a coherent innovation and digitalisation policy, and strengthen the effectiveness of existing instruments to support research, innovation and digitalisation in circular economy for domestic firms

132. In the Czech Republic, there is currently no coherent innovation and/or digitalisation policy for circular economy - a clear link between research, innovation, digitalisation and circular economy largely is missing from the policy framework (OECD, 2018 $[1]$; Eco-innovation observatory, 2018 $\left.{ }_{[71]}\right)$. There is therefore a need for streamlining these topics into a coherent strategy at the national level, including a clear vision and support for firms carrying out circular economy related innovations. An alternative would be to establish a strategic innovation and digitalisation programme, which would support the circular economy, as one of strategic innovation areas backed by the Government. Whether developing a strategy or establishing a programme, there is a need for strengthening the coordination mechanism between the different public bodies across the government responsible for R\&D\&I and digitalisation related to the circular economy, in order to better coordinate the cross-sectoral issues. This is role could be performed by the Research, Development and Innovation Council in the Czech Republic.

133. In terms of the specific policy instruments already in place in the Czech Republic, the Innovation Strategy 2019-2030 foresees strengthening the support for domestic companies, spinoffs and start-ups (arising from both academic research and industry needs) in their innovation and digitalisation endeavours (Research Development and Innovation Council, 2019[77]). Even though these initiatives go in the right direction, more needs to be done to render the current $\mathrm{R} \& \mathrm{D}$ support instruments more effective, especially in facilitating the transition towards a circular economy (refer to Box 6.12).

\section{Box 6.12. The status of current R\&D\&I support in the Czech Republic}

Despite the increased $R \& D$ spending in recent years, results of $R \& D$ activities remain weak, and the effectiveness and efficiency of the spending is questioned (OECD, 2018 ${ }_{[1]}$; Government of the Czech Republic, 2016 ${ }_{[84]}$; European Commission, 2019 $\left.9_{[2]}\right)$. The 2019 European Semester report for the Czech Republic identified that there has been limited progress in removing the bottlenecks hampering R\&D\&I both in general terms, and more specifically in the context of circular economy (European Commission, 2019 [83]; Eco-innovation observatory, 2018 ${ }_{\text {[71] }}$ ). For instance, even though TACR has a ZETA programme supporting cooperation between academia and businesses (focusing on students and young researchers), there is still limited cooperation between these two, hampering commercialisation of research results and their alignment with business needs (OECD, 2018 ${ }_{[1]}$; European Commission, 2019 ${ }_{\text {[83] }}$; Government of the Czech Republic, 2016 [84]). In addition, domestic research and innovation activities are still limited, with Czech companies (mainly SMEs) lagging significantly behind their foreign counterparts $\left(\right.$ OECD, 2018 ${ }_{[1]}$; European Commission, 2019 ${ }_{[83]}$; Government of the Czech Republic, 2016 $\left.6_{[84]}\right)$. In practice this implies that the strategic decisions on future investment are made outside the country, and that foreign companies' activities in the Czech Republic often focus on low value added products and services (OECD, 2018 $\left.{ }_{[1]}\right)$. An analysis of the Czech foreign trade and its position in global value chains showed that indeed "the Czech Republic remains more an assembly shop" rather than being involved in more strategic decisions and innovations and production of higher value added products and services (Deloitte Czech Republic, $\left.2019_{[85]}\right)$. The most notable example of this is the car manufacturing industry in Czech Republic.

134. In order to make the existing policy framework and instruments more effective and efficient, it is recommended for the Czech Republic to re-evaluate the current design of its direct and indirect public support to R\&D. Examples of international good practices on implementing instruments for public support include R\&D reliefs and tax credits for 
innovative projects, as well as tax incentive schemes for environmentally friendly technologies, discussed in more detail within Box 6.13.

\section{Box 6.13. International good practices in designing public support to $R \& D$}

There are several examples of implementing direct and indirect public support to stimulate R\&D. For example, companies working on innovative projects in the UK have different types of R\&D reliefs available to them, in function of their size and the R\&D contract the company has (whether subcontractor or not) (Government UK, 2020 [86]). It offers a specific R\&D relief for small and medium sized enterprises (SMEs), which can deduct an extra $130 \%$ of their eligible costs from their yearly profit in addition to the normal $100 \%$ deduction (i.e. a total of $230 \%$ deduction); and claim a tax credit up to $14.5 \%$ of the surrenderable loss if the company is loss making. This technically means that the company can surrender its losses to receive a cash benefit equal to $14.5 \%$ of surrenderable loss. Large companies instead, can claim an R\&D expenditure credit up to $13 \%$ (from 1 April 2020).

In the Netherlands, several tax incentive schemes for innovation and R\&D exist. As an example, there are two tax incentive schemes for investing in environmentally friendly technology. The Environmental investment deduction scheme (MIA scheme) allows an entrepreneur to deduct up to $36 \%$ of the investment costs for an environmentally friendly investment on top of the regular investment tax deduction. The Arbitrary depreciation of environmental investments scheme (Vamil scheme) allows the entrepreneur to decide when to write off $75 \%$ of the investments costs, and thereby provides an advantage with regard to liquidity and interest (Netherlands Enterprise Agency, n.d.[87]).

135. In terms of improving the existing cooperation instruments, it is also recommended to strengthen the cooperation between private sector and academia (for example through introduction of grants for collaborative $R \& D$, extending the scope of innovation vouchers, or supporting the establishment of collaborative research centres). Besides the financial support, it is suggested to consider enhancing such collaboration through the establishment of an online tool to help match-making R\&D collaboration opportunities. Furthermore, in terms of information instruments, it is crucial to strengthen awareness by both entrepreneurs and investors about the opportunities offered by new circular and digital business models. These can be accompanied by the introduction of soft measures, such as business support services, innovation hubs, and decision-making tools for business managers, which could further strengthen the actual adoption of circular activities by companies. Successful outcomes of innovations could then be awarded by additional economic incentives (such as innovation awards). Finally, with regard to regulatory instruments, it is recommended to evaluate the current legislation and standards, and to remove any barriers that stand in the way of adopting new business models (for instance the legislation limiting the reuse of recovered and recycled material, as proposed in Economic instruments section).

\section{Target investment instruments in innovation technologies for circular economy}

136. There is significant room for stepping up the provision of appropriate funding instruments in support of early-stage and proof of concept projects in the Czech Republic, and to stimulate venture capital for new eco-technologies and innovation for circular economy (European Commission, 2019 ${ }_{[83]}$; Eco-innovation observatory, 2018 ${ }_{[71]}$ ). In the Czech Republic, this proves especially critical in the area of the reuse of secondary raw materials and separately collected recyclables in products (refer to Box 6.14). A better targeted investment into such innovations for domestic firms could create incentives for 
companies to invest in $\mathrm{R} \& \mathrm{D}$, demonstration projects and recycled product marketing efforts. In the absence of a dedicated state-supported circular economy fund for start-ups, the key recommendation is to set up support and provide advice for businesses on tapping into equity investments, and simultaneously to arrange for training to Czech investors and financial intermediaries on circular economy innovation projects.

\section{Box 6.14. Financing start-up innovations in the Czech Republic}

With the cancellation of the National Innovation Fund, which aimed at providing targeted funding for start-ups and spin-offs, the financing of innovation in the Czech Republic is still under development (European Commission, 2019 ${ }_{[83]}$ ). Currently, the only other available source of venture capital financing companies can tap into are the CzechInvest (Business and Investment Development Agency in the Czech Republic) and the European Investment Fund (Zachova, 2018 ${ }_{[88]}$ ). While the former helps to arrange domestic and foreign investments for SMEs and innovative start-ups in the areas of manufacturing, business support services and technology centres, the Central Europe Fund of Funds provides a source of financing for already established SMEs and small mid-caps to help them with the expansion of production or entry into new markets (European Investment Fund, n.d. $[89])$.

One specific challenge in the circular economy related area in the Czech Republic is the innovation in the reuse of secondary raw materials and separately collected recyclables in products, which could be manufactured locally. Such innovations could partly mitigate the issue of low demand for such materials (which in turn adversely affect the costs of separate collection of recyclables for municipalities). A better targeted investment into such innovations for domestic firms would therefore have a great potential for creating incentives for companies to invest in R\&D\&I, demonstration projects and recycled product marketing efforts.

137. As an alternative, it is suggested to re-launch the innovation investment fund for such projects, yet with a different design than the original National Innovation Fund (refer to Box 6.15). Other considerations may include setting up a dedicated circular economy innovation fund offering grants, or introducing innovation vouchers for circular economy technologies. Finally, in order to stimulate the markets for secondary raw materials, it is recommended to consider introducing tax deduction for products with specific amount of recycled material content (as suggested in other priority areas).

\section{Box 6.15. International good practices of innovation funding instruments in the $\mathrm{EU}$}

An interesting example is provided by the Netherlands, known as the Seed Capital fund. This fund is administered by the Netherlands Enterprise Agency and funded by the Ministry of Economic Affairs and Climate Policy. It provides capital for investment funds backing innovative entrepreneurs in the technology and creative sectors. Funds are raised jointly by private lenders and the government, this model offering investors some security, while also helping innovators to find investors. Investors can then apply for a loan (Netherlands Enterprise Agency, n.d. [900]).

There are several other examples of innovation funding instruments across the EU Member States, ranging from specific "From waste to resource" funding in the Netherlands (VANG programme) to regional programmes aimed at accelerating the development of innovative start-ups (such as the Brussels Greenlab.brussels). For more examples refer to Doranova et al. (2016 $\left.6_{[91]}\right)$. 
Support the growth of advanced digital technologies particularly relevant for the transition to a circular economy

138. With regard to digital technologies and their application to business models, Czech firms have been found to belong to Europe's top performers in e-commerce. However, they have also been found to rarely make use of advanced digital technologies, such as enterprise resource planning software, advanced cloud services, big data or blockchain technology (European Commission, 2019 [83]). Those technologies are considered as detrimental for boosting innovation, productivity, and competitiveness, and facilitating the adoption of new business models. While this applies to innovation and digitalisation of the Czech industry in general, digital transformation is especially important for accelerating the transition towards the circular economy. In fact, data collection, information management, and knowledge sharing facilitated by digital technologies, make circular business models operational, improve the business case for existing circular economy activities, and enable the development of new circular business models. It is therefore recommended for the Czech Republic to consider making the concept of circular economy and its links to digitalisation more explicit within the existing digitalisation policies (i.e. Action Plan on the Development of Digital Market, Action Plan for Society 4.0, Digital Czechia Government Programme 2018+). At a later stage, a possibility of developing a national strategy to stimulate the uptake of the sharing economy may be explored (see Box 6.16). Digitalisation for a circular economy transition could be further facilitated by improving the cooperation mechanism between the different Ministries, the Government office, the relevant agencies and stakeholders in the circular economy, innovation and digitalisation areas. Such coordination could be led by the Research, Development and Innovation Council jointly with the Government Council for Information Society, which are advisory bodies to the Czech Government in the areas of R\&D and information society, respectively. Promoting inter-sectoral, cross-agency and interdepartmental collaboration would facilitate addressing the cross-cutting issues related to advanced technologies and innovative circular activities (for instance "Green Deals" between the Government and the private sector - see Box 6.16). To further facilitate the uptake of digital circular activities, it is important to identify and eliminate impediments to digital circular economy, some of which might be caused by lagging and ambiguous regulatory frameworks (affecting for instance the online sales of repaired and refurbished products). On the level of individual firms, awareness raising initiatives and education activities are required to inform business managers about the uses and the possibilities presented by advanced digital technologies for circular economy innovations. 


\section{Box 6.16. International good practices in mainstreaming digital innovation for the uptake of circular business models}

Denmark is one of the first Member States having developed strategies in place for the country's digital growth and growth through sharing economy (in 2017) (Ministry of Environment and Food and Ministry of Industry Business and Financial Affairs, 2018 ${ }_{[92]}$ ). These strategies jointly target the introduction of good framework conditions for Danish businesses when utilising the potential of digital technologies and of the sharing economy, respectively. More specifically, while the former aims to address creation of enabling environments for digital growth, introduction of future-proof regulation, strengthening digital competencies and digital boost of SMEs, and making a better use of data and IT security, the objectives of the latter are centred around a broad effort of guidance, a digital reporting solution for sharing economy, and simplified tax deductions for rental of summer houses and permanent residences, among others.

An example of successful cooperation in innovation between the government, companies and other stakeholders to address cross-cutting issues, among others related to advanced technologies and innovative circular activities, are the Green Deals in the Netherlands. These are mutual agreements defining the innovative initiative and the actions involved for all stakeholders as clearly as possible, including quantitative targets. The government then commits itself to remove obstacles for concrete sustainable projects by modifying regulations. Several of the hundreds of Green Deals signed involved projects related to innovation in circular economy, but mostly with regard to recycling (Green Deal, n.d.[93]).

139. Besides playing a crucial role in firms' business models, digital innovation and the uptake of digital solutions also help improving circular economy policy making (see Box 6.17). However, such impact of digital transformation has not yet been transposed to policy making in the Czech Republic so far. It is therefore recommended for the Czech Government to explore data-driven approaches to its foresight capacities, in order to better anticipate societal trends and needs, and as such to increase efficiencies and better target specific policymaking. This will also require increasing the Government's ability to help scaling digitalisation (through introducing standards on data collection, linking disparate sources of data and assuring its interoperability) and its preparedness to address data privacy concerns and digital security vulnerabilities (such as data security, privacy, ownership, transparency, and use, driven by increased granularity and sharing of data across government agencies and public private partnerships). 


\section{Box 6.17. International good practices of using digital technologies to support the effective delivery of circular economy policies}

Besides fuelling circular activities in the private sector, digital innovation, data and uptake of digital solutions can also be leveraged by policy-makers to create greater efficiencies, improve sustainability, and spur economic development (OECD, 2021 forthcoming $\left.{ }_{[69]}\right)$. For instance, digital technologies and the large volumes of data help to:

- Enable innovative policy design: digitally-enhanced municipal waste management through Internet of Things (IoT) and sensors (possibly also accompanied by radio frequency mesh and $\mathrm{WiFi}$ ), facilitate better efficiency and improved quality of waste collection services. An example of smart waste collection has been implemented in the city of Nitra in Slovakia, where smart sensors allow real-time monitoring of waste levels in semi-underground bins (NKS, 2017 [94]).

- Expand civic engagement in local and national policymaking: digital platforms in combination with artificial intelligence (AI) and machine learning algorithms enable civil servants to tap into collective intelligence and make better-informed decisions, while improving government's responsiveness to issues raised by citizens. An example of such citizen participation platform is the Belgium's CitizenLab, which had been used among others to crowdsource policy priorities in waste management for the city of Liège (Liège, $\left.2020_{[95]}\right)$.

- Incentivise compliance, improving policy implementation and waste prevention: in the area of environmental crime, one example of a policy enforcement initiative is the UK's project on introducing monitoring and clamping down on illegal movements of waste. As a response to tax avoidance and illegal exports through mislabelled waste, the UK Government seeks to introduce compulsory electronic tracking of waste through electronic chips, sensors, AI and big data analytics (NKS, 2017[94]). 


\section{Implementation plan}

140. The discussion about strategic priorities for circularising the Czech economy has revolved around identification of opportunities and high-level policy recommendations, informed by existing good practices from across the other EU Member States. In order to deliver the ambitions of the Circular Czechia 2040 strategic framework, the Implementation plan proposed in this chapter develops a list of actions to be taken forward once the circular economy strategic framework will have been adopted by the Czech Government. For this to be actionable and transformative, the Czech Republic should consider drawing up an action plan (based on the below proposed actions and complemented with measures resulting from own analyses) and setting a clear set of deliverables, accompanied by an implementation timeframe. Additionally, for a successful implementation, a cooperation with a broad base of interest groups, partnerships, as well as inter-ministerial and cross-sectoral cooperation are important.

141. Building on the policy recommendations proposed for individual priority areas in Chapter 6. , the implementation actions are prioritised along the elements of the Circular Czechia 2040 strategic framework. More specifically, this implementation plan outlines 40 actions across five action areas: (1) production and design ${ }^{31}$; (2) consumption and consumer behaviour; (3) waste management; (4) research, innovation and digitalisation; and (5) education and knowledge. ${ }^{32}$

\section{A more circular production and design}

142. One of the priorities to introduce a more circular production and design in the Czech Republic is to implement some actions within EPR schemes. Besides these, there are several other concrete actions that can be undertaken. The following implementation actions were identified for production and design:

- Ensure effective implementation and enforcement of the take-back obligations of WEEE under the EPR

- Set a recycling and recovery target at the level of individual WEEE PROs (or industry), establish a coordination mechanism across all PROs operating in the

\footnotetext{
${ }^{31}$ As indicated in Figure 6.1, the production and design priority area has not been addressed in depth in this report. The actions proposed herewith are derived from background analysis of the other priority areas, and are overlapping with the production and design stages of the value chain. Therefore they only constitute part of the policy recommendations, and shall be complemented with measures identified through a deep-dive analysis by the Ministry of the Environment.

${ }^{32}$ Note that the implementation actions are interdependent and overlapping, in particular across the value chain (production, consumption and waste management). It is therefore possible that one action be relevant for circularising more than one priority area. In such case, the implementation actions are repeated across the respective priority areas. Priority areas Research, innovation and digitalisation and Education and knowledge are considered as horizontal areas applicable across the value chain, hence cross referencing has not been done. Note also that for the economic instruments priority area, no separate list of implementation actions has been presented. These have been directly integrated within the other priority areas.
} 
market, and increase the density and effectiveness of take-back and separate collection points for WEEE.

- Consider introducing a deposit-refund system to ensure adequate recovery rates. DRS are well suited for products such as these, which have hazardous content and frequently find themselves mixed within other MSW. A DRS would therefore provide an incentive to consumers to return these products to collection points and help to increase collection rates.

\section{- Expand the EPR system to new products}

- Evaluate the future potential of introducing EPR schemes for textiles and furniture, in order to hold producers, distributors and importers responsible for providing or managing the recycling of those products at the end of their usage (an example is the EPR for clothing, home textiles and footwear in France).

\section{- Ensure good application and enforcement of eco-modulation fee in EPR schemes}

- Enforce the introduction of eco-modulated fees according to the impact of specific material inputs/products on the environment (e.g. eco-modulated fees based on environmental friendliness of raw materials used and eco-design of products, bonuses for products containing at least $50 \%$ of recycled materials or when sorting instructions are included with the products part, as in EPR schemes in France, the Netherlands and Belgium). Putting a new information system in place is a precondition for monitoring the recycled materials content in products.

- Reassess the possibility of extending the DRS system to PET beverage bottles, if there are challenges to meet the targets

- To reinforce the reduction of collection targets, consider reassessing the potential extension of across-the-board DRS to PET beverage bottles. An example is the introduction of a DRS for single-use plastic bottles and cans deposited for recycling in Germany in 2003.

- Introduce a wider use of product taxes (excises) to act as advance disposal fees for commodities that will result in costly to collect and/or difficult to recycle endof-life wastes

- If EPRs are ineffective, discourage consumer purchasing and production of disposable or hard-to-recycle products by applying additional product taxes (excises), making such products more expensive. Some examples include the Irish plastic bag tax, disposable tableware in Belgium (also labelled as "picnic" tax), Denmark and Latvia, textiles in France and Denmark, and consumer electrical products in Hungary, Italy, Malta, Poland, Portugal and Slovakia. There are also discussions ongoing about introducing EPR systems that resemble earmarked taxes on some products (e.g. cigarette butts, wet wipes, balloons).

\section{- Explore the potential of legislating longer warranty periods}

- Consider extending legal warranties, or establishing warranty duration according to the expected lifespan of the specific product, in order to induce the design of products with extended lifetimes, and extend consumers' rights to get their defective goods repaired or replaced. Such extended warranty policies were introduced in various European countries: three years in Sweden; six years 
in Ireland and UK (except Scotland where it is five years); five years in Iceland and Norway; and in line with expected lifespan in the Netherlands and Finland.

- Introduce compulsory circular considerations in (green) public procurement and its enforcement

- Introduce criteria and additional incentives for circular green procurement based on concepts like life cycle analysis and life cycle costing, functional procurement, or servitisation. Targets should be introduced at all levels of government, building on the existing declarations and activities in this area.

- Foster multi-stakeholder voluntary agreements and public-private cooperation to prevent [food- and bio-]waste and associated packaging

- Drive the establishment of public-private collaborations among different stakeholders along the product life cycle, in order to facilitate the achievement of packaging and bio-waste reduction targets, the development of logistics for distributing surplus food, and the valorisation of discarded organic material (see for example the Courtauld Commitment in the UK or the Milan Urban Food Policy Pact in Italy).

143. Other measures relevant for a more circular production and design, overlapping with circular consumption and consumer behaviour priority area $\operatorname{are}^{33}$ :

- Expand quality certification of reusable components or products, secondary raw materials and recyclable waste

- Reduce VAT for repairing, refurbishment and remanufacturing activities

144. Other measures relevant for a more circular production and design, overlapping with waste management priority area $\operatorname{are}^{34}$ :

- Introduce incentives and supporting measures to strengthen the demand for recyclables and trade with secondary raw materials

- Explore the potential of increasing (virgin) materials taxes to enhance the incentive for use of secondary materials

- Strengthen regulation of using hazardous materials as raw materials and product components

\section{A more circular consumption and consumer behaviour}

145. There are several implementation actions that can be taken forward to stimulate a more circular consumption and consumer behaviour, ranging from softer to more regulatory approaches. These are as follows:

- Implement nudges to improve waste sorting rate and quality

- Introduce system nudges to improve the waste sorting rates, and the quality of recyclables by reducing the impurities. These may include free bins for

\footnotetext{
${ }^{33}$ For more information on these proposed actions, please refer to the relevant paragraph in this section.

${ }^{34}$ For more information on these proposed actions, please refer to the relevant paragraph in this section.
} 
recycling, transparent waste bags, just-in-time waste collection to prevent overfilling of containers, and reducing the size of the lids of containers. An example is the introduction of containers with a different lid size in Barcelona (Spain) to reduce impurities in selectively collected bio-waste.

\section{- Foster separate door-to-door waste collection}

- Implement Czech Republic-wide door-to-door collection of recyclables in order to induce citizens to separate recyclables with low collection frequency (such as bio-waste, WEEE, and textiles).

- Develop awareness campaigns about environmental benefits and good practices related to household waste sorting, in order to make citizens familiar with the new collection systems. See examples of door-to-door separate waste collection accompanied with introduction of transparent bags for the collection of the residual waste in Milan (Italy).

\section{- Extend the coverage of PAYT arrangements for waste collection}

- Mainstream the adoption of PAYT schemes, to better reflect the cost of waste management. The new Waste Act already provides incentives for municipalities to introduce PAYT systems more widely. At the same time, in order to minimise the potential for illegal diversion of waste, consider making the enforcement policies more effective where necessary. In low density areas implement pay-per-bag (i.e. introducing compulsory purchasing of special bags for residual waste using a smart card associated to each household) or pay-perbin charges (i.e. introducing different collection fees applied for different bins). In high density areas implement chamber systems with smart containers operated by personal ID cards (i.e. introducing individual billing system based on a flat rate plus a variable fee reflecting the number of uses of the residual waste containers). See example of PAYT schemes in Bergamo (Italy), Berlin and Schwerin (Germany).

\section{- Strengthen bio-waste separate collection}

- Reinforce the recently introduced compulsory sorting of bio-waste throughout the Czech Republic with increased landfill tax and possible future introduction of an incineration tax. An example is the Waste Law adopted in Catalonia (Spain) in 1993 and amended in 2008, with regional landfill tax adopted in 2004 starting at EUR 10 per tonne and being in 2020 at EUR 47.10 per tonne, and waste incineration included in the tax base since 2008 at a rate of EUR 5 per tonne, increased to EUR 23.60 per tonnes by 2020 .

\section{- Introduce home composting programmes}

- Expand organic waste separation to all residential areas, especially blocks of flats, which have still limited access to organic waste separation. Provide organic waste separation infrastructure of the same density, as is paper/glass/plastics waste separation infrastructure.

- Reduce waste charges to foster home composting, and provide citizens with training, support and infrastructure (i.e. distributing composting units). As an illustration, home composting programmes with a reduction of the waste fee were successfully introduced and managed at municipal levels since the early 1990s in Finland. 


\section{- Strengthen existing measures addressing the reduction of plastic bags use}

- The recent law introduces an obligation for stores in the Czech Republic to make plastic carrier bags available to the consumers for a price corresponding to at least to the cost of their purchase (with the exception of very lightweight bags with wall thickness below 15 microns). Consider introducing additional measures alternative to or complementary with the existing regulation and the EPR schemes, in order to further reduce the consumption of single-use plastic bags. These may range from voluntary agreements including reduction targets (e.g. voluntary agreement between the regional government and all distribution and manufacturing organisations in Catalonia, with a reduction target of 50\% in 2012), to requiring stores to offer alternative packaging options (e.g. Estonia in 2017), to environmental taxes on all non-reusable plastic bags, to banning some types of bags (e.g. the Irish plastic bag tax introduced in 2002 at EUR 0.15 per bag, and further increased to EUR 0.22 per bag in 2007).

\section{- Support the uptake of second-hand markets and stores}

- Scale up the support targeting the creation and the uptake of dedicated spaces for second-hand and exchange markets, where people can buy, sell, exchange, or donate second-hand objects. Such initiatives could ultimately contribute to creating jobs for special social groups. For instance, the municipal second-hand store Halle 2 was established by the city of Munich (Germany) to sell goods collected at the recycling centres, to extend their lifespan, and to provide training and job perspectives for special social groups, such as long-term unemployed and young people. In the Czech Republic, examples of repair and reuse initiatives supported by the Ministry of the Environment include Opravarna.cz, which operates a web portal affiliating repair and service businesses.

- Expand quality certification of reusable components or products, secondary raw materials and recyclable waste

- Introduce quality standards and ecolabels for reused components or products, secondary raw materials, or recyclable waste, to further boost the market for second-hand, refurbished, remanufactured, and upcycled consumer goods. For example, the Revolve Reuse Quality Standard was introduced in Scotland to increase customer confidence in reused products.

\section{- Reduce VAT for repairing, refurbishment and remanufacturing activities}

- Consider reducing the VAT for repaired, refurbished, and remanufactured goods, in order to make them more affordable and competitive, and thereby also generate positive indirect impacts on job creation and waste generation. As an example, in Sweden the VAT was cut from $25 \%$ to $12 \%$ on the repair of bicycles, shoes, clothes and other textiles, and $50 \%$ of the labour costs of repairing large appliances were made deductible from the personal income tax. Similarly, in the Czech Republic the VAT for repair of textiles, footwear and bicycles has recently been decreased to $10 \%$. 
146. Other measures relevant for a more circular consumption and consumer behaviour, overlapping with circular production and design priority area $\operatorname{are}^{35}$ :

- Introduce compulsory circular considerations in (green) public procurement and its enforcement

- Explore the potential of legislating longer warranty periods

\section{A more effective waste management}

147. Implementation actions in this area include waste taxes and charges, tax reductions, direct subsidies, regulatory measures as well as innovative instruments, such as trading compliance certificates. They are outlined below.

- Progressively increase landfill tax, and introduce significant supporting measures, potentially including an incineration tax

- Landfill tax needs to significantly increase. The new proposed Waste Act is going in this direction. There are certain design features which could increase the effectiveness of the landfill tax, such as removing or decreasing the share of proceeds from the landfill tax to municipalities and enforcing fees for landfilling hazardous waste. The progressively increasing landfill tax could be further reinforced by banning the landfilling of specific waste types, e.g. biodegradable or untreated waste. Several EU Member States have a landfill ban on certain waste streams or a fraction of specific waste stream, e.g. Flanders, Netherlands, Germany and Austria.

- Additional measures could also include introducing an incineration tax in order to stimulate recycling, rather than incineration, of reusable and recyclable waste in the long term, once landfilling is limited.

- Introduce incentives and supporting measures to strengthen the demand for recyclables and trade with secondary raw materials

- Such incentives include financial incentives (tax deductions for products with recycled content material) and subsidies (direct and indirect through taxes), subsidies for R\&D projects and recycled product marketing efforts. In the future, consider mandating minimum recycled content standards to be met by all producers, in combination with economic instruments such as trade compliance certificates or high fees for non-compliance. Alternatively consider EPR system to encourage higher rates of recycled content in manufacturing.

- Simultaneously remove current fiscal and regulatory impediments. For instance, consider reviewing building code/standards that prevent the use of secondary materials in construction, and consider reclassifying CDW into material (end-of-waste criteria), building on the example of already issued Decree No. 130/2019 on end-of-waste criteria for asphalt mixtures.

${ }^{35}$ For more information on these proposed actions, please refer to the relevant paragraph in this section. 
- Introduce fiscal incentives to stimulate upcycling of waste into high-quality highvalue products and introduce other supporting measures

- Stimulate the upcycling of waste into high-quality high-value materials and products, through financial support of decentralised reuse and recycling capacities. These could focus on upcycling of recovered materials and certification of quality of reusable materials and elements. Such capacities should be designed in cooperation with different levels of public governance, and reflect the needs for particular waste flows. The financing of such regional and local recycling and reuse centres could be made from proceeds from virgin material taxes.

- The financial support for the introduction of recycling and processing technologies could be further strengthened by incentives and measures facilitating the uptake of trade with secondary raw materials and recyclable waste (e.g. commodity exchange, $R \& D$ subsidies, tax reductions).

- Other supporting measures to further induce the shift to reusable and recyclable waste away from incineration and towards mechanical and chemical recycling, could be the introduction of an incineration tax. Examples of Member States where such combination of landfilling and incineration taxes lead to a shift towards recycling are France, Spain (Catalonia), Austria and Denmark. Also the planning of technologies for treatment of residual waste (e.g. mechanical biological treatment (MBT) facilities or waste-to-energy facilities), should not yield over-dimensioned capacities, taking into consideration the future potential of waste prevention and opportunities for reuse and recycling of waste. An incineration tax was introduced in addition to a landfill tax in several EU Member States (e.g. France, the Netherlands) but also in the UK.

- Explore the potential of increasing (virgin) materials taxes to enhance the incentive for use of secondary materials

- Assess to what extent increasing the tax for the extraction of construction materials has the potential to incentivise the use of secondary raw materials, namely in road construction (for materials which are not widely traded internationally). The virgin material tax could be combined with an ecomodulated EPR fee based on the life cycle costing, so that the full life cycle external costs (including waste management costs and end-of-life costs of products) are reflected in the economic cost of virgin materials extraction. Virgin materials taxes have been employed by some countries to incentivise changes in the use of rock, gravel and other construction aggregates, e.g. aggregates taxation in Sweden and the UK. EPR fee for construction materials has been introduced in the UK for example.

- Explore introduction of taxes on plastics (virgin polymers and plastic packaging, with initial focus on non-recyclable plastics packaging) and potentially a fertiliser tax, in order to internalise externalities of their production and use. A fertiliser tax could push the fertiliser industry and the farmers to valorise the biomass in fertiliser technologies and at the same time contribute to decreasing the harmful emissions from fertilisers. For instance, in the late 1990s Denmark introduced a tax of DKK 5 (EUR 0.7) per kg N for fertilisers to target non-farm use, along with a tax levied on the amount of mineral phosphorus in animal feed. At the same time, the Netherlands introduced a levy on mineral 
surpluses for intensive dairy farms. A tax on virgin plastic could stimulate the use of recycled plastics, or renewable and more durable alternatives. There are examples of initiatives to introduce such a tax, for instance Italy is planning to introduce a tax on products made from virgin plastics, and the UK is planning to implement a tax on plastics packaging which does not contain at least $30 \%$ recycled plastic from April 2022.

- Strengthen regulation of using hazardous materials as raw materials and product components

- Better regulate the use of hazardous materials in raw materials and products, in order to reduce amounts of generated hazardous waste and hazardous substances in recovered materials. This could comprise taxation of hazardous materials and products, as well as EPR schemes covering consumer goods containing hazardous substances (e.g. paints, which form the largest part of hazardous component of MSW - introduced in the United States). In terms of the EU level regulation, the Czech Republic might consider taking an active role in working with the European institutions to help accelerate the changes to the REACH regulation.

148. Other measures relevant for a more effective waste management, overlapping with the circular production and design priority area $\operatorname{are}^{36}$ :

- Ensure effective implementation and enforcement of the take-back obligations of WEEE under the EPR

- Expand the EPR system to new products

- Ensure good application and enforcement of eco-modulation fee in EPR schemes

- Reassess the possibility of extending the DRS system to PET beverage bottles, if there are challenges to meet the targets

- Foster multi-stakeholder voluntary agreements and public-private cooperation to prevent [food- and bio-]waste and associated packaging

149. Other measures relevant for a more effective waste management, overlapping with the circular consumption and consumer behaviour priority area $\operatorname{are}^{37}$ :

- Implement nudges to improve waste sorting rate and quality

- Foster separate door-to-door waste collection

- Extend the coverage of PAYT arrangements for waste collection

- Strengthen bio-waste separate collection

- Introduce home composting programmes

- Strengthen existing measures addressing the reduction of plastic bags use

\footnotetext{
${ }^{36}$ For more information on these proposed actions, please refer to the relevant paragraph in this section.

${ }^{37}$ For more information on these proposed actions, please refer to the relevant paragraph in this section.
} 


\section{Research, innovation, and digitalisation for circular economy}

150. The list of implementation actions identified in the research, innovation and digitalisation area include the following. These actions may be relevant across the entire value chain.

- Establishing a clear link between research, innovation, digitalisation and circular economy within a coherent strategy or programme

- Such strategy or programme should take into account the synergies between the competitiveness strategy, the R\&D\&I policy, the smart specialisation strategy, as well as the waste management and raw materials policies, and be backed by a strong commitment from the Government. For example, within the RE: Source innovation programme, the Swedish government has appointed two agencies to invest in a strategic innovation programme that focuses on developing circular economy and resource efficiency innovations (RE: SOURCE, n.d.[96]). This programme brings together companies, universities and authorities to collaborate in strategically important areas, and provides specific funding for projects under this programme and five platforms to develop solutions for its priority areas.

- Consider making the concept of circular economy and its links to digitalisation more explicit within the existing digitalisation policies. At a later stage possibly also consider developing a national strategy to stimulate the uptake of the sharing economy (e.g. see the Government Strategy for Denmark's digital growth, and Government Strategy for growth through sharing economy).

- Improve the coordination between the different Ministries, the Government office, the relevant agencies and stakeholders in the circular economy, innovation and digitalisation areas

- Promoting inter-sectoral, cross-agency and interdepartmental collaboration on the topics of R\&D\&I and digitalisation for circular economy would facilitate addressing the cross-cutting issues related to advanced technologies and innovative circular activities, and thereby contribute to a coherent development and implementation of the national strategy for innovation and digitalisation (e.g. "Green Deals" between the Dutch Government and the private sector). In the Czech Republic, this is role could be performed by the Research, Development and Innovation Council jointly with the Government Council for Information Society.

- Evaluate the introduction of new instruments to strengthen the direct and indirect public support to $R \& D$

- To render the current R\&D public support instruments more effective in facilitating the transition towards a circular economy, re-evaluate the design of the economic and financial instruments to R\&D for domestic firms, notably considering the introduction of R\&D reliefs for SMEs and tax credits for large companies. For example, the SMEs in the UK can deduct up to $230 \%$ of their eligible costs from their yearly profit, and claim a tax credit up to $14.5 \%$ of the surrenderable loss, and large companies can claim an R\&D expenditure credit up to $13 \%$. 
- Consider re-launching an innovation investment fund, with a different design than the original National Innovation Fund

- To further boost eco-innovations in high growth technology-based circular economy business models, consider re-launching the innovation investment fund that would channel capital into firms focusing on increasing the efficient use of resources at all stages of production and consumption. For example, the Seed Capital fund administered by the Netherlands Enterprise Agency and funded by the Ministry of Economic Affairs and Climate Policy, provides capital for investment funds backing innovative entrepreneurs in the technology and creative sectors, with funding being raised jointly by private lenders and the government (Netherlands Enterprise Agency, n.d.[90]).

- Evaluate the potential of setting up a dedicated circular economy innovation fund offering grants or of introducing innovation vouchers for circular economy technologies

- Consider creating a grant funding opportunity for innovative projects that have the potential to deliver on environmental, economic and social opportunities of the circular economy. For instance, Scotland has set up a Circular Economy Investment Fund offering a grant support to SMEs and NGOs for innovative circular economy projects resulting from Circular Economy Business Support Service and nearing commercialisation (Zero Waste Scotland, n.d. $[97]$ ).

- Consider deploying innovation voucher schemes to stimulate R\&D\&I projects by SMEs, and collaborative projects by firms and research institutes, to enhance innovation in circular economy and promote transfer of research results towards commercialisation. As an example, the Region of Thüringen introduced innovation vouchers for projects targeting one of the four fields of specialisation: industrial production and systems; sustainable and intelligent mobility and logistics; healthy life and health economy; sustainable energy and utilisation of resources (European Commission, n.d.[98]).

- Create additional economic incentives for successful outcomes of innovations

- As an additional incentive to stimulate the adoption of innovative circular activities, consider creating award schemes for successful outcomes of circular economy related innovations. For example, the Czech Ministry of Industry and Trade has an annual award for Turning Waste into Resources (European Resource Efficiency Knowledge Centre, n.d.[99]]).

- Improve the existing cooperation instruments between the private sector and academia. Further enhance such cooperation through establishment of online tools to help businesses find opportunities for collaboration in $R \& D$, innovation and digitalisation

- In order to encourage firms to cooperate with public research institutions, introduce grants for collaborative R\&D that would fund projects where firms and established researchers from academia collaborate. Extend the scope of innovation vouchers for firms to purchase services from universities and public research institutes. In terms of long-term $R \& D$ collaboration, support the establishment of "collaborative research centres" (possibly with a dedicated circular economy strategic area) through public grants covering the costs of universities' R\&D. Further enhance cooperation through the establishment of 
an online tool to help firms find opportunities for collaboration in R\&D, innovation and digitalisation. Some examples include the Collaborative R\&D grant in Canada (Natural Sciences and Engineering Research Council of Canada, $2020_{[100]}$ ), and Konfer as an example of an online tool for partner search used in the UK (National Centre for Universities and Business, $\left.2020_{[101]}\right)$.

\section{- Implement digital solutions for improved circular economy policy making}

- Mainstream the use of data-driven approaches in policymaking foresight exercises, for better anticipating societal trends and needs, and as such increasing efficiencies and target specific policymaking.

- Increase the capacity to scale digitalisation by making public data more available (i.e. open data) and interoperable (i.e.by introducing standards on data collection, linking disparate data sources, and assuring data interoperability). Improving the connection between data and systems, contributes to more effective decision-making (e.g. based on more precise life cycle assessments) and promotes more innovation and cooperation (within and across public and private sectors). Address data privacy concerns and digital security vulnerabilities (such as data security, privacy, ownership, transparency, and use, driven by increased granularity of data, increased data sharing across government agencies and public private partnerships).

- Foster digital circular business models that increase the utilisation of goods and services, and support reuse, repair and second-hand markets, and remove any existing regulatory barriers that impede the establishment of such business models

- Introduce regulatory instruments to foster a sharing economy (powered by digital technologies) in order to accelerate the sharing of existing (and often underutilised) assets, help the Czech citizens reap benefits from it, and dematerialise the Czech economy. For example, the Sharing Economy Action Plan developed in Amsterdam (the Netherlands) seeks to facilitate and finance the creation of sharing economy projects. At the same time, in order to minimise the potential unintended consequences of the fast expansion of sharing business models, it is important to carefully balance the uptake of such models with consumer protection, safety and quality assurance (e.g. improving safety through driver registration for ride hailing services; reducing the influx of travellers into quiet residential neighbourhoods for temporary lodging platforms), and to resolve the pressure on the existing policy frameworks (e.g. taxation).

- Review the legislation limiting the reuse of recovered and recycled material, especially road construction requirements for the use of recycled aggregate.

- To further facilitate the uptake of digital circular activities, identify and eliminate impediments to digital circular economy (e.g. evaluate the potential of championing the introduction of "right to repair" legislation and providing clear definition of "refurbished products" to facilitate the online sale of such products; carefully balance protection of consumers and growth-limiting regulation of ride hailing and temporary lodging platforms). 
- At different levels of governments provide support to new circular business models and to bottom up initiatives by citizens and NGOs

- Create support mechanisms, at different levels of governments, for new circular business models, and bottom up initiatives of citizens and NGOs, in order to amplify the positive circular impacts from community-based co-production, sharing schemes, second-hand shops, re-use centres, and repair shops. As an example, the Netherlands has several initiatives in this area through ShareNL and local sharing economy strategies (Amsterdam).

- Support the establishment of national, regional, and municipal circular economy hubs, in order to facilitate the promotion of circular economy along entire values, to encourage cooperation between public and private actors, and to increase the commitment by local governments, companies, civil society, and academia to improving the efficient use of available resources and decreasing waste generation. Some examples include the Circular Flanders hub of the Flemish circular economy; City of Wiltz (Luxembourg) as a Circular Economy Hotspot integrating the rules of the circular economy into its building regulations and promoting the ecological construction of buildings.

\section{Education and knowledge for circular economy}

151. There are several education and knowledge implementation actions that could be taken forward. These actions could be applied across the entire value chain.

- Increase awareness campaigns and introduce education programmes to encourage food waste prevention

- To combat food waste, develop theoretical-practical workshops, web-toolkits and guides on good practices to avoid food wastage in kitchens (e.g. Cornellà aprofita els aliments awareness campaign in the Metropolitan Area of Barcelona (Spain)), programmes to help organisations and businesses improve their sustainable food management practices (e.g. Sustainable Management of Food programme in the United States), and donation actions for collecting food in good condition from markets and shops that would have discarded for aesthetic or commercial reasons (e.g. the Food Waste Combat example of socio-circular innovation in Romania). Some of the existing initiatives by the Czech Ministry of Environment include Zachraň jídlo [Save the food], Jídlov [Jídlov], Nesnězeno [Not Eaten].

- Develop awareness campaigns, increase capacity building initiatives, and foster self-repair to extend the life cycle of products

- Increase awareness raising and education campaigns to reduce the impact of textiles purchase, use and disposal. For instance, the WRAP "Love Your Clothes" campaign in the UK is an example of an awareness raising campaign about the value of clothes and how their lifetime can be extended aiming to encourage people to make the most of them.

- To foster reuse, refurbishment, reparability and durability of EEE, develop awareness campaigns on the quality and safety of repaired, refurbished, and remanufactured products and their environmental benefits on waste prevention. To further overcome barriers to reuse, introduce information instruments and education programmes to increase consumer's repair knowledge and their 
awareness about financial and environmental benefits to repairing. Examples include advising service and workshops offered within Repaired better than new initiative in the Metropolitan Area of Barcelona (Spain) and Repair Café International Foundation in the Netherlands.

\section{- Increase information campaigns about benefits of green products}

- To facilitate the understanding of ecolabels by consumers, develop awareness raising initiatives about environmental benefits of green products, their logos and labels, and reduce the complexity of the existing ecolabels. Step up the requirements for information tools, labels/logos and the provision of trustworthy and relevant information on products at their points of sale. Facilitate the introduction of new ecolabelled products of daily use and their penetration in the local markets, in order to accelerate their recognition by consumers, increase their familiarity and confidence in purchasing such products, and ultimately drive the interest by producers to obtain ecolabelling. As an illustration, the German Blue Angel ecolabel established in 1978 includes 12000 environmentally friendly products and services from around 1600 companies. Further drive the uptake of ecolabelling of products and services through green public procurement.

- Develop information awareness campaigns for entrepreneurs and investors on the possibilities presented by new circular and digital business models, and the possibilities presented by advanced digital technologies

- To further technological, social and system innovations, strengthen the information awareness about business opportunities that new circular and digital business models bring about. Examples include established initiatives such as the Czech circular hotspot, recently launched in cooperation between CzechInvest, the Czech Circular Economy Institute and the Embassy of the Kingdom of the Netherlands (CzechInvest, 2020 [102]).

- Awareness raising initiatives and education activities are especially relevant for SMEs and start-ups, which besides their already lesser exposure to domestic R\&D\&I activities, might also not be fully aware of the opportunities offered by existing software and hardware solutions and might lack skills in accessing and using data, information and knowledge generated by these technologies.

- Provide support and advice to businesses to tap into equity investments, and provide training to investors and financial intermediaries on circular economy innovation projects

- In order to facilitate early stage funding, advise businesses on how to tap into equity investments (either via fund of funds managed by the European Investment Fund or other venture capital funds). Simultaneously, to make Czech investors and financial intermediaries better understand specific financial and other risks related to circular economy innovation projects (and thereby also increase their willingness to invest), provide them with training and knowledge on such projects.

- Establish soft measures to facilitate the decision making towards the adoption of circular approaches and innovative business models on the firm level

- In order to stimulate the uptake of new circular economy and digital business models and activities, support the establishment and functioning of business 
support services, innovation hubs and decision-making tools. These will allow businesses to explore new business models, technologies, products or services embedding circular economy principles, and guide business managers through the actual adoption. For example, Scotland has set up the Circular Economy Business Support Service to provide one-on-one consultancy for SMEs across all sectors (Zero Waste Scotland, 2020 [103] $)$, while Luxembourg has set up a decision-making tool (Fit4Circularity) through which it helps companies to identify and assess their growth potential, and to adopt circular economy approaches and innovative business models (The Government of the Grand Duchy of Luxembourg Luxinnovation, $\left.2020_{[104]}\right)$. Once in place, consider implementing a systemic evaluation of the effectiveness of such measures.

\section{- Develop a digitalised information flow management system}

- Systemise, digitalise and extend compulsory monitoring and reporting on quality, quantity and use of selected material flows, in order to provide an understanding of the physical resources and their successive transformations throughout their life cycles within the economy.

- Gradually develop an information system on selected material flows, which will enable effective and digitalised information flow management. Such system could be developed as a freely accessible digitalised information base, linking existing information at macro-, meso-, and micro-levels. This should also enable working with big data and thereby effectively controlling selected material flows and efficiency of their uses. Moreover, the system should be need-driven, and based on long term strategy and effective priority setting procedures in place.

\section{- Support the digitalisation of construction industry}

- Facilitate the digitalisation of construction industry in order to help optimising the life cycle of construction projects. This could either be achieved through facilitating the creation of a platform for circular innovation and investments that would allow bringing together major stakeholders (e.g. Platform CB'23 public private discussion platform in the Netherlands), or through supporting the industry-wide implementation of building information modelling (BIM) (e.g. in 2016 the UK government mandated every construction project funded by the central government to be delivered with "fully collaborative 3D BIM").

- Encourage linking materials (and waste) flow information with information on financial flows (accounting data), establishing material flow cost accounts so as to better understand potential environmental and financial benefits of resource efficiency and better flow management.

- Foster "passportisation" of new and existing buildings to strengthen informed decisions on circularity measures. At the same time complete introduction of compulsory pre-demolition audits and CDW management plans. 


\section{Monitoring and evaluation plan}

\section{The need for a monitoring framework}

\section{General overview}

152. A circular economy (CE) monitoring framework is required to enable measuring the progress towards specific targets and the various elements of the circular economy over time through a set of indicators. It helps the policymakers understand how the various circular economy aspects are developing and whether strengthening existing and/ or implementing additional measures is necessary in some specific areas. The monitoring should also form the basis for setting new circular economy long-term priorities (European Commission, 2018 $\left.{ }_{[12]}\right)$ and deliver feedback to strategy and planning development for the different actors in the economy (Alaerts et al., 2019 ${ }_{[105]}$ ). This is consistent with the two general aims of indicators, forward-looking to provide guidance, and backward-looking to provide feedback and review of performance (Ekins et al., 2019 [106]).

153. When developing a CE monitoring framework, it should not be forgotten that a circular economy is a means to an end, i.e. circular strategies help minimise environmental impacts while maximising socio-economic benefits, rather than an end itself. This makes linking circular economy activities to set targets and environmental impacts crucial (Potting et al., 2018 $\left.{ }_{[107]}\right)$. Since the circular economy concept cuts across a variety of sectors, territories and has multiple dimensions, it is impossible to capture it with a single indicator. This is why existing CE monitoring frameworks include a larger set of relevant indicators. They can also be structured using a multi-tiered approach, from more general to more concrete thematic indicators ${ }^{38}$. Having a multi-layered system allows for the introduction of a limited number of key indicators (for communication purposes) on for example national level, complemented by several additional indicators going into more detailed information (e.g. regional, city, sectoral or product groups levels; alternatively a set of indicators for each strategic objective of the CE strategy).

154. There are a number of circular economy monitoring frameworks that have been already developed for policy makers to support their circular economy strategies (for example European (Box 8.1), French, Dutch (Box 8.2) ${ }^{39}$. Such monitoring frameworks may contain a $\mathrm{CE}$ related target, or not, and have a set of underpinning $\mathrm{CE}$ indicators.

\section{Box 8.1. EU's Circular Economy Monitoring Framework}

The EU's Circular economy monitoring framework offers a default set of 10 macro-level indicators (in total 23 individual indicators) grouped into four stages and aspects of the circular economy: (1)

\footnotetext{
${ }^{38}$ An example of this is the EU Resource Efficiency Scoreboard with a single headline indicator, dashboard of macro-level indicators on materials, land, water and carbon and multiple thematic indicators, or the Amsterdam monitoring framework with primary indicators on raw materials, dashboard of indicators in thematic areas covering recycling, energy and biodiversity and transition indicators that reflect institutional change.

${ }^{39} \mathrm{CE}$ monitoring frameworks in a number of selected EU Member States were analysed in a more detail in the Background report on the EU national circular economy strategies.
} 
Production and consumption; (2) Waste management; (3) Secondary raw materials; and (4) Competitiveness and innovation for the circular economy.

The selection of the 10 high-level (and 23 specific) indicators went through a robust scrutiny process, including their assessment against a number of criteria (relevance, acceptance, credibility, ease of use, robustness and existing data), public consultation, and discussion with MS representatives and other experts. Table 8.1 presents these indicators.

Table 8.1. Indicators in the EU's Circular Economy Monitoring Framework

\begin{tabular}{|c|c|c|}
\hline No & Name indicator & Description \\
\hline \multicolumn{3}{|r|}{ Production and consumption } \\
\hline 1 & $\begin{array}{l}\text { EU self-sufficiency for } \\
\text { raw materials }\end{array}$ & $\begin{array}{r}\text { The share of a selection of key materials (including critical raw materials) used in the } \\
\text { EU that are produced within the EU }\end{array}$ \\
\hline 2 & $\begin{array}{l}\text { Green public } \\
\text { procurement* }\end{array}$ & $\begin{array}{r}\text { The share of major public procurements in the EU that include environmental } \\
\text { requirements }\end{array}$ \\
\hline 3a-c & Waste generation & $\begin{array}{l}\text { Generation of municipal waste per capita; total waste generation (excl. major mineral } \\
\text { waste) per GDP unit and in relation to domestic material consumption }\end{array}$ \\
\hline 4 & Food waste* & Amount of food waste generated \\
\hline \multicolumn{3}{|r|}{ Waste management } \\
\hline $5 a-b$ & Overall recycling rates & Recycling rate of municipal waste and of all waste except major mineral waste \\
\hline $6 a-f$ & $\begin{array}{r}\text { Recycling rates for } \\
\text { specific waste streams }\end{array}$ & $\begin{array}{r}\text { Recycling rate of overall packaging waste, plastic packaging, wood packaging, WEEE, } \\
\text { recycled biowaste per capita and recovery rate of CDW }\end{array}$ \\
\hline \multicolumn{3}{|r|}{ Secondary raw materials } \\
\hline $7 a-b$ & $\begin{array}{r}\text { Contribution of } \\
\text { recycled materials to } \\
\text { raw materials demand }\end{array}$ & $\begin{array}{l}\text { Secondary raw materials' share of overall materials demand - for specific materials and } \\
\text { for the whole economy (i.e. End-of-life recycling input rates; circular material use (CMU) } \\
\text { rate) }\end{array}$ \\
\hline $8 a-c$ & $\begin{array}{r}\text { Trade in recyclable } \\
\text { raw materials }\end{array}$ & Imports, exports and intra EU trade of selected recyclable raw materials \\
\hline \multicolumn{3}{|r|}{ Competitiveness and innovation } \\
\hline 9a-c & $\begin{array}{r}\text { Private investments, } \\
\text { jobs and gross value } \\
\text { added }\end{array}$ & $\begin{array}{r}\text { Gross investment in tangible goods, number of persons employed and GVA in the CE } \\
\text { sectors }\end{array}$ \\
\hline 10 & Patents & Number of patents related to waste management and recycling \\
\hline
\end{tabular}

Note: * indicator under development

Source: (European Commission, 2018 $\left.{ }_{[12]}\right)$.

\section{Targets}

155. Regarding a CE target, even though the EU has not set a CE target yet, many EU Member States have done so. Several Member States use a resource productivity target, even though not always calculated in the same way (e.g. Germany, Denmark, France, Austria). ${ }^{40}$ Several CE targets mentioned in the national strategies are not necessarily new

40 Germany: Doubling of abiotic material productivity (measured as gross domestic product (GDP)/abiotic domestic material intensity) by 2020 compared to 1994, to maintain until 2030 an average annual increase of $1.5 \%$ in total raw material productivity, defined as (GDP+ monetary value of imports)/raw material input; Denmark: Boosting resource productivity by $40 \%$ based on amount of materials, and by $15 \%$ based on their value between $2014-2030$; France: $30 \%$ reduction in resource consumption in relation to GDP between 2010 and 2030; Austria: to achieve a four- to ten-fold increase in resource productivity above 2008 levels by 2050 (European Environment Agency, 2018 $[135])$. The Netherlands: targets a $50 \%$ reduction in the use of primary raw materials by 
CE targets but include existing targets in the area of waste, climate or other environmental areas (e.g. targets on waste generation, recycling or greenhouse gas (GHG) emissions reductions). Based on the experience of a number of Member States, a single target for CE transition is set based on a single indicator which forms the basis for monitoring the target.

\section{Box 8.2. Examples of national CE monitoring frameworks}

\section{France}

France has developed a monitoring system consisting of ten indicators, published in 2017 (Magnier et al., 2017 $\left.{ }_{[108]}\right)$. The work on the initial set of indicators to monitor the circular economy has started already in 2014, when the Monitoring and Statistics Directorate worked with other partner organisation to define, and later narrow down, the list of indicators. The short-list considered CE related legislative measures adopted in France and in the EU, their comparability at EU level, and whether indicators acted as "integrators" of the three stages of the cycle: supply, consumer demand and behaviour and end-of-life. Four indicators apply to the early phases (extraction/use of resources and sustainable purchasing, eco-design, industrial and territorial ecology and the functional economy), followed by two indicators for the demand (responsible consumption and extension of product lifespan), and two indicators for the waste management (recycling). The last indicator captures employment in the circular economy in the whole cycle.

\section{The Netherlands}

As a response to the Dutch Circular Economy Strategy to 2050 published in 2016, PBL Netherlands Environmental Assessment Agency was asked by the Dutch Government to develop a CE monitoring framework to measure progress made towards the CE target and objectives included in this strategy. A proposal was made in 2018, which contained a monitoring framework based on developing indicators to monitor the desired effects (e.g. GHG and other emissions, biodiversity, toxicity, land and water use; value added and jobs) as well as the transition itself (Potting et al., $\left.2018_{[107]}\right)$. This has given rise to a four year work programme Monitoring and Control of Circular Economy 2019-2023, a project led by PBL together with other partner institutions, whose aim is to develop an operational monitoring system for the Dutch transition to a full circular economy by 2050 and the reaching of the CE target by 2030 . The results of this programme will develop a set of key CE indicators to monitor the effects (socio-economic and environmental) as well as the transition to a $\mathrm{CE}$ (e.g. indicators such as the number of people active in $\mathrm{CE}, \mathrm{CE}$ campaigns, new legislation, consumer behaviour) and inform the government of the progress made and knowledge necessary to adjust or design policy (Prins and Rood, 2020 [109]; PBL, 2019 ${ }_{[110]}$ ).

156. Circular economy targets have thus far not been investigated by literature in a systematic way. A recent study found out that existing CE targets are limited to a few examples, mainly in the area of material efficiency, recovery and recycling (Morseletto, $\left.2020_{[111]}\right)$. The same study found that targets in the areas of refurbish, repair and remanufacture are basically non-existent, a few examples can be found on a corporate level (Morseletto, 2020 $\left.{ }_{[111]}\right)$. International Resource Panel is also conducting work on defining sustainable levels of resource use, i.e. target values for sustainable use of materials, land and water (International Resource Panel and UN Environment, 2018 ${ }_{[112]}$ ). Such threshold levels are needed to set 'safe operating space' for resources, which can then be taken into account by governments when setting CE targets.

2030. There are several sector-specific targets, e.g. by 2020, capping the annual volume of household residual waste to $100 \mathrm{~kg}$ per capita; by 2025 to $30 \mathrm{~kg}$ per capita per year. 


\section{Indicator sets}

157. With respect to CE related indicator sets, these largely contain macro-level indicators related to resource flows, waste generation, recycling rates, recovery of specific waste streams, secondary materials use, but also jobs related to circular activities. Some policy related CE monitoring frameworks also include additional indicators capturing other $\mathrm{CE}$ aspects on national level, such as household spending on maintenance and repair, and car-sharing (French monitoring framework), societal behaviour indicators, such as the percentage of citizens choosing alternatives to buying a new product or mass media coverage in terms of the number of articles published on circular economy (EU ecoinnovation indicators) or business behaviour in terms of financing sources for circular economy or practices related to extending the lifetime of products (EU eco-innovation indicators (European Commission, 2020 ${ }_{[113]}$ ), Dutch monitoring framework).

158. Some of the latter, namely those related to the sharing economy, consumer behaviour and product-related services (e.g. extending the life time of products, carsharing) fall into the category of what could be called meso-level indicators. There are multiple definitions in the literature on what meso-level indicators are. Recent scholarly work (Alaerts et al., 2019 ${ }_{[105]}$ ) defines the meso-level indicators as those trying to connect the micro- with the macro-level indicators, and in this way provide direct feedback to policy on specific products and services, address consumer and business behaviour as well as societal needs related to circular economy. Examples of potential meso-level indicators include, for example, number of passenger kilometres per year, the stock of cars in a country, occupancy rate in cars, materials use in cars to be used to measure trends in circular mobility (meso-level) (Alaerts et al., 2019 $\left.{ }_{[105]}\right)$. On the other hand, in China, the meso-level indicators address eco-industrial parks, i.e. industrial symbiosis.

159. The literature (Alaerts et al., 2019 ${ }_{[105]}$; Giljum et al., 2011 ${ }_{[114]}$; Ekins et al., 2019 [106]; Potting et al., 2018 $_{[107]}$; Moraga et al., 2019 [115]) strongly suggests including meso-level indicators in the circular economy (or resource efficiency) monitoring frameworks besides the common macro-level indicators used by policy makers. Moreover, sometimes even micro-level indicators are being suggested to be included. Micro-level indicators pertain to circularity of products, services, organisations and supply chains, which can offer additional feedback on the CE transition. However, these indicators often focus on the life-cycle assessment of impacts and are difficult to upscale to meso- and macro-level, levels more relevant for policy making.

160. The key advantages and disadvantages of using macro-, meso- and micro-level indicators as part of the circular economy monitoring frameworks are summarised in Table 8.2 . 
Table 8.2. Key advantages and disadvantages of using various types of indicators by policy makers to measure progress on circular economy

\begin{tabular}{|c|c|c|c|}
\hline Aspects & Macro-level indicators & Meso-level indicators & Micro-level indicators \\
\hline $\begin{array}{l}\text { Policy relevance vs } \\
\text { availability of } \\
\text { indicators }\end{array}$ & $\begin{array}{r}\text { Allow assessment of some } \\
\text { circularity aspects (mainly } \\
\text { economic system) and } \\
\text { society-wide effects but } \\
\text { miss non-economic aspects, } \\
\text { e.g. consumer and } \\
\text { businesses perspective. }\end{array}$ & $\begin{array}{r}\text { Allow connection of macro- and } \\
\text { micro-level indicators, direct } \\
\text { relevance to policy, e.g. addressing } \\
\text { societal needs and services, sectors } \\
\text { (mobility, housing, etc.), but } \\
\text { monitoring all indicators not feasible } \\
\text { (only for major products/ services). }\end{array}$ & $\begin{array}{r}\text { Allow assessment of } \\
\text { product/ service level } \\
\text { circularity aspects but } \\
\text { difficult to upscale to } \\
\text { macro level. }\end{array}$ \\
\hline $\begin{array}{l}\text { Timeliness vs } \\
\text { robustness of data } \\
\text { collection }\end{array}$ & $\begin{array}{r}\text { Lack of timeliness due to } \\
\text { low frequency or a time lag } \\
\text { in publishing data for official } \\
\text { statistics/ input output data. } \\
\text { Better timeliness for other } \\
\text { data but lack of robustness } \\
\text { (e.g. a basic survey, biased } \\
\text { data, etc.) }\end{array}$ & $\begin{array}{r}\text { Could be more timely (e.g. annually } \\
\text { collected) and still robustly collected } \\
\text { (i.e. part of official statistics) but need } \\
\text { of monitoring of multiple indicators to } \\
\text { provide information on meso-level. } \\
\text { Some indicators need more robust } \\
\text { data collection. }\end{array}$ & $\begin{array}{r}\text { Timely and robust data } \\
\text { collection but need an } \\
\text { upscaling method to macro } \\
\text { level. }\end{array}$ \\
\hline $\begin{array}{l}\text { Aggregate vs } \\
\text { detailed level of } \\
\text { information }\end{array}$ & $\begin{array}{r}\text { Provide only aggregate } \\
\text { information, e.g. economic } \\
\text { system, sector. CE activities } \\
\text { do not show effect if small } \\
\text { scale (e.g. sharing } \\
\text { economy). }\end{array}$ & $\begin{array}{r}\text { Detailed level information on specific } \\
\text { products/ services can provide } \\
\text { information on behaviour/ services. } \\
\text { But monitoring all/ many products/ } \\
\text { services not feasible. }\end{array}$ & $\begin{array}{r}\text { Capture product/ service } \\
\text { level information but } \\
\text { difficult to upscale to policy } \\
\text { relevant information. }\end{array}$ \\
\hline
\end{tabular}

Note: Macro-level corresponds to city, province, region, nation; meso-level fits with eco-industrial parks ${ }^{41}$, while micro level corresponds to single company or consumer (Saidani et al., 2017 $\left.{ }_{[116]}\right)$.

Source: own elaboration of challenges based primarily on analysis from (Alaerts et al., 2019 [105]; Giljum et al., 2011 [114])

161. Besides the above suggestion, it has also been proposed that there is a need for additional indicators to properly measure the effects and the transition process itself. A CE indicator set for policy makers should connect CE to environmental impacts and capture possible rebound effects of a circular economy (Potting et al., 2018 [107]; Alaerts et al., $\left.2019_{[105]}\right)$. The Netherlands is for example developing a CE monitoring framework to capture the impacts as well as the transition process itself.

162. Based on the selected literature (Saidani et al., 2019 [117] $_{\text {; Ekins et al., 2019 }}$ [106]; Potting et al., 2018 ${ }_{[107]}$ ), and an international expert workshop on the topic (Koch and Coelho, 2020 $\left.{ }_{[118]}\right)$, a CE indicator set could include the following dimensions:

- Consumption of resource inputs - i.e. indicator(s) measuring the use of primary resources (take into account direct/ indirect resource consumption). The goal of a $\mathrm{CE}$ is to reduce primary resource use over time. Several existing indicators measure this dimension and are being commonly used in the CE monitoring frameworks (e.g. resource productivity, domestic material consumption, etc.).

- Generation of waste as outputs - i.e. indicator(s) measuring the amount of resources that leave the economy as waste. The goal is to reduce waste generation. Several existing indicators (and targets) exist to measure this dimension. There is work ongoing by UNECE to update waste indicators to include circularity aspects.

- Use of R-strategies - i.e. indicator(s) measuring resource efficiency, e.g. the use of reuse, repair, recycling, remanufacturing, etc. Several indicators already exist that

${ }^{41}$ But this definition of meso-level is not coherent across studies (Moraga et al., 2019 ${ }_{[115]}$ ). 
measure the use of R-strategies (e.g. recycling, recovery). However, modified or new indicators are needed to measure robustly such strategies, as remanufacture, repair or value retention. This is a crucial element in the monitoring framework as it measures the circularity concept itself (e.g. inner loops).

- Impacts of $\boldsymbol{C E}$ activities - i.e. indicator(s) measuring the environmental, socioeconomic impacts of CE activities on overarching goals. This dimension is currently underdeveloped. Existing indicators cover socio-economic impacts, such as turnover and jobs related to CE. However, coverage of environmental impacts on meso- or macro-level is largely missing (e.g. measuring the contribution of CE to decarbonisation).

- Level of aggregation - i.e. choose to what extent indicator(s) measure different levels of aggregation (macro-, meso- and micro-) and transversality (generic, sector-, product-, material-, and service-specific). Large variation exists in impacts, resource efficiency, consumption and waste generation among such groups. Feasibility of monitoring various levels and groups needs to be taken into account when designing the monitoring framework and including different levels of aggregation.

\section{Current gaps in the circular economy monitoring frameworks and research needs}

\section{Current challenges}

163. Monitoring progress towards a circular economy using a robust methodology, good quality and timely data, and capturing all main aspects of the transition is a challenging task. This is because the transition is not limited to certain materials or sectors, but affects the entire economy and is sector cross-cutting. Based on the literature discussed in the previous section, the main challenges for having policy relevant circular economy monitoring framework can be summarised as follows:

- Evidence-based CE targets - current CE related targets focus predominantly on material efficiency, recovery and recycling. Policy relevant CE targets are not yet researched in a systematic way.

- Timeliness of existing macro-level indicators - often macro-level indicators, namely those relying on input-output data, have a relatively long time-lag or are updated infrequently, which make them outdated for direct policy making;

- Ensuring the right level of aggregation to monitor a wide range of circular activities - often current indicators, in particular macro-level indicators, provide aggregate information on circularity aspects related to the economic system, e.g. national accounts or sectors. They are often linked to CE related sectors, such as waste or recycling, and these indicators report information on the entire sector. On the other hand, micro-level indicators related to circularity of products and services capture only very detailed information, often not directly connected to policy making. Many CE activities cut across a number of sectors (e.g. eco-design of products, green public procurement) or involve only a part of a sector (e.g. building modulation within the construction sector, remanufacturing within the manufacturing, circular mobility/ car-sharing within the transport sector). Such activities lack proper monitoring as current statistics do not exist or are not based on robust data collection and methods, or indicators are not incorporated into 
monitoring frameworks. Many CE activities are currently still low-scaled, and their impacts do not show in aggregated macro-level indicators.

- Availability of indicators capturing behaviour (including rebound effects) and circular economy impacts (socio-economic and environmental) - indicators capturing these CE aspects are currently based only on infrequent or one-off surveys (e.g. EU Flash Eurobarometer), on micro-level information only (e.g. product and organisation environmental footprint), or are non-existent. These indicators are needed to monitor the transition and complement the already established macro- and micro-level indicators on resources, waste, revenues and employment.

- Data availability for indicators - a general issue with CE indicators is that much relevant data on circularity and its effects is lacking. There are commercial databases with some additional data (e.g. company and consumer information) but these are not publicly available. On meso-level, the need to monitor detailed information on a number of indicators for a specific product group or service is needed (as shown on the example of circular mobility). Indicators also need to be updated regularly to provide information on trends, relevant to policy making.

- Coherence and consistency of data and indicator methodologies - current indicators are often incomparable across countries as they rely on different data sources and indicator methodologies. The EU CE monitoring framework addresses these challenges for the EU Member States. However, it was clear from the analysis of national CE strategies that the calculation method of the same type of indicator (e.g. resource productivity) can still differ per Member States.

\section{Research needs}

164. In order to address the aforementioned challenges, a number of research areas are outlined below.

\section{Targets}

- Further research is needed into deepening the knowledge and empirical evidence on CE targets and development of CE targets for R-strategies other than resource efficiency, recovery and recycling (Morseletto, 2020 $[111]$ ).

Timeliness

- In order to improve the timeliness of some macro-level indicators with a longer time lag, it is suggested to assess the potential of using more now-casting and early estimates methods. This has been done for example for the EU resource efficiency indicators (Rademaekers et al., 2013 ${ }_{[119]}$ ) and also proposed with regard to the Beyond-GDP indicators (Stiglitz, Fitoussi and Durand, 2018 ${ }_{[120]}$ ).

\section{Capturing smaller scale and sector cross-cutting CE activities}

- Research into upscaling / descaling methods for micro- and macro-level data would be beneficial to ensure capturing a wide range of CE activities, namely those lying somewhere in between the macro- and micro-levels. Several CE related studies have shown that small scale $\mathrm{CE}$ activities and $\mathrm{CE}$ activities cutting across sectors (e.g. remanufacturing, extending the lifetime of products, sharing economy) are 
difficult to capture by current statistics (Cambridge Econometrics, Trinomics B.V.

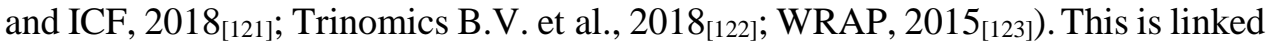
to the need for developing new meso-level indicators and indicators capturing $\mathrm{CE}$ impacts and behaviour.

Capturing societal needs, behaviour, and socio-economic and environmental impacts

- There is a clear need for research into developing new (meso-level) indicators capturing certain $\mathrm{CE}$ activities (e.g. sharing, renting, virtualising) that would complement macro-level based CE monitoring frameworks (Alaerts et al., $2019_{[105]}$; Moraga et al., 2019 $\left.{ }_{[115]}\right)$. This could be for example done by incorporating a few questions on circularity into the regular household and business surveys. A similar approach is being taken to help measure the sharing economy (for example in the UK and by Eurostat).

- Further research is also needed into environmental impacts of CE activities and the related indicators as not all $\mathrm{CE}$ activities might have positive environmental impacts (Ekins et al., 2019 ${ }_{[106]}$ ). Some initiatives are existing to assess the environmental impacts of $\mathrm{CE}$ activities. These are for example, the work of the European Commission together with the Joint Research Centre (JRC) on footprints for consumer goods - Product Environment Footprint indicator, the EEA work on measuring the impact of CE policies on decarbonisation, and the work of PBL in the Netherlands for the development of a CE monitoring framework.

- Research has been also suggested into indicators measuring rebound effects of CE policies (Alaerts et al., 2019 [105]; Ekins et al., 2019 $9_{[106]}$; Koch and Coelho, 2020 ${ }_{[118]}$ ).

Data availability

- There is a need for continued efforts to make relevant data available to researchers and policy makers (Ekins et al., 2019 [106]; Koch and Coelho, 2020 $\left.{ }_{[118]}\right)$.

- Research would also be required into the implementation of data integration approaches using data from a variety of sources (public, company, products, and surveys).

\section{Coherence and consistency of data}

- Some suggest harmonisation of indicators and comparison of the methodology with other countries (Ekins et al., 2019 $[106]$ ), and research into alignment of macro-, meso- and micro-level indicators to measure system changes from bottom-up and top-down initiatives (Ekins et al., 2019 [106]).

- Implementation of robust methodologies, i.e. following the quality requirements of official statistics, for all CE indicators (or selected ones) would be also beneficial.

\section{Monitoring framework for the circular economy in the Czech Republic}

165. The working paper on indicators to monitor the transition to a circular economy prepared by the Ministry of the Environment in the Czech Republic in February 2020 presents a number of existing CE monitoring frameworks in the EU (EU CE Monitoring framework, $\mathrm{CE}$ indicators in the EU Eco-innovation framework, French CE monitoring 
framework, CE indicators proposed by the European Academies Science Advisory Council). Moreover, it maps a potential set of indicators that could be used to monitor progress in the area of the circular economy in the Czech Republic. This includes indicators outlined in the EU CE Monitoring Framework (Box 8.1), as well as additional potential relevant indicators as included in the Czech Strategic Framework 2030 and relevant indicators used to monitor progress towards the Sustainable Development Goals as included in the 2019 Europe Sustainable Development Report (SDSN and IEEP, 2019 ${ }_{[124]}$ ) (Box 8.3).

\section{Box 8.3. Potential indicators for a circular economy in the Czech Republic}

There have been three sets of potential indicators proposed in the working paper on indicators by the Ministry of the Environment. These are relevant indicators proposed in three documents:

1. EU CE Monitoring framework (see Box 8.1 for the list of indicators).

2. Czech Strategic Framework 2030

- The share of production of secondary raw materials in overall domestic material input (DMI) (\%) [Key area 'Economic model', strategic objective on natural resources] this indicator is similar to the circular material use rate indicator (the latter uses domestic material consumption (DMC) rather than DMI).

- Total waste generation [Key area 'Economic model', strategic objective on natural resources] - this indicator is not further specified in the framework but waste generation is covered by the EU CE Monitoring framework.

- Resource productivity (GDP/ Domestic Material Consumption (DMC) [Key area 'Economic model', strategic objective on natural resources] - this indicator is not part of the EU CE Monitoring framework but is the headline indicator of the EU Resource Efficiency monitoring framework.

3. 2019 Europe Sustainable Development Report

- Circular material use rate (\%), from Eurostat, used figures are for 2016 [SDG 12 Responsible Consumption and Production] - this indicator is also used in the EU CE Monitoring framework.

- Recycling rate of municipal waste (\%), from Eurostat, used figures are for 2017 [SDG11 - Sustainable Cities and Communities] - this indicator is also used in the EU CE Monitoring framework.

- Freshwater abstraction (\% of long term average available water), from Eurostat, used figures are for 2017 [SDG6 - Clean Water and Sanitation]

Note: Presented examples of indicators in Box 8.3 are based on own selection from the list of indicators in the Czech Strategic Framework 2030 and the 2019 Europe Sustainable Development Report. These indicators were deemed as most relevant to the circular economy.

Source: Ministry of the Environment of the Czech Republic (draft version February 2020), Working paper on indicators to monitor the transition to a circular economy.

166. Indicators related to the circular economy objective in the Czech Strategic Framework 2030 and the 2019 Europe Sustainable Development report are largely those already captured in the EU CE Monitoring framework (i.e. CMU, waste generation, share of secondary raw materials use) or those commonly used in other policies (i.e. resource productivity). However, the Czech Strategic Framework 2030 offers several indicators 
related to other strategic objectives, which could potentially be used to monitor the CE transition as well in a complementary manner, e.g. indicators on R\&D and education. The SDGs monitoring framework offers in addition indicators related to sustainable consumption and production, such as indicators on emissions (SDSN and IEEP, 2019 [124]), however, these are linked more to air and soil pollution. In overall, these are all existing indicators.

167. Indicators proposed within the forthcoming State Environmental Policy of the Czech Republic 2030 with an outlook to 2050 to tackle the objective of circular economy are also the commonly used indicators on resources consumption and waste management, namely resource productivity, CMU, waste treatment methods, waste treatment of municipal waste. In addition, a proposal is made for an indicator to monitor progress towards greater use of recycled water, i.e. the number of supported projects for the use of rainwater and greywater.

168. As mentioned in the indicator working paper of the Ministry of the Environment, it will be important for the Czech Republic to determine a set of selected indicators that can be used to monitor progress in the transition towards a circular economy, but also to select indicators, which are already used in some existing policy and having a developed monitoring methodology (e.g. resources consumption, and waste generation and treatment. The aim is also to keep the resulting indicator set to a manageable number.

169. The Czech Republic may however, consider introducing a couple of more ambitious circular economy indicators, which are not currently available yet or not yet regularly updated. These might be related to for example, measuring environmental footprints of certain products, innovative business models (e.g. sharing economy) or consumer attitudes towards the CE.

\section{Recommendations}

170. Based on the above analysis, the recommendations for a circular economy monitoring system for the Czech Republic are outlined below.

Agree on clear targets (or a single target) that the CE strategy is trying to achieve and identify linkages to other relevant policy targets that the strategy will support

171. The Czech Republic may consider to set (a) clear target(s) that the CE strategy is trying to achieve. Many Member States have set a resource productivity target along with waste generation and recycling targets. If no CE target is set, clear objectives of what the CE strategy aims to achieve could be spelled out (e.g. SDG goals, etc.).

172. Existing waste, energy and climate targets could be linked to the indicator set, where relevant.

\section{Developing an indicator set}

173. The Czech Republic may consider developing an indicator set that monitors progress towards these target(s) or the CE transition as outlined in the vision and strategic objectives of the Circular Czechia 2040, if no target was set. The process of setting up an indicator set could consist of two consecutive phases:

- Phase 1: The use of existing indicators and CE monitoring frameworks (e.g. indicators of the EU CE monitoring framework and those listed in Box 8.3 as suggested by the working paper on indicators prepared by the Ministry of the 
Environment). The Background report on the EU national circular economy strategies shows that the EU Member States use existing indicators by default ( $A$ simple monitoring framework).

- Phase 2: Invest in a research study to expand the monitoring system in phase one with better tailored indicators and additional data (An elaborated monitoring framework). This will depend on the available resources within the Czech Republic, the political will as well as the level of ambition. The Background report on the EU national circular economy strategies to this report shows that a few EU Member States have taken this path, e.g. designed a specific work programme to develop the CE monitoring framework (the Netherlands, Finland), set up a cooperation study of a number of partner organisations (France), or formulated indicators development as part of their priority areas (Scotland, Slovenia).

174. The second phase can take into account the development of new indicators to measure CE aspects that have been disregarded for the moment due to lack of data or research. This includes areas such as remanufacture, reuse, sharing, digitalisation (part of the R-strategies), consumer and business perspectives or environmental impacts of CE activities (the development of so-called meso-level and impact indicators).

175. In both options, it is also important to align and link the indicator set to indicators in other policy areas, such as climate change, biodiversity, agriculture and SDGs. It is also important to take into account data availability and feasibility of updating regularly the agreed set of CE indicators (i.e. the number of key indicators and the additional efforts needed to monitor them). The selected key indicators should be easily understood and communicated by policy makers to the public (some suggest using a maximum of ten key indicators (Prins and Rood, 2020 $[109])$.

176. The CE monitoring framework could be structured using a multi-tiered approach, from more general to more concrete thematic indicators. As mentioned above, this would allow for the introduction of a limited number of key indicators (for communication purposes) on for example progress towards the main CE related targets. This could be complemented by thematic indicators for each of the priority areas of the $\mathrm{CE}$ strategic framework. The downside to having a more elaborated multi-layered indicator set is the creation of additional administrative burden to develop new indicators and regularly update the monitoring framework.

177. An initial long-list of indicators to consider for the Czech Republic could look like the suggestions below. The list takes into account the three main sources of potential indicators for the Czech Republic, as discussed in the working paper on indicators prepared by the Ministry of the Environment (i.e. the EU CE Monitoring framework (contains 23 individual indicators), the Czech Strategic Framework 2030 and the 2019 Europe Sustainable Development Report). In addition, it takes into account the suggestions for indicators proposed in the forthcoming State Environmental Policy of the Czech Republic 2030 with an outlook to 2050. A single headline indicator is suggested based on this list, complemented with a number of indicators for each priority area of the Circular Czechia 2040 strategy. This dashboard might be complemented with additional indicators developed under option 2 (highlighted in grey in Table A.1.). However, under this option the list of indicators becomes even more extensive, and prioritisation / elimination of indicators will need to be made. 
Address data gaps for measuring the progress towards the circular economy

178. The Czech Republic might need to address data gaps related to the selected indicator set. For example, by following the EU CE Monitoring framework, there is a need for data on green public procurement and food waste. It should also be checked which data is already collected by public authorities and other organisations that could be relevant for the indicator set but which are not yet consolidated into datasets or reported on. Ideally, all selected indicators are linked to the national statistical system. Furthermore, the Czech Republic may consider harmonising the two waste management information systems (the national system managed by CENIA on behalf of the Ministry of the Environment and official statistics managed by the CZSO) to create a consolidated, transparent and integrated system.

\section{Participation in major international initiatives}

179. The Czech Republic may consider to continue identifying and taking part in opportunities for international collaboration on CE monitoring frameworks. It may want to coordinate and try to align its national CE monitoring system with other countries, and share the burden of developing internationally agreed indicators. 


\section{Communication plan}

180. This chapter provides an overview of the key elements of a communication plan, guidance for developing such plan for the Circular Czechia 2040 strategy, and the calendar of events where this strategy could be communicated at. This communication material is complemented by a brochure and a slide deck (standalone material). This material is intended to facilitate dissemination of the findings and to support the development of a fullfledged communication strategy for the Circular Czechia 2040 strategy. The material as developed by the OECD is mainly targeted at communication with institutional stakeholders (i.e. ministries and other levels of government, as well as circular economy experts). This does not include the communication with a broader group of stakeholders (i.e. private sector, NGOs, general public). The Ministry of the Environment, in collaboration with other ministries, is best placed to develop the communication material (i.e. calendar of national events, messaging, resources) to target those groups of stakeholders, which needs to be in local language.

\section{Key elements of a communication plan}

181. For an effective communication of the Circular Czechia 2040 strategy it is recommended that the Ministry of the Environment of the Czech Republic draws up a tailored communication plan. The purpose of this is to set the communication objectives, decide on means of communication (or communication channels), develop the key messages, produce a portfolio of communication and dissemination products and activities, and determine the timings, resources and responsibilities for the communication of the strategy (Dave Fleet, 2008 ${ }_{[125]}$; Moylan, 2015 [126]; OECD Development Centre, 2014 ${ }_{[127]}$; European Commission, 2007 ${ }_{[128]}$; Interreg Europe, 2016 $6_{[129]}$; OECD, 2014 ${ }_{[130]}$ ). More specifically, the key elements to be considered in the development of such a communication plan include:

- Objectives: What is the purpose of the communication? (i.e. national vs. international communication; internal/ inter-ministerial vs. external communication)

- Target audiences / stakeholder groups: Who is the audience, and what is the level of stakeholders targeted? (i.e. national vs. regional/municipal vs. local actors; public sector vs. business and industry vs. international organisations vs. NGOs vs. scientific community vs. civil society)

- Messaging: What are the key messages to be conveyed? (i.e. educational vs. actionable messages)

- Channels: What channels and tactics are to be used? (i.e. media vs. social media vs. events - conferences, workshops, webinars)

- Timings: When should the communication occur? (i.e. timing and frequency)

- Resources: Which resources need to be committed? (i.e. financial and human resources)

- Responsibilities: Who is responsible for the communication? (i.e. public relations vs. policy experts vs. political level) 
- Measurement: What will the success look like? (i.e. expected outcomes)

Guidance for developing the communication plan for the Circular Czechia 2030 strategy

182. The following paragraphs and the information reported in Table 9.1 develop some of the key elements of the communication plan for the Circular Czechia 2040 strategy.

183. To start with, the general objectives of the communication plan should revolve around:

- Ensuring that the communication of the strategy is understood and implemented by policy makers at different levels of governance;

- Ensuring that information about circular economy reaches the public, in an accessible, comprehensible, and timely manner;

- Engaging the key stakeholders and the wider public in the circular economy transition.

184. More specifically, the plan should aim at demonstrating the practical application of circular economy concepts, by showcasing existing and emerging good practices across the Czech Republic and abroad, and underlining those practices with hard data on the circular economy benefits, for example on the amount of resources saved and jobs created. Other specific objectives of the communication plan in the Czech Republic should include increasing the awareness of the agenda, changing the perceptions, encouraging the knowledge sharing, and promoting new business models (Perella, 2015 [131]).

185. To reach these objectives, the communication plan needs to target all stakeholder groups relevant for the circular economy transition in the Czech Republic. These include stakeholders from public administration (on both national and regional/municipal levels), private sector (both start-ups and incumbents, as well as financing institutions), academia and circular economy experts, civil society and the public. The purpose of communication and the key messages to be delivered across individual stakeholder groups are outlined in Table 9.1.

186. In terms of communication channels, the communication plan should consider three main channels of providing information and communication activities:

- Internet communication - this refers to developing a dedicated website for a strategy or a webpage within an existing website. For example, a dedicated webpage for the Circular Czechia 2040 strategy may be set up within the existing website of the Ministry of the Environment. Other activities may include: contacting relevant partners and placing an advertisement / reference about the strategy on other related websites; placing an ad/ PR article/ or a press release about the strategy on a top news portal and other relevant outlets; internal direct mailing to an existing database of contacts; and social media (LinkedIn, Facebook, Twitter).

- Printed promotional material - this refers to developing brochures and leaflets that can be distributed to the interested parties (and offered for download on the internet). Such printed promotional material can be disseminated during events and meetings. The OECD, together with the Ministry of the Environment, developed a 20 page brochure to promote and disseminate the findings of this OECD report and of the Circular Czechia 2040 strategy. 
- Events and workshops - organising and participating in stakeholder events and workshops is another means of communicating a strategy. The Ministry of the Environment may consider organising relevant events to present or promote the Circular Czechia 2040 strategy, or participate in other national and international events. The OECD developed a slide deck that can be used for this purpose. 
Table 9.1. Key elements for developing the Circular Czechia 2040 strategy communication plan

\begin{tabular}{|c|c|c|c|c|c|}
\hline Stakeholders & Purpose & Messaging & Channels & Timings & Responsibilities \\
\hline Involved ministries & $\begin{array}{l}\text { - Ensure cooperation with other relevant departments } \\
\text { at the Ministry of the Environment to implement } \\
\text { measures proposed by the strategy } \\
\text { - Ensure cooperation with other relevant ministries to } \\
\text { facilitate implementation of measures and adoption of } \\
\text { the strategy by the Government. } \\
\text { - Increase awareness of the agenda } \\
\text { - Encourage knowledge sharing }\end{array}$ & $\begin{array}{l}\text { - Calls to action (persuade other departments and ministries to take } \\
\text { an active approach, possibly through the level of Secretaries of } \\
\text { state) } \\
\text { - Communicating real life examples (to increase awareness of the } \\
\text { agenda) }\end{array}$ & $\begin{array}{l}\text { Direct communication } \\
\text { (bilateral, negotiations) }\end{array}$ & $\begin{array}{l}\text { Throughout the } \\
\text { strategy } \\
\text { development } \\
\text { and } \\
\text { implementation }\end{array}$ & $\begin{array}{l}\text { Ministry of } \\
\text { Environment; } \\
\text { Cabinet of the } \\
\text { Prime Minister } \\
\text { (to endorse the } \\
\text { project) }\end{array}$ \\
\hline $\begin{array}{l}\text { Regional/municipal } \\
\text { actors }\end{array}$ & $\begin{array}{l}\text { - Ensure cooperation with regional and municipal actors } \\
\text { - Provide tools and guidelines for communication at } \\
\text { local level }\end{array}$ & $\begin{array}{l}\text { - Educational messages (explaining the terminology, } \\
\text { communicating circular benefits) } \\
\text { - Communicating real life examples (to increase awareness of the } \\
\text { agenda) } \\
\text { - Calls to action (persuade regional and municipal authorities to } \\
\text { implement circular economy measures, promote circular business } \\
\text { models) }\end{array}$ & $\begin{array}{l}\text { Direct communication } \\
\text { Workshops } \\
\text { Printed material } \\
\text { (framework and } \\
\text { manuals) }\end{array}$ & $\begin{array}{l}\text { Throughout the } \\
\text { strategy } \\
\text { development } \\
\text { and } \\
\text { implementation }\end{array}$ & $\begin{array}{l}\text { Ministry of } \\
\text { Environment; } \\
\text { Ministry of } \\
\text { Regional } \\
\text { Development }\end{array}$ \\
\hline Private sector & $\begin{array}{l}\text { - Raise awareness with companies and organizations } \\
\text { about the obligations and opportunities around } \\
\text { circular design, use and reuse of materials, } \\
\text { components and products, and their end of life and } \\
\text { waste management } \\
\text { - Encourage cooperation with the private sector to } \\
\text { implement the strategy, and provide statistics and real } \\
\text { life examples to others } \\
\text { - Raise awareness with banks and financing institutions } \\
\text { about the circular economy business models }\end{array}$ & $\begin{array}{l}\text { - Communicating real life examples (to increase awareness of the } \\
\text { agenda) } \\
\text { - Creative storytelling (use CEOs of frontrunners to communicate } \\
\text { with the private sector) } \\
\text { - Educational messages (explaining the terminology, } \\
\text { communicating circular benefits) } \\
\text { - Calls to action (invite the private sector to invest in circular } \\
\text { economy projects) } \\
\text { - Providing statistics (to the extent possible) }\end{array}$ & $\begin{array}{l}\text { Presentations } \\
\text { Workshops } \\
\text { Printed promotional } \\
\text { material } \\
\text { Internet } \\
\text { communication } \\
\text { Direct communication }\end{array}$ & $\begin{array}{l}\text { Throughout the } \\
\text { strategy } \\
\text { development } \\
\text { and } \\
\text { implementation }\end{array}$ & $\begin{array}{l}\text { Ministry of } \\
\text { Environment; } \\
\text { Ministry of } \\
\text { Industry and } \\
\text { Trade }\end{array}$ \\
\hline $\begin{array}{l}\text { Academia / } \\
\text { Circular economy } \\
\text { experts }\end{array}$ & $\begin{array}{l}\text { - Inform academics and circular economy experts about } \\
\text { the strategy } \\
\text { - Encourage their cooperation on national and } \\
\text { international levels, as well as with the private sector } \\
\text { (through research projects, associations, etc.) } \\
\text { - Encourage the inclusion of circular economy concepts } \\
\text { into the tertiary education curricula }\end{array}$ & $\begin{array}{l}\text { - Communicating real life examples (to increase awareness of the } \\
\text { agenda) } \\
\text { - Creative storytelling (use CEOs of frontrunners to communicate } \\
\text { with the private sector) } \\
\text { - Educational messages (explaining the terminology, } \\
\text { communicating circular benefits) } \\
\text { - Calls to action (invite academics and experts to participate in } \\
\text { relevant research projects and associations) } \\
\text { - Providing statistics (to the extent possible) }\end{array}$ & $\begin{array}{l}\text { Presentations } \\
\text { Workshops } \\
\text { Internet } \\
\text { communication }\end{array}$ & $\begin{array}{l}\text { After the } \\
\text { strategy } \\
\text { implementation }\end{array}$ & $\begin{array}{l}\text { Ministry of } \\
\text { Environment; } \\
\text { Ministry of } \\
\text { Education, Youth } \\
\text { and Sports }\end{array}$ \\
\hline
\end{tabular}

TOWARDS A NATIONAL STRATEGIC FRAMEWORK FOR THE CIRCULAR ECONOMY IN THE CZECH REPUBLIC 


\begin{tabular}{|c|c|c|c|c|c|}
\hline $\begin{array}{l}\text { Civil society / } \\
\text { NGOs }\end{array}$ & $\begin{array}{l}\text { - Raise awareness about circular economy } \\
\text { - Encourage cooperation with the civil society/ NGOs to } \\
\text { actively promote circular economy and to participate } \\
\text { in the implementation of the strategy }\end{array}$ & $\begin{array}{l}\text { - Educational messages (explaining the terminology, } \\
\text { communicating circular benefits) } \\
\text { - Calls to action (invite the general public to adopt circular practices) } \\
\text { - Providing statistics (to the extent possible) }\end{array}$ & $\begin{array}{l}\text { Direct communication } \\
\text { Internet } \\
\text { communication } \\
\text { Events }\end{array}$ & $\begin{array}{l}\text { Throughout the } \\
\text { strategy } \\
\text { development } \\
\text { and } \\
\text { implementation }\end{array}$ & $\begin{array}{l}\text { Ministry of } \\
\text { Environment }\end{array}$ \\
\hline General public & $\begin{array}{l}\text { - Raise awareness about circular economy } \\
\text { - Encourage the general public to adopt circular } \\
\text { consumption practices (especially circular } \\
\text { consumption and waste sorting) }\end{array}$ & $\begin{array}{l}\text { - Communicating real life examples (to increase awareness of the } \\
\text { agenda) } \\
\text { - Creative storytelling (use CEOs of frontrunners to communicate } \\
\text { with the general public) } \\
\text { - Educational messages (explaining the terminology, } \\
\text { communicating circular benefits) } \\
\text { - Calls to action (invite the general public to adopt circular practices) } \\
\text { - Providing statistics (to the extent possible) }\end{array}$ & $\begin{array}{l}\text { Internet } \\
\text { communication } \\
\text { Events } \\
\text { Campaigns } \\
\text { Printed material } \\
\text { (leaflets) } \\
\text { Curricula }\end{array}$ & $\begin{array}{l}\text { After the } \\
\text { strategy } \\
\text { implementation }\end{array}$ & $\begin{array}{l}\text { Ministry of } \\
\text { Environment; } \\
\text { Regions and } \\
\text { municipalities; } \\
\text { Ministry of } \\
\text { Education, Youth } \\
\text { and Sports }\end{array}$ \\
\hline
\end{tabular}

Note: Information about the human and financial resources is to be added by the Ministry of the Environment of the Czech Republic, which is better placed to provide such breakdown. The Ministry shall also refine the information on responsibilities by key stakeholders.

Source: Own elaboration based on background literature on communication development (Dave Fleet, 2008 [125]; Moylan, 2015[126]; OECD Development Centre, 2014[127]; European Commission, 2007[128]; Interreg Europe, 2016[129]; OECD, 2014[130]; Perella, 2015 [131]). 
187. In order to implement the key activities outlined in Table 9.1, the financial and human resources should be available. Moreover, the communication plan needs to be integrated within the governance roles and capacities of the different ministries. While the Ministry of the Environment could be responsible for delivering nation-wide communication targeting the general public as well as specialised communication directed to circular economy experts, other ministries could engage with other parts of the stakeholder spectrum. For instance: the Ministry of Regional Development could be the body taking up the communication towards regions and local authorities to help roll out regional and local action on circular economy; the Ministry of Industry and Trade could carry forward the communication towards industrial actors and businesses to help building wide coalition of interest; and the Ministry of Education, Youth and Sports could deliver the messages to schools and universities to empower young people.

188. To implement the medium-term communication plan, it is a good practice to draw up short-term communication plans on an annual basis. The objective of such plans is to coordinate communication activities targeting different stakeholder groups in the forthcoming periods. It is furthermore recommended to measure the effectiveness of the communication and resources invested, as well as to evaluate the implementation of the communicated topics and fulfilment of short-term goals. The lessons learnt should then be incorporated into the communication activities of the following period.

\section{Calendar of events for communication to institutional stakeholders}

189. Table 9.2 provides a calendar of the most important events addressing the topic of circular economy. The table also provides information along some assessment criteria to help select the events based on their geographical scope and audience, as well as level and type of participation by the Czech Republic, and political relevance and impact in media and social-media. Given that the preparation of the strategy will only be completed towards the end of 2021, it is worth to look at the events taking place annually, later in the year and well beyond it (some of which have not been announced yet).

190. For national events, the Ministry of the Environment might consider developing a similar calendar, as indicated in Table 9.3. 
Table 9.2. Proposed calendar of international events for the communication of the Circular Czechia 2040 strategy

\begin{tabular}{|c|c|c|c|c|c|c|c|c|}
\hline Events & $\begin{array}{l}\text { Event frequency } \\
\text { and timing }\end{array}$ & Organiser & $\begin{array}{l}\text { Geographical } \\
\text { scope }\end{array}$ & Number and type of participants & $\begin{array}{l}\text { Required level of } \\
\text { participation by the } \\
\text { Czech Republic }\end{array}$ & $\begin{array}{l}\text { Type of participation } \\
\text { by the Czech } \\
\text { Republic }\end{array}$ & $\begin{array}{l}\text { Political } \\
\text { relevance }\end{array}$ & $\begin{array}{l}\text { Impact in } \\
\text { media and } \\
\text { social media }\end{array}$ \\
\hline World Economic Forum & Annual in January & WEF & Global & $\begin{array}{r}3000+ \\
\text { High-level participants, most of them with less specialised } \\
\text { knowledge on CE }\end{array}$ & $\begin{array}{r}\text { Prime minister } \\
\text { (Deputy) minister }\end{array}$ & $\begin{array}{r}\text { Participate in a } \\
\text { session as a panellist }\end{array}$ & High & High \\
\hline $\begin{array}{l}\text { World Circular Economy } \\
\text { Forum }\end{array}$ & $\begin{array}{l}\text { Annual in } \\
\text { September }\end{array}$ & SITRA & Global & $\begin{array}{r}2000+ \\
(4000+\text { in online edition) } \\
\text { Circular economy stakeholders from across the board }\end{array}$ & $\begin{array}{r}\text { (Deputy) minister } \\
\text { State secretary } \\
\text { Director }\end{array}$ & $\begin{array}{r}\text { Host an edition, a } \\
\text { session or a side } \\
\text { event }\end{array}$ & High & High \\
\hline World Resources Forum & $\begin{array}{r}\text { Annual (with } \\
\text { different topic each } \\
\text { year) }\end{array}$ & WRI & Global & $\begin{array}{l}300+ \\
\text { Stakeholders in resource governance from private sector, } \\
\text { public sector, international organisations, academia, NGOs }\end{array}$ & Director & $\begin{array}{l}\text { Participate in a } \\
\text { session as a panellist, } \\
\text { or hold a presentation }\end{array}$ & Medium & Medium \\
\hline $\begin{array}{l}\text { Circular Economy } \\
\text { Stakeholder Conference }\end{array}$ & $\begin{array}{l}\text { Annual in } \\
\text { November }\end{array}$ & $\begin{array}{r}\text { European Circular } \\
\text { Economy } \\
\text { Stakeholder } \\
\text { Platform }\end{array}$ & European & Circular economy stakeholders from across the board & (Deputy) director & Hold a presentation & Medium & Medium \\
\hline EU Green Week & $\begin{array}{r}\text { Annual (with } \\
\text { different focus each } \\
\text { year) }\end{array}$ & $\begin{array}{r}\text { European } \\
\text { Commission }\end{array}$ & European & $\begin{array}{r}\text { Participants from a wide variety of backgrounds, from EU } \\
\text { institutions, business and industry, NGOs, public sector, } \\
\text { scientific community, academia }\end{array}$ & (Deputy) director & Hold a presentation & Medium & Medium \\
\hline ISWA World Congress & $\begin{array}{r}\text { Annual in October } \\
\text { (with different focus } \\
\text { each year) }\end{array}$ & ISWA & Global & $\begin{array}{r}\text { Up to } 1500 \\
\text { Practitioners, policy makers, researchers, and academics } \\
\text { specialised in sustainable waste management, circular } \\
\text { economy and resource efficiency }\end{array}$ & (Deputy) director & Hold a presentation & Medium & Medium \\
\hline $\begin{array}{l}\text { Ellen MacArthur } \\
\text { Foundation Summit }\end{array}$ & Annual & $\begin{array}{l}\text { Ellen MacArthur } \\
\text { Foundation }\end{array}$ & Global & $\begin{array}{r}500+ \\
\text { Business leaders, policymakers, academics, innovators, } \\
\text { and pioneers in circular economy }\end{array}$ & (Deputy) director & $\begin{array}{r}\text { Participate in a } \\
\text { session as a panellist }\end{array}$ & Medium & Medium \\
\hline $\begin{array}{l}\text { OECD Working Party on } \\
\text { Resource Productivity and } \\
\text { Waste }\end{array}$ & $\begin{array}{r}\text { Three times in a } \\
\text { biennium }\end{array}$ & OECD & $\begin{array}{r}\text { OECD countries and } \\
\text { selected non- } \\
\text { member countries }\end{array}$ & $\begin{array}{r}80-150 \\
\text { Circular economy and waste management specialists on } \\
\text { national level }\end{array}$ & (Deputy) director & Hold a presentation & Medium & Low \\
\hline $\begin{array}{l}\text { TSI project stakeholder } \\
\text { meetings }\end{array}$ & Ad Hoc & OECD & $\begin{array}{l}\text { National level in one/ } \\
\text { several V4 countries }\end{array}$ & $\begin{array}{r}50-100 \\
\text { Public sector, business and industry, municipalities and } \\
\text { regions, NGOs, academia }\end{array}$ & (Deputy) director & Hold a presentation & Low & Low \\
\hline
\end{tabular}


104

Table 9.3. Proposed draft calendar of national events for the communication of the Circular Czechia 2040 strategy (to be completed by

the Ministry of the Environment)

\begin{tabular}{|c|c|c|c|c|c|c|c|c|}
\hline Events & $\begin{array}{c}\text { Event } \\
\text { frequency and } \\
\text { timing }\end{array}$ & Organiser & $\begin{array}{l}\text { Geographical } \\
\text { scope }\end{array}$ & Number and type of participants & $\begin{array}{l}\text { Required level of } \\
\text { participation by the } \\
\text { Czech Republic }\end{array}$ & $\begin{array}{l}\text { Type of participation by } \\
\text { the Czech Republic }\end{array}$ & $\begin{array}{l}\text { Political } \\
\text { relevance }\end{array}$ & $\begin{array}{l}\text { Impact in media } \\
\text { and social media }\end{array}$ \\
\hline $\begin{array}{l}\text { International Engineering Fair } \\
\text { Czech Republic }\end{array}$ & Annual in Fall & tbd & Czech & $\begin{array}{r}10^{\prime} 000+ \\
\text { Expert audience from different areas of } \\
\text { business and industry, start-ups, and financing, } \\
\text { some with very specialised/ applied knowledge } \\
\text { on CE }\end{array}$ & Director & $\begin{array}{r}\text { (Co-) organise a workshop / } \\
\text { side-event on circular } \\
\text { economy }\end{array}$ & Medium & High \\
\hline $\begin{array}{l}\text { Odpad Zdrojem } \\
\text { [Waste as a Resource] }\end{array}$ & $\begin{array}{r}\text { Annual (with } \\
\text { different topic } \\
\text { each year) }\end{array}$ & INCIEN & Czech & $\begin{array}{r}\text { Expert audience with specialised/ applied } \\
\text { knowledge on } \mathrm{CE} \text {, including representatives } \\
\text { from public administration, municipalities, } \\
\text { private sector }\end{array}$ & (Deputy) director & $\begin{array}{r}\text { (Co-) organise an edition, } \\
\text { host a session, or } \\
\text { participate as a panellist }\end{array}$ & Low & Medium \\
\hline Zero Waste Festival Prague & $\mathrm{tbc}$ & $\begin{array}{r}\text { Zero Waste } \\
\text { Festival Prague }\end{array}$ & Czech & $\begin{array}{l}\text { ? } \\
\text { Addressing environmental protection and the } \\
\text { concept of zero-waste.to educate civil society } \\
\text { and introduce individual bottom-up project } \\
\text { ideas }\end{array}$ & (Deputy) director & $\begin{array}{r}\text { Participate in a session as } \\
\text { a panellist, or hold a } \\
\text { presentation }\end{array}$ & Low & Low \\
\hline $\begin{array}{l}\text { Events organised as part of } \\
\text { relevant European research } \\
\text { projects (e.g. Interreg, Horizon } \\
\text { Europe, etc.) }\end{array}$ & Ad hoc & Project consortia & $\begin{array}{l}\text { Czech (and } \\
\text { beyond) }\end{array}$ & $\begin{array}{r}\text { Depends on the project. Often regional/ local } \\
\text { stakeholders }\end{array}$ & Policy officer & $\begin{array}{r}\text { Participate in a session as } \\
\text { a panellist, or hold a } \\
\text { presentation }\end{array}$ & Low & Low \\
\hline
\end{tabular}

Source: Own elaboration. 


\section{References}

ADEME (2017), Etude comparative de la taxation de l'elimination des dechets en Europe

[Comparative study of the taxation of waste disposal in Europe], http://www.ademe.fr/mediatheque.

Agència de Residus de Catalunya (2020), Pacte per la bossa (Bag Pact),

http://residus.gencat.cat/ca/ambits_dactuacio/prevencio/pacte_per_la_bossa/index.html.

Agrawala, S., D. Dussaux and N. Monti (2020), "What policies for greening the crisis response and economic recovery?: Lessons learned from past green stimulus measures and implications for the COVID-19 crisis", OECD Environment Working Papers, No. 164, OECD Publishing, Paris, https://dx.doi.org/10.1787/c50f186f-en.

Alaerts, L. et al. (2019), "Towards a more direct policy feedback in circular economy monitoring via a societal needs perspective", Resources, Conservation and Recycling, Vol. 149, pp. 363371, http://dx.doi.org/10.1016/j.resconrec.2019.06.004.

Bocken, N. et al. (2016), "Product design and business model strategies for a circular economy", Journal of Industrial and Production Engineering, Vol. 33/5, pp. 308-320, http://dx.doi.org/10.1080/21681015.2016.1172124.

Bukhari, M., R. Carrasco-Gallego and E. Ponce-Cueto (2018), "Developing a national programme for textiles and clothing recovery", Waste Management \& Research, Vol. 36/4, pp. 321-331, http://dx.doi.org/10.1177/0734242x18759190.

Cambridge Econometrics, Trinomics B.V. and ICF (2018), Impacts of circular economy policies on the labour market, European Commission, Luxembourg, http://dx.doi.org/doi:10.2779/574719.

CENIA (2020), Information System for Statistics and Reporting, https://issar.cenia.cz (accessed on 3 June 2021).

CENIA (2019), Statistická ročenka životního prostředí České republiky 2018 (Statistical Environmental Yearbook 2018), Ministry of the Environment of the Czech Republic, https://www.cenia.cz/publikace/statisticka-rocenka-zivotniho-prostredi-cr/statisticka-rocenkazivotniho-prostredi-cr-2018/.

Circle Economy and INCIEN (2019), Circular Prague, https://assets.websitefiles.com/5d26d80e8836af2d12ed1269/5de95a133e0b522c1f9d4ea6 Prague-Final-Report20190406 MR-compressed\%20(1).pdf. 
Cirkulární Hub Praha (n.d.), Cirkulární Hub Praha [Circular Hub Prague],

https://incien.org/prvni-cirkularni-hub-v-cr-otevrel-sve-dvere/ (accessed on 3 June 2021).

Czech Statistical Office (2019), Direct public support for research and development in the Czech Republic, https://www.czso.cz/documents/10180/90577077/21100119.pdf/59943f21-bb9a$\underline{4744-889 \mathrm{c}-88 \mathrm{c} 8 \mathrm{db} 16 \mathrm{~b} 480 \text { ? version }=1.1}$.

Czech Statistical Office (2019), Nepř́má veřejná podpora výzkumu a vývoje v České republice za rok 2017 [Indirect state support to research and development in the Czech Republic for year 2017], Český statistický úřad, Praha, https://www.czso.cz/csu/czso/neprima-verejna-podporavyzkumu-a-vyvoje.

Czech Statistical Office (2019), Produkce, využití a odstranění odpadu a produkce druhotných surovin $v$ roce 2018 [Generation, reuse and disposal of waste and production of secondary raw materials in 2018], https://www.czso.cz/csu/czso/cri/produkce-vyuziti-a-odstraneni-odpadu-aprodukce-druhotnych-surovin-v-roce-2018.

CzechInvest (2020), Czech circular hotspot, https://www.czechinvest.org/en/AboutCzechInvest/About-Us/Internal-projects/Czech-circular-hotspot.

Dave Fleet (2008), "Strategic Communications Planning”, https://davefleet.com/wpcontent/uploads/2008/08/comm-plan-ebook.pdf (accessed on 24 February 2021).

Deloitte Czech Republic (2019), Made in World Analýza českého zahraničního obchodu a pozice $v$ globálních hodnotových řetězcích (Analysis of the Czech Foreign Trade and its position in Global Value Chains), https://www2.deloitte.com/content/dam/Deloitte/cz/Documents/aboutdeloitte/made-in-world.pdf.

DigiDealGO (2020), Over DigiDeal, https://www.digidealgo.nl/.

Doranova, Asel; Roman, Laura; Bahn-Walkowiak, Bettina; Wilts, Henning; O’brien, Meghan; Giljum, Stefan; Kong, Mary Ann; Hestin, M. (2016), Policies and Practices for EcoInnovation Up-take and Circular Economy Transition EIO bi-annual report, https://ec.europa.eu/environment/ecoap/sites/ecoap_stayconnected/files/eio_2016_report.pdf.

Dutch Ministry of Infrastructure and the Environment (2016), A circular economy in the Netherlands by 2050., https://www.government.nl/binaries/government/documents/policynotes/2016/09/14/a-circular-economy-in-the-netherlands-by2050/17037+Circulaire+Economie EN.PDF.

Eco-innovation observatory (2018), Eco-innovation in the Czech Republic: EIO Country Profile 2016-2017, https://ec.europa.eu/environment/ecoap/sites/ecoap_stayconnected/files/field/fieldcountry-files/cz_eio_country_profile_2016-2017_0.pdf.

Eco-TLC (2019), "2018 Annual Report”, https://www.ecotlc.fr/ressources/Documents site/EcoTLC 2018-Annual-Report web.pdf.

Ekins, P. et al. (2019), The Circular Economy: What, Why, How and Where, http://www.oecd.org/cfe/regional-policy/Ekins-2019-Circular-Economy-What-Why-HowWhere.pdf (accessed on 22 May 2020). 
EKO-KOM (2019), EKO-KOM, https://www.ekokom.cz/ (accessed on 3 June 2021).

EKO-KOM (2019), "Skladba směsného komunálního odpadu z domácností ČR [Composition of mixed municipal waste from households in CR]", https://www.ekokom.cz/news/715/212/Skladba-smesneho-komunalniho-odpadu-z-domacnosti$\underline{\mathrm{cR}}$.

EKO-KOM (2018), Výroční shrnutí 2018 [Annual Summary 2018], https://www.ekokom.cz/uploads/attachments/Obecne/Vyrocni shrnuti 2018 EKO KOM.pdf.

Ellen MacArthur Foundation (2020), The circular economy: a transformative Covid-19 recovery strategy - How policymakers can pave the way to a low carbon, prosperous future, https://www.ellenmacarthurfoundation.org/assets/downloads/The-circular-economy-atransformative-Covid19-recovery-strategy.pdf (accessed on 2 December 2020).

Euractiv (2020), EU countries warm up recovery fund engine, https://www.euractiv.com/section/politics/news/eu-countries-warm-up-recovery-fund-engine/ (accessed on 15 December 2020).

European Commission (2020), A new Circular Economy Action Plan: For a cleaner and more competitive Europe, https://eur-lex.europa.eu/resource.html?uri=cellar:9903b325-6388-11eab735-01aa75ed71a1.0017.02/DOC_1\&format=PDF.

European Commission (2020), Recovery plan for Europe, https://ec.europa.eu/info/strategy/recovery-plan-europe en (accessed on 2 December 2020).

European Commission (2020), Societal behaviours | Eco-innovation Action Plan, https://ec.europa.eu/environment/ecoap/indicators/societal-behaviours_en?cookies=disabled (accessed on 22 May 2020).

European Commission (2019), 2019 European Semester: Assessment of progress on structural reforms, prevention and correction of macroeconomic imbalances, and results of in-depth reviews under Regulation (EU) No 1176/2011, https://eur-lex.europa.eu/legalcontent/GA/TXT/?uri=CELEX:52019DC0150.

European Commission (2019), Commission Staff Working Document Sustainable Products in a Circular Economy - Towards an EU Product Policy Framework contributing to the Circular Economy, http://ec.europa.eu/environment/circulareconomy/pdf/sustainable products circular economy.pdf (accessed on 16 November 2019).

European Commission (2019), Report on the implementation of the Circular Economy Action Plan, http://eur-lex.europa.eu/legalcontent/EN/TXT/PDF/?uri=CELEX:52019DC0190\&from=EN (accessed on 16 November 2019).

European Commission (2019), The EU Environmental Implementation Review 2019 - Country Report Czech Republic, Directorate-General for Environment, European Commission, https://ec.europa.eu/environment/eir/pdf/report cz en.pdf. 
European Commission (2019), The European Green Deal, European Commission, Brussels, https://eur-lex.europa.eu/legalcontent/EN/TXT/?qid=1576150542719\&uri=COM\%3A2019\%3A640\%3AFIN (accessed on 20 November 2020).

European Commission (2018), A European Strategy for Plastics in a Circular Economy, https://eur-lex.europa.eu/resource.html?uri=cellar:2df5d1d2-fac7-11e7-b8f501aa75ed71a1.0001.02/DOC_1\&format=PDF (accessed on 16 November 2019).

European Commission (2018), Communication on a monitoring framework for the circular economy, https://ec.europa.eu/environment/circular-economy/pdf/monitoring-framework.pdf (accessed on 16 November 2019).

European Commission (2018), Communication on the implementation of the circular economy package: options to address the interface between chemical, product and waste legislation, http://eur-lex.europa.eu/legal-content/EN/TXT/PDF/?uri=CELEX:52018DC0032\&from=EN (accessed on 16 November 2019).

European Commission (2018), Proposal for a Directive of the European Parliament and of the Council on the reduction of the impact of certain plastic products on the environment, https://ec.europa.eu/environment/circular-economy/pdf/single-use_plastics_proposal.pdf (accessed on 16 November 2019).

European Commission (2018), Raw Materials Scoreboard 2018: chapter 19 Construction and Demolition Waste, https://rmis.jrc.ec.europa.eu/uploads/scoreboard2018/indicators/19. Construction and demolit ion waste.pdf.

European Commission (2018), Report on Critical Raw Materials and the Circular Economy, https://ec.europa.eu/docsroom/documents/27327 (accessed on 16 November 2019).

European Commission (2017), Circular economy research and innovation: connecting economic and environmental gains, https://ec.europa.eu/programmes/horizon2020/sites/horizon2020/files/ce booklet.pdf.

European Commission (2015), Closing the loop - An EU action plan for the Circular Economy, http://eur-lex.europa.eu/resource.html?uri=cellar:8a8ef5e8-99a0-11e5-b3b701aa75ed71a1.0012.02/DOC_1\&format=PDF (accessed on 16 November 2019).

European Commission (2014), Development of Guidance on Extended Producer Responsibility $(E P R)$, https://ec.europa.eu/environment/waste/pdf/target_review/Guidance\%20on\%20EPR\%20\%20Final\%20Report.pdf.

European Commission (2011), Taxes on natural resources reduce use of raw materials, DG Environment News Alert Service, https://ec.europa.eu/environment/integration/research/newsalert/pdf/262na1_en.pdf.

European Commission (2007), Guidelines for the drawing up Communication Plans for 20072013 programming period of Structural Funds, 
https://ec.europa.eu/regional policy/archive/country/commu/conferences/november07/doc/pres entations/2b/2b_claudia_salvi_communication_plan_guidelines.doc (accessed on 24 February 2021).

European Commission (n.d.), Regional innovation Monitor - Innovation Vouchers, https://ec.europa.eu/growth/tools-databases/regional-innovation-monitor/supportmeasure/innovation-vouchers-12.

European Commission and TNS Political \& Social (2014), Flash Eurobarometer 388 "Attitudes of [28] Europeans towards waste management and resource efficiency", http://dx.doi.org/10.2779/14825.

European Environment Agency (2018), EEA Environmental indicator report 2018 - in support to the monitoring of the Seventh Environment Action Programme, Publications Office of the European Union, Luxembourg, https://www.eea.europa.eu/airs/2018/resource-efficiency-andlow-carbon-economy/resource-efficiency.

European Environmental Agency (2013), Managing municipal solid waste-a review of achievements in 32 European countries, https://www.eea.europa.eu/publications/managingmunicipal-solid-waste/download.

European Investment Fund (n.d.), Central Europe Fund of Funds (CEFoF), https://www.eif.org/what_we_do/resources/CEFoF/index.htm.

European Resource Efficiency Knowledge Centre (n.d.), Award 'Turning Waste into Resources', https://resourceefficient.eu/en/support-programme/award-turning-waste-resources.

Eurostat (2020), "Generation of waste by waste category, hazardousness and NACE Rev. 2 activity statistics", https://ec.europa.eu/eurostat/databrowser/view/ENV WASGEN custom 356800/default/tabl e?lang=en (accessed on 14 December 2020).

Eurostat (2020), Material flows and resource productivity, https://ec.europa.eu/eurostat/web/environment/material-flows-and-resource-productivity.

Eurostat (2020), Municipal waste by waste management operations statistics, https://ec.europa.eu/eurostat/databrowser/view/ENV WASMUN custom 354233/default/tabl e?lang=en (accessed on 14 December 2020).

Eurostat (2020), Treatment of waste by waste category, hazardousness and waste management operations statistics, https://ec.europa.eu/eurostat/databrowser/view/env_wastrt/default/table?lang=en (accessed on 16 December 2020).

Eurostat (2019), Waste Statistics, https://ec.europa.eu/eurostat/statisticsexplained/index.php/Waste statistics.

G20 (2017), G20 Resource Efficiency Dialogue, http://www.g20.utoronto.ca/2017/2017-g20resource-efficiency-dialogue-en.pdf (accessed on 9 July 2018). 
G7 (2017), G7 Bologna Environment Ministers' Meeting - Communiqué, http://www.g7italy.it/sites/default/files/documents/Communiqu\%C3\%A9\%20G7\%20Environ ment $\% 20-\% 20$ Bologna/index.pdf.

Giljum, S. et al. (2011), "A comprehensive set of resource use indicators from the micro to the macro level”, Resources, Conservation and Recycling, Vol. 55/3, pp. 300-308, http://dx.doi.org/10.1016/j.resconrec.2010.09.009.

Government of the Czech Republic (2016), National Research and Innovation Strategy for Smart Specialisation of the Czech Republic (National RIS3 Strategy), http://www.czechresearch.com/wp-content/uploads/2016/09/National_RIS3_strategy_2016_EN.pdf.

Government UK (2020), Guidance - Claiming Research and Development tax reliefs, https://www.gov.uk/guidance/corporation-tax-research-and-development-rd-relief.

Green Deal (n.d.), Green Deal - English, https://www.greendeals.nl/english (accessed on 3 June 2021).

INCIEN (2020), Institute of the Circular Economy, https://incien.org/tag/incien-cz/.

INCIEN (2019), Odpad zdrojem 2019 [Waste as a resource 2019], https://incien.org/odpadzdrojem-2019/.

International Resource Panel and UN Environment (2018), 2018-2021 IRP Work Programme, International Resource Panel, https://internationalresourcepanel.org/sites/default/files/documents/document/media/20182021_irp_work_programme_v2_0.pdf.

Interreg Europe (2016), Interreg Europe Programme Communication Strategy 2014-2020, https://www.interregeurope.eu/fileadmin/user upload/documents/Programme-communicationstrategy-and-annexes.pdf (accessed on 24 February 2021).

Irish Environment (2015), Plastic Bag Levy, http://www.irishenvironment.com/iepedia/plasticbag-levy/.

Italian Ministry of Economy and Finance (1996), Legge 28 Dicembre 1995 No 549, https://www.gazzettaufficiale.it/eli/id/1995/12/29/095G0612/sg.

Koch, J. and P. Coelho (2020), International Workshop on Targets for a Circular Economy, https://circulareconomy.europa.eu/platform/en/news-and-events/all-news/internationalworkshop-targets-circular-economy.

Koszewska, M. (2018), "Circular Economy - Challenges for the Textile and Clothing Industry", Autex Research Journal, Vol. 18/4, pp. 337-347, http://dx.doi.org/10.1515/aut-2018-0023.

LE Europe et al. (2018), Behavioural Study on Consumers' Engagement in the Circular Economy, European Commission, http://dx.doi.org/10.2818/956512.

Liège (2020), Poursuivre vers une ville : zéro-déchet, https://www.reinventonsliege.be/projets/poursuivre-vers-une-ville-zero-dechet. 
Magnier, C. et al. (2017), Ten Key Indicators for Monitoring the Circular Economy, .

Environmental Information Department, Ministry of the Environment, Energy and Marine

Affairs, France, http://temis.documentation.developpementdurable.gouv.fr/docs/Temis/0086/Temis-0086452/22978_2017_ENG.pdf (accessed on 22 May 2020).

Ministry of Education Youth and Sports; Research Development and Innovation Council (2012), National priorities of oriented research, experimental development and innovations, http://www.czech-research.com/wp-content/uploads/2016/09/National-priorities-of-orientedresearch-experimental-development-and-innovations.pdf.

Ministry of Environment and Food and Ministry of Industry Business and Financial Affairs (2018), Strategy for circular economy, https://stateofgreen.com/en/uploads/2018/10/Strategyfor-Circular-Economy-1.pdf.

Ministry of Environment of the Czech Republic (2019), Množství obalových odpadů, které vznikly $v$ České republice a byly materiálově využity nebo spáleny ve spalovnách odpadů s energetickým využitim [Amount of packaging waste generated in the Czech Republic and materially or energetically recovered], https://www.mzp.cz/C1257458002F0DC7/cz/informace problematika odpadu/\$FILE/oodpObaly Recyklace-20190927.002.pdf.

Ministry of Industry and Trade of the Czech Republic (2019), Politika druhotných surovin České republiky pro období 2019-2022 (Secondary Raw Materials Policy of CR 2019-2022), https://www.mpo.cz/assets/cz/prumysl/politika-druhotnych-surovin-cr/2019/1/IV_Politikadruhotnych-surovin-CR.pdf.

Ministry of Industry and Trade of the Czech Republic (2017), Surovinová politika České republiky $v$ oblasti nerostných surovin a jejich zdroju (Raw Materials Policy of CR in the field of minerals and their resources), https://www.mpo.cz/cz/stavebnictvi-a-suroviny/surovinovapolitika/statni-surovinova-politika-nerostne-suroviny-v-cr/nova-surovinova-politika-v-oblastinerostnych-surovin-a-jejich-zdroju---mpo-2017--229820/.

Ministry of Industry and Trade of the Czech Republic (2015), Operational Programme Enterprise and Innovations for Competitiveness 2014-2020, https://www.mpo.cz/en/business/grants-andbusiness-support/opeic-2014-2020/operational-programme-enterprise-and-innovations-forcompetitiveness-2014---2020--169167/.

Ministry of the Environment of the Czech Republic (2019), Česko čeká velká odpadková revoluce, vláda dnes schválila novou odpadovou legislativu [Press release on the newly approved waste legislation package], https://www.mzp.cz/cz/news_20191207_cesko_ceka_velka_odpadkova_revoluce_vlada_dnes_ schvalila novou odpadovou legislativu (accessed on 2 January 2020).

Ministry of the Environment of the Czech Republic (2019), Souhrnná data o odpadovém hospodárstvi ČR v letech 2009-2018 [Summary data about waste management in the Czech Republic in 2009-2018], https://www.mzp.cz/C1257458002F0DC7/cz/odpady_podrubrika/\$FILE/OODPSouhrnna_data_2009_2018-20191025.pdf. 
Ministry of the Environment of the Czech Republic (2019), Zpráva o plnění cílů Plánu odpadového hospodářství České republiky za obdobi 2017-2018 [Monitoring the implementation of the waste management plan objectives in CR for 2017-2018], https://www.mzp.cz/C1257458002F0DC7/cz/plneni_narizeni_vlady/\$FILE/OODPZprava plneni POH CR 2017 2018-20191217.pdf.

Ministry of the Environment of the Czech Republic (2017), Program předcházení vzniku odpadì $\check{C} R$ Prüběžná hodnotici zpráva [Interim evaluation report on the CR's Waste Prevention Programme], https://www.mzp.cz/C1257458002F0DC7/cz/predchazeni vzniku odpadu navrh/\$FILE/OOD P-PPVO prubezna hodnotici zprava-20171006.pdf.

Ministry of the Environment of the Czech Republic (2017), Zpráva o plněni cílu Plánu odpadového hospodárství České Republiky za obdobi 2015 - 2016 [Report on fulfillment of targets of the Waste Management Plan of the Czech Republic for years 2015-2016], https://www.mzp.cz/C1257458002F0DC7/cz/plneni_narizeni_vlady/\$FILE/OODPZprava_o_plneni_POH_CR_2015_2016_20170105.pdf.

Ministry of the Environment of the Czech Republic (2014), Czech republic's waste prevention programme, https://www.mzp.cz/C1257458002F0DC7/cz/predchazeni vzniku odpadu navrh/\$FILE/OOEN WPP Czech-20150407.pdf.

Ministry of the Environment of the Czech Republic (2014), Waste Management Plan of the Czech Republic for the period 2015-2024, https://www.mzp.cz/C1257458002F0DC7/cz/plan_odpadoveho_hospodarstvi_aj/\$FILE/OODP -WMP CZ translation-20151008.pdf.

Ministry of the Environment of the Czech Republic (n.d.), Dostbyloplastu [Enough of plastics], https://www.dostbyloplastu.cz/ (accessed on 3 June 2021).

Ministry of the Environment of the Czech Republic (n.d.), Projekt TAČR "Hledáni nových způsobů informačni podpory při realizaci Programu predcházení vzniku odpadů ČR" [Project TACR "Searching for new ways of information support in the implementation of the Waste Prevention Program of the Czech Republic"], https://www.mzp.cz/cz/program predchazeni vzniku odpadu (accessed on 21 February 2020).

Ministry of the Interior of the Czech Republic (2018), Stanovisko odboru veřejné správy, dozoru a kontroly Ministerstva vnitra č. 4/2009 [Opinion of the Department of Public Administration, Supervision and Control of the Ministry of the Interior No 4/2009], https://www.mvcr.cz/clanek/2009-62148.aspx.

Moraga, G. et al. (2019), "Circular economy indicators: What do they measure?", Resources, Conservation and Recycling, Vol. 146, pp. 452-461, http://dx.doi.org/10.1016/j.resconrec.2019.03.045.

Morseletto, P. (2020), "Targets for a circular economy", Resources, Conservation and Recycling, Vol. 153, p. 104553, http://dx.doi.org/10.1016/j.resconrec.2019.104553. 
Moylan, T. (2015), Developing a Communications Strategy in the Public Sector,

https://www.linkedin.com/pulse/public-sector-communications-developing-strategy-tommoylan/ (accessed on 24 February 2021).

National Centre for Universities and Business (2020), Konfer online tool, https://konfer.online/ (accessed on 3 June 2021).

Natural Sciences and Engineering Research Council of Canada (2020), Collaborative Research and Development Grants (including DND/NSERC Research Partnership Grants), https://www.nserc-crsng.gc.ca/professors-professeurs/rpp-pp/crd-rdc eng.asp.

Netherlands Enterprise Agency (n.d.), MIA and Vamil, https://english.rvo.nl/subsidiesprogrammes/mia-and-vamil (accessed on 3 June 2021).

Netherlands Enterprise Agency (n.d.), Seed Capital, https://www.rvo.nl/subsidies-regelingen/seed- [90] capital.

NKS (2017), Waste management in Nitra, http://www.ceeweb.org/wp-content/uploads/NitraWaste-management_V4.pdf.

OECD (2020), Making the green recovery work for jobs, income and growth, OECD Policy

Responses to Coronavirus (COVID-19), http://www.oecd.org/coronavirus/policyresponses/making-the-green-recovery-work-for-jobs-income-and-growth-a505f3e7/\#sectiond1e34 (accessed on 2 December 2020).

OECD (2019), Business Models for the Circular Economy: Opportunities and Challenges for Policy, OECD Publishing, Paris, https://dx.doi.org/10.1787/g2g9dd62-en.

OECD (2019), Global Material Resources Outlook to 2060: Economic Drivers and Environmental Consequences, OECD Publishing, Paris, https://dx.doi.org/10.1787/9789264307452-en.

OECD (2019), OECD.Stat: Municipal waste, Generation and Treatment, https://stats.oecd.org/Index.aspx?DataSetCode=MUNW.

OECD (2019), The Sharing and Gig Economy: Effective Taxation of Platform Sellers : Forum on Tax Administration, OECD Publishing, Paris, https://dx.doi.org/10.1787/574b61f8-en.

OECD (2018), OECD Environmental Performance Reviews: Czech Republic 2018, OECD Environmental Performance Reviews, OECD Publishing, Paris, https://dx.doi.org/10.1787/9789264300958-en.

OECD (2014), Engaging with the Public - 12 Lessons from DAC Peer Reviews and the Network of DAC Development Communicators, https://www.oecd.org/dac/peerreviews/12\%20Lessons\%20Engaging\%20with\%20the\%20public.pdf (accessed on 24 February 2021).

OECD (2021 forthcoming), Digitalisation for the transition to a resource efficient and circular economy. 
OECD (2021 forthcoming), Draft Report on the Implementation of the OECD Recommendation on Resource Productivity.

OECD Development Centre (2014), Good practices in development communication, http://www.oecd.org/dev/DevCom\%20Publication\%20Good\%20Practices\%20in\%20Develop ment\%20Communication.pdf (accessed on 24 February 2021).

Office of the Government of the Czech Republic (2018), Digitální Česko - Vládní program digitalizace České republiky 2018+ [Digital Czechia - Government programme 2018+], https://www.mvcr.cz/clanek/rada-vlady-pro-informacnispolecnost.aspx?q=Y2hudW09Ng\%3d\%3d (accessed on 3 June 2021).

Office of the Government of the Czech Republic (2015), Národní politika výzkumu, vývoje a inovaci České republiky na léta 2016-2020 (National Research, Development and Innovation Policy of the Czech Republic for the period 2016-2020), https://www.vyzkum.cz/FrontClanek.aspx?idsekce=682145.

Opravarna (n.d.), Opravarna, https://www.opravarna.cz (accessed on 3 June 2021).

PBL (2019), Werkprogramma Monitoring en sturing Circulaire Economie [Circular Economy Monitoring and Steering Work Programme], Planbureau voor de Leefomgeving, The Hague, https://www.pbl.nl/sites/default/files/downloads/pbl-2019-werkprogramma-voor-monitoringen-sturing-circulaire-economie-2019-2023_3861.pdf (accessed on 22 May 2020).

Perella, M. (2015), "Communicating the circle: Are circular economy communication strategies starting to connect?", Go Circular, http://www.maxineperella.com/uploads/5/0/6/3/50632287/communicating_the_circle.pdf (accessed on 24 February 2021).

PLATFORM CB'23 (2020), About platform CB'23, http://www.platformcb23.nl.

Potting, J. et al. (2018), Circular economy: what we want to know and can measure. Framework and baseline assessment for monitoring the progress of the circular economy in the Netherlands, PBL Netherlands Environmental Assessment Agency, The Hague, https://www.pbl.nl/sites/default/files/downloads/pbl-2018-circular-economy-what-we-want-toknow-and-can-measure-3217.pdf (accessed on 10 May 2020).

Prins, A. and T. Rood (2020), Op weg naar een robuuste monitoring van de circulaire economie. Resultaten-2019 van het Werkprogramma Monitoring en Sturing Circulaire Economie [Towards robust monitoring of the circular economy. Results 2019 of the Circular Economy Monitoring and Steering Work Programme], PBL, The Hague, https://www.pbl.nl/monitoringcirculaire-economie (accessed on 22 May 2020).

Provincia di Bergamo (2020), Osservatorio rifiuti interattivo, https://www.provincia.bergamo.it/.

Rademaekers, K. et al. (2013), Nowcasting of and target setting for resource efficiency indicators, European Commission, Brussels, https://ec.europa.eu/environment/enveco/resource efficiency/pdf/studies/RE\%20indicators.pdf (accessed on 22 May 2020). 
RE: SOURCE (n.d.), RE: SOURCE Research and innovation for sustainable material use, https://resource-sip.se/.

Rekola (n.d.), Rekola bike sharing scheme, https://www.rekola.cz/ (accessed on 3 June 2021).

Research Development and Innovation Council (2019), Innovation Strategy of the Czech Republic 2019-2030, https://www.businessinfo.cz/app/content/files/engdocs/innovation-strategy-czechrepublich-the-country-for-the-future-2019-2030.pdf.

Research Development and Innovation Council (2019), Innovation Strategy of the Czech Republic 2019-2030, https://www.businessinfo.cz/app/content/files/engdocs/innovation-strategy-czechrepublich-the-country-for-the-future-2019-2030.pdf.

Rreuse (2020), Rreuse, https://www.rreuse.org (accessed on 3 June 2021).

Saidani, M. et al. (2019), “A taxonomy of circular economy indicators", Journal of Cleaner Production, Vol. 207, pp. 542-559, http://dx.doi.org/10.1016/j.jclepro.2018.10.014.

Saidani, M. et al. (2017), "How to Assess Product Performance in the Circular Economy? Proposed Requirements for the Design of a Circularity Measurement Framework", Recycling, Vol. 2/1, p. 6, http://dx.doi.org/10.3390/recycling2010006.

Šajn, N. (2019), Environmental impact of the textile and clothing industry: What consumers need to know, European Parliamentary Research Service, https://www.europarl.europa.eu/RegData/etudes/BRIE/2019/633143/EPRS_BRI(2019)633143 EN.pdf.

Šauer, P., L. Pařízková and A. Hadrabová (2008), "Charging systems for municipal solid waste: Experience from the Czech Republic", Waste Management, Vol. 28/12, pp. 2772-2777, http://dx.doi.org/10.1016/j.wasman.2008.03.030.

Sdrolia, E. and G. Zarotiadis (2018), "A comprehensive review for green product term: from definition to evaluation", Journal of Economic Surveys, Vol. 33/1, pp. 150-178, http://dx.doi.org/10.1111/joes.12268.

SDSN and IEEP (2019), The 2019 Europe Sustainable Development Report. Towards a strategy for achieving the Sustainable Development Goals in the European Union, Sustainable Development Solutions Network and Institute for European Environmental Policy, Paris and Brussels, https://s3.amazonaws.com/sustainabledevelopment.report/2019/2019_europe_sustainable_deve lopment_report.pdf (accessed on 22 May 2020).

Stadt Schwerin (2000), Umweltbericht für die Landeshauptstadt Schwerin. Kapitel VIII. Abfalwirtschaft [Environmental report for the State capital Schwerin. Chapter VIII. Waste Management.].

Stiglitz, J., J. Fitoussi and M. Durand (eds.) (2018), For Good Measure: Advancing Research on Well-being Metrics Beyond GDP, OECD Publishing, Paris, https://dx.doi.org/10.1787/9789264307278-en. 
Sud, M. (2020), "Managing the biodiversity impacts of fertiliser and pesticide use: Overview and insights from trends and policies across selected OECD countries", OECD Environment Working Papers, No. 155, OECD Publishing, Paris, https://dx.doi.org/10.1787/63942249-en.

The Government of the Grand Duchy of Luxembourg Luxinnovation (2020), Performance programmes Fit 4 Circularity, https://www.luxinnovation.lu/innovate-inluxembourg/performance-programmes/fit-4-circularity/.

Trinomics B.V. et al. (2018), Environmental potential of the collaborative economy, European Commission, Luxembourg, http://dx.doi.org/10.2779/518554.

Weber, T. and M. Stuchtey (2019), Pathways towards a German Circular Economy - Lessons from European Strategies Preliminary Study, Circular Economy Initiative Deutschland, Munich, https://en.acatech.de/wp-content/uploads/sites/6/2019/09/Circular_Economy_EN.pdf.

Wencke Gwozdz/Kristian Steensen Nielsen/Tina Müller (2017), “An Environmental Perspective on Clothing Consumption: Consumer Segments and Their Behavioral Patterns", Sustainability, Vol. 9/5, p. 762, http://dx.doi.org/10.3390/su9050762.

WRAP (2015), Economic growth potential of more circular economies, WRAP, Banbury, http://www.wrap.org.uk/sites/files/wrap/Economic\%20growth\%20potential\%20of_more\%20ci rcular\%20economies.pdf.

WRAP (2012), Valuing our clothes. The true cost of how we design, use and dispose of clothing in the $U K$, https://www.wrap.org.uk/sites/files/wrap/VoC\%20FINAL\%20online\%202012\%2007\%2011.p df.

Zachova, A. (2018), "Národní inovační fond nebude, české startupy ale zoufat nemusí [There will be no National Innovation Fund but Czech start ups do not have to worry]", Euractiv, https://euractiv.cz/section/all/news/narodni-inovacni-fond-nebude-ceske-startupy-ale-zoufatnemusi/.

Zachová, A. et al. (2020), Green recovery after COVID-19: Last chance for V4 to climate transition?, https://www.euractiv.com/section/climate-environment/news/green-recovery-aftercovid-19-last-chance-for-v4-to-climate-transition/ (accessed on 15 December 2020).

Zero Waste Scotland (2020), Circular Economy Business Support Service, https://www.zerowastescotland.org.uk/circular-economy/business-support-service (accessed on 3 June 2021).

Zero Waste Scotland (n.d.), Circular Economy Investment Fund, https://www.zerowastescotland.org.uk/circular-economy/investment-fund (accessed on 3 June 2021). 
Annex A. Monitoring framework 
Table A.1. Initial indicator set for monitoring $\mathrm{CE}$ in the Czech Republic (long-list)

\begin{tabular}{|c|c|c|c|c|c|}
\hline No. & Priority area & Indicator & Description & Existing key monitoring framework(s) & Source \\
\hline 1 & Headline indicator & Circular material use rate $(\%)$ & $\begin{array}{l}\text { The share of material recovered and fed back into the } \\
\text { economy - thus saving extraction of primary raw materials - in } \\
\text { overall material use. Defined as the ratio of the circular use of } \\
\text { materials to the overall material use. Measures self-sufficiency } \\
\text { in raw materials of a country by replacing virgin materials by } \\
\text { secondary materials. }\end{array}$ & $\begin{array}{r}\text { EU CE monitoring framework; } \\
2019 \text { Europe Sustainable Development Report; } \\
\text { forthcoming State Environmental Policy of the } \\
\text { Czech Republic } 2030 \text { with an outlook to 2050; } \\
\text { a variation of this indicator also included in the } \\
\text { Czech Strategic Framework } 2030\end{array}$ & $\begin{array}{r}\text { Eurostat (2017) } \\
\text { Czech Statistical Office } \\
\text { (CZSO) (2017) } \rightarrow \text { have } \\
\text { additional data on } \\
\text { secondary raw materials }\end{array}$ \\
\hline & \multicolumn{5}{|c|}{ Dashboard } \\
\hline 2 & Products and design & Green public procurement & $\begin{array}{l}\text { The share of public procurement above the EU thresholds (in } \\
\text { number and value) including environmental elements. }\end{array}$ & EU CE monitoring framework & Indicator under development \\
\hline 3 & Products and design & $\begin{array}{l}\text { Additional indicator(s) needed to capture eco- } \\
\text { design (e.g. the number of eco-label holders) }\end{array}$ & $\begin{array}{r}\text { The number of eco-label holders in a given year (within the } \\
\text { Czech context it might not be the best indicator of eco-design } \\
\text { as the numbers are very low) }\end{array}$ & France & $\begin{array}{l}\text { Ministry of the Environment } \\
\text { (MoE) data }\end{array}$ \\
\hline 4 & $\begin{array}{l}\text { Consumption and } \\
\text { consumers }\end{array}$ & $\begin{array}{r}\text { Generation of municipal waste per capita ( } \mathrm{kg} \\
\text { per cap) (could be also under waste } \\
\text { management) }\end{array}$ & $\begin{array}{l}\text { Waste collected by or on behalf of municipal authorities and } \\
\text { disposed of through the waste management system }\end{array}$ & EU CE monitoring framework & $\begin{array}{r}\text { Eurostat (2018)/ CZSO } \\
\text { MoE (2018) }\end{array}$ \\
\hline 5 & $\begin{array}{l}\text { Consumption and } \\
\text { consumers }\end{array}$ & $\begin{array}{l}\text { Additional indicator(s) needed to capture } \\
\text { consumption and consumers (e.g. car-sharing) }\end{array}$ & $\begin{array}{l}\text { E.g. Measuring the trend of uptake of car-sharing, e.g. through } \\
\text { the number of passenger kilometres per year, the stock of cars } \\
\text { in a country, occupancy rate in cars (other indicator can be } \\
\text { developed }\end{array}$ & France & $\begin{array}{l}\text { Data not systematically } \\
\text { collected and aggregated }\end{array}$ \\
\hline 6 & $\begin{array}{l}\text { Consumption and } \\
\text { consumers }\end{array}$ & $\begin{array}{r}\text { Additional indicator(s) needed to capture } \\
\text { repair services }\end{array}$ & $\begin{array}{l}\text { E.g. household spending on product repair and maintenance } \\
\text { (other indicator can be developed) }\end{array}$ & France & $\begin{array}{l}\text { Data not systematically } \\
\text { collected and aggregated }\end{array}$ \\
\hline 7 & $\begin{array}{l}\text { Consumption and } \\
\text { consumers }\end{array}$ & $\begin{array}{l}\text { Additional indicator to capture waste } \\
\text { generation from households (e.g. food waste) }\end{array}$ & E.g. the amount of food waste generated by households & Not included & $\begin{array}{r}\text { Data not systematically } \\
\text { collected and aggregated }\end{array}$ \\
\hline 8 & Waste management & Recycling rate of municipal waste (\%) & $\begin{array}{r}\text { The share of recycled municipal waste in the total municipal } \\
\text { waste generation }\end{array}$ & $\begin{array}{r}\text { EU CE monitoring framework; } \\
2019 \text { Europe Sustainable Development Report; } \\
\text { the forthcoming State Environmental Policy of } \\
\text { the Czech Republic } 2030 \text { with an outlook to } 2050\end{array}$ & $\begin{array}{r}\text { Eurostat (2018) } \\
\text { MoE (2018) }\end{array}$ \\
\hline 9 & Waste management & $\begin{array}{r}\text { Recycling rate of all waste excluding major } \\
\text { mineral waste }(\%)\end{array}$ & $\begin{array}{r}\text { Recycled waste is waste treated, which was sent to recovery } \\
\text { operation other than energy recovery and backfilling (for } \\
\text { simplification referred to as recycling). }\end{array}$ & $\begin{array}{r}\text { EU CE monitoring framework; } \\
\text { the forthcoming State Environmental Policy of } \\
\text { the Czech Republic } 2030 \text { with an outlook to } 2050\end{array}$ & $\begin{array}{r}\text { Eurostat (2016) } \\
\operatorname{MoE}(2018)\end{array}$ \\
\hline 10 & Waste management & Recycling rate of overall packaging (\%) & $\begin{array}{r}\text { The share of recycled packaging waste in all generated } \\
\text { packaging waste }\end{array}$ & EU CE monitoring framework & $\begin{array}{r}\text { Eurostat (2017) } \\
\text { MoE (2018) }\end{array}$ \\
\hline 11 & Waste management & Recycling rate of plastic packaging (\%) & Recycling rate of plastic packaging & EU CE monitoring framework & Eurostat (2017); MoE (2018) \\
\hline 12 & Waste management & Recycling rate of wooden packaging (\%) & $\begin{array}{r}\text { The share of recycled wooden packaging waste in all } \\
\text { generated wooden packaging waste }\end{array}$ & EU CE monitoring framework & Eurostat (2017) \\
\hline
\end{tabular}

TOWARDS A NATIONAL STRATEGIC FRAMEWORK FOR THE CIRCULAR ECONOMY IN THE CZECH REPUBLIC 


\begin{tabular}{|c|c|c|c|c|c|}
\hline 13 & Waste management & Recycling rate of e-waste (\%) & $\begin{array}{l}\text { Calculated by multiplying the 'collection rate' as set out in the } \\
\text { WEEE Directive with the 'reuse and recycling rate' }\end{array}$ & EU CE monitoring framework & Eurostat (2017); MoE (2018) \\
\hline 14 & Waste management & Recycling of biowaste (kg per capita) & $\begin{array}{r}\text { Ratio of composted/methanised municipal waste over the total } \\
\text { population. }\end{array}$ & EU CE monitoring framework & $\begin{array}{r}\text { Eurostat (2018) } \\
\text { MoE (2018) }\end{array}$ \\
\hline 15 & Waste management & $\begin{array}{r}\text { Recovery rate of construction and demolition } \\
\text { waste (CDW) (\%) }\end{array}$ & $\begin{array}{l}\text { Ratio of CDW prepared for re-use, recycled or subject to } \\
\text { material recovery, including through backfilling operations, } \\
\text { divided by the construction and demolition waste treated. }\end{array}$ & EU CE monitoring framework & Eurostat (2016) \\
\hline 16 & $\begin{array}{l}\text { Industry, raw materials, } \\
\text { construction, energy }\end{array}$ & $\begin{array}{r}\text { Generation of waste excluding major mineral } \\
\text { wastes per GDP unit (kg per } 1000 \text { EUR) } \\
\text { (could be also under waste management) }\end{array}$ & $\begin{array}{l}\text { Defined as all waste generated in a country (in mass unit), } \\
\text { excluding major mineral wastes, per GDP unit. }\end{array}$ & EU CE monitoring framework & Eurostat (2016) \\
\hline 17 & $\begin{array}{l}\text { Industry, raw materials, } \\
\text { construction, energy }\end{array}$ & $\begin{array}{l}\text { Generation of waste excluding major mineral } \\
\text { wastes per domestic material consumption (\%) } \\
\text { (could be also under waste management) }\end{array}$ & $\begin{array}{l}\text { Defined as all waste generated in a country, excluding major } \\
\text { mineral wastes, divided by the domestic material consumption } \\
\text { (DMC) of a country }\end{array}$ & EU CE monitoring framework & Eurostat (2016) \\
\hline 18 & $\begin{array}{l}\text { Industry, raw materials, } \\
\text { construction, energy }\end{array}$ & Resource productivity (GDP/ DMC) & $\begin{array}{l}\text { Measures the total amount of materials directly used by an } \\
\text { economy in relation to GDP. }\end{array}$ & $\begin{array}{r}\text { EU Resource Efficiency headline indicator; } \\
\text { Czech Strategic Framework 2030; } \\
\text { forthcoming State Environmental Policy of the } \\
\text { Czech Republic } 2030 \text { with an outlook to } 2050\end{array}$ & Eurostat (2018) \\
\hline 19 & $\begin{array}{l}\text { Industry, raw materials, } \\
\text { construction, energy }\end{array}$ & End-of- life recycling input rate (\%) & $\begin{array}{l}\text { Contribution of recycled materials to raw materials demand. } \\
\text { Measures for a given raw material how much of its input into } \\
\text { the production system comes from recycling of "old scrap". }\end{array}$ & EU CE monitoring framework & Data not available \\
\hline 20 & $\begin{array}{l}\text { Industry, raw materials, } \\
\text { construction, energy }\end{array}$ & Imports from non-EU countries (tonnes) & $\begin{array}{l}\text { Measure the quantities of selected waste categories and by- } \\
\text { products imported by EU Member States from third countries. }\end{array}$ & EU CE monitoring framework & Eurostat (2019) \\
\hline 21 & $\begin{array}{l}\text { Industry, raw materials, } \\
\text { construction, energy }\end{array}$ & Exports to non-EU countries (tonnes) & $\begin{array}{l}\text { Measure the quantities of selected waste categories and by- } \\
\text { products exported by EU Member States to third countries. }\end{array}$ & EU CE monitoring framework & Eurostat (2019) \\
\hline 22 & $\begin{array}{l}\text { Industry, raw materials, } \\
\text { construction, energy }\end{array}$ & Intra-EU trade (tonnes) & $\begin{array}{l}\text { The quantities of selected waste categories and by-products } \\
\text { imported by EU Member States from another Member State. }\end{array}$ & EU CE monitoring framework & Eurostat (2019) \\
\hline 23 & $\begin{array}{l}\text { Industry, raw materials, } \\
\text { construction, energy }\end{array}$ & $\begin{array}{r}\text { Gross investment in tangible goods (\% of GDP } \\
\text { at current prices) }\end{array}$ & $\begin{array}{l}\text { Defined as investment during the reference year in all tangible } \\
\text { goods. Included are new and existing tangible capital goods, } \\
\text { whether bought from third parties or produced for own use. }\end{array}$ & EU CE monitoring framework & Data not available \\
\hline 24 & Bioeconomy and food & Food waste (million tonne) & $\begin{array}{r}\text { Measures the waste generated in the production, distribution } \\
\text { and consumption of food. }\end{array}$ & EU CE monitoring framework & Data not available \\
\hline 25 & Bioeconomy and food & $\begin{array}{r}\text { Additional indicators needed to capture } \\
\text { bioeconomy (e.g. Gross value added (GVA) in } \\
\text { the bioeconomy sector (as \% GDP)) }\end{array}$ & $\begin{array}{r}\text { Bioeconomy can be measured through socio-economic } \\
\text { indicators such as revenues and jobs. }\end{array}$ & Finnish green growth indicators & $\begin{array}{l}\text { Data not systematically } \\
\text { collected and aggregated }\end{array}$ \\
\hline 26 & $\begin{array}{l}\text { Research, innovation and } \\
\text { digitalisation }\end{array}$ & $\begin{array}{r}\text { Number of patents related to recycling and } \\
\text { secondary raw materials }\end{array}$ & $\begin{array}{l}\text { The number of patents related to recycling and secondary raw } \\
\text { materials. The attribution was done using the relevant codes in } \\
\text { the Cooperative Patent Classification. }\end{array}$ & EU CE monitoring framework & $\begin{array}{r}\text { JRC (2015); } \\
\text { Data not systematically } \\
\text { collected and aggregated }\end{array}$ \\
\hline
\end{tabular}




\section{0}

\begin{tabular}{|c|c|c|c|c|c|}
\hline 27 & $\begin{array}{l}\text { Research, innovation and } \\
\text { digitalisation }\end{array}$ & $\begin{array}{r}\text { Additional indicators can be proposed in R\&D } \\
\text { and digitalization (e.g. spending on R\&D in } \\
\text { CE, the use of digital technologies) }\end{array}$ & $\begin{array}{r}\text { E.g. to estimate the spending on R\&D related to } C E, \\
\text { digitalization of the population) }\end{array}$ & $\begin{array}{r}\text { Not included } \\
\text { The Netherlands considers it }\end{array}$ & $\begin{array}{l}\text { Data not systematically } \\
\text { collected and aggregated }\end{array}$ \\
\hline 28 & Education and knowledge & $\begin{array}{r}\text { Number of persons employed in CE (\% of total } \\
\text { employment) }\end{array}$ & $\%$ of total jobs in circular economy related sectors. & $\begin{array}{r}\text { EU CE monitoring framework } \\
\text { France }\end{array}$ & Data not available \\
\hline 29 & Education and knowledge & $\begin{array}{r}\text { Additional indicators can be proposed to } \\
\text { capture education (e.g. linked to the number of } \\
\text { courses/ programmes related to CE) }\end{array}$ & $\begin{array}{r}\text { E.g. education in CE can be captured for example through the } \\
\text { number of courses/ programmes offered in CE related } \\
\text { disciplines.) }\end{array}$ & $\begin{array}{r}\text { Not included } \\
\text { The Netherlands considers it }\end{array}$ & $\begin{array}{l}\text { Data not systematically } \\
\text { collected and aggregated }\end{array}$ \\
\hline 30 & Economic instruments & $\begin{array}{r}\text { Gross value added at factor cost (\% of GDP at } \\
\text { current prices) }\end{array}$ & $\begin{array}{l}\text { Value added at factor costs is the gross income from operating } \\
\text { activities after adjusting for operating subsidies and indirect } \\
\text { taxes. }\end{array}$ & EU CE monitoring framework & Data not available \\
\hline 31 & Economic instruments & $\begin{array}{r}\text { Additional indicators can be proposed to } \\
\text { capture economic instruments (e.g. linked to } \\
\text { tax revenues or tax credits generated from CE } \\
\text { related fiscal instruments }\end{array}$ & $\begin{array}{l}\text { E.g. revenues generated from CE related taxes, or the amount } \\
\text { of tax credits given to CE related products and services. }\end{array}$ & Not included & $\begin{array}{l}\text { Data not systematically } \\
\text { collected and aggregated }\end{array}$ \\
\hline
\end{tabular}

Note: Rows highlighted in grey colour are indicators not included in the EU CE Monitoring framework and the EU Resource efficiency monitoring framework. They could be included as a second priority. Cells highlighted in orange specify that data or indicator is not available. Circular Czechia 2040 includes two more priority areas not covered by this report: water management and smart cities, smart regions and infrastructure. Monitoring of these areas might also be needed. Source: Own elaboration. 